\title{
Instituições fiscais e eficiência governamental: um estudo de caso sobre a saúde pública municipal no Estado de São Paulo.
}

Por Murilo de Oliveira Junqueira

Tese apresentada para a obtenção do título de doutor em Ciência Política no Departamento de Ciência Política da Universidade de São Paulo.

Orientadora: Lorena Barberia

São Paulo

Junho de 2017 
Autorizo a reprodução e divulgaçăo total ou parcial deste trabalho, por qualquer meio convencional ou eletrônico, para fins de estudo e pesquisa, desde que citada a fonte.

Catalogação na Publicação Serviço de Biblioteca e Documentação

Faculdade de Filosofia, Letras e Ciências Humanas da Universidade de São Paulo

Junqueira, Murilo de Oliveira Junqueira

Instituicdes fiscais e eficiencia governamental: um estudo de caso sobre a saúde pública municipal no Estado de Săo Paulo / Murilo de Oliveira Junqueira Junqueira $;$ orientadora Lorena Guadalupe Barberia Barberia. - Sào Paulo, 2017. $115 \mathrm{f}$.

Tese (Doutorado)- Faculdade de Filosofia, Letras e Ciencias Humanas da Universidade de Sào Paulo. Departamento de Ciencia Politica. Área de concentraçäo: Ciencia Politica.

1. POLfIICAS PUBLICAS. 2. FEDERALISMO. 3. INSTITUIÇŌES. 4. SAÓdE PÜBLICA. 5. EFICIÊNCIA ORGANIZACIONAL. I. Barberia, Lorena Guadalupe Barberia, orient. II. Titulo. 


\section{Índice:}

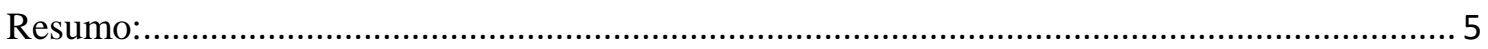

Capítulo 1 - Teorias sobre os determinantes da qualidade do governo. ........................................ 6

1.1 - Centralização, descentralização e desenvolvimento político. ....................................... 9

1.1.1 - Formalização das hipóteses sobre a teoria da modernização ................................ 12

1.1.2 - O poder local à sombra do coronelismo ............................................................... 14

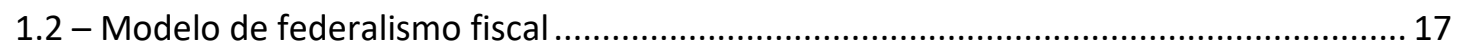

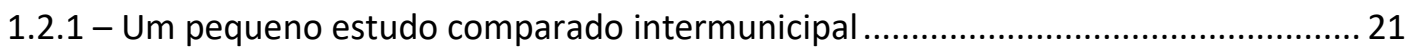

1.2.2 - Formalização da hipótese sobre a influência do financiamento público .................. 24

1.3 - 0 caso de análise: os Municípios do Estado de São Paulo .............................................. 28

1.4 - O conceito de eficiência na gestão pública ................................................................. 30

Capítulo 2 - Um novo indicador de eficiência dos gastos públicos em saúde. ............................ 34

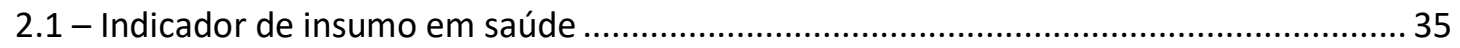

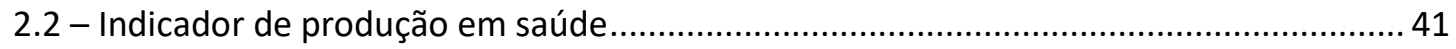

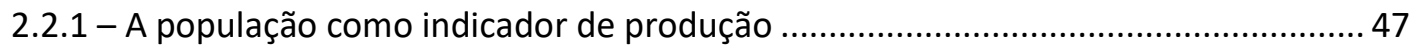

2.3 - Indicadores de preço dos insumos em saúde .................................................................. 49

2.4 - Correção de erros de mensuração e outliers ……………………………................. 52

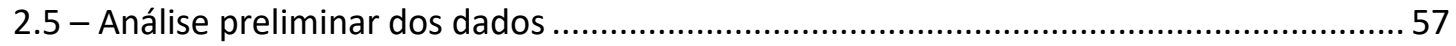

Capítulo 3 - A análise de eficiência por Fronteiras Estocásticas................................................ 62

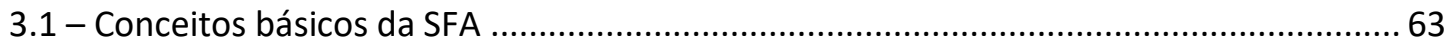

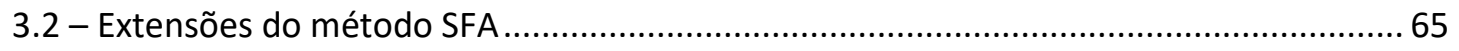

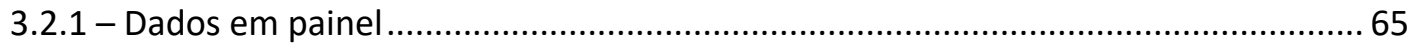

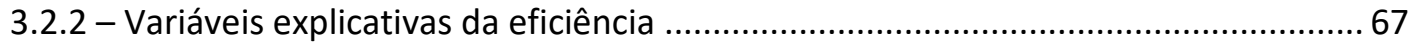

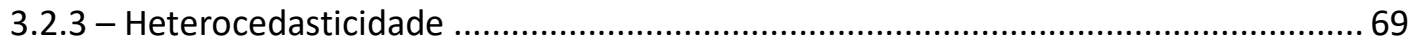

3.3 - Escolha entre diferentes modelos de fronteira de eficiência ........................................69

Capítulo 4 - Escala, desenvolvimento e instituições da eficiência de saúde. ................................ 77

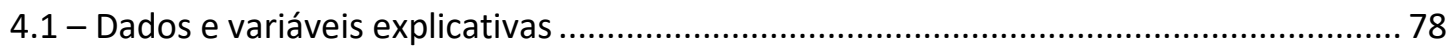

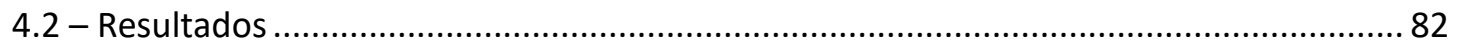

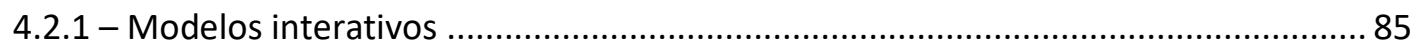

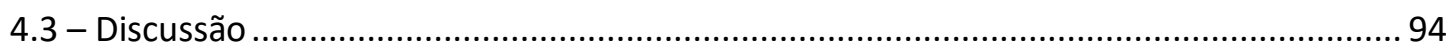

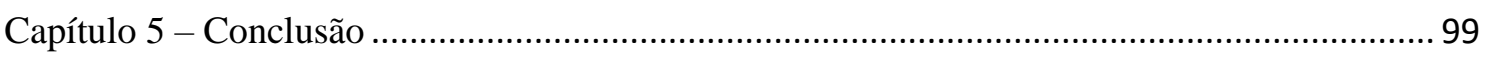

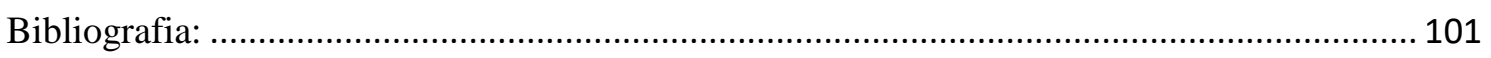

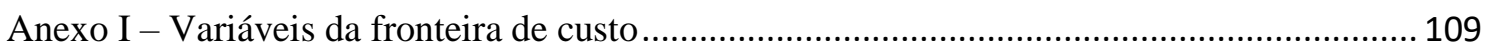

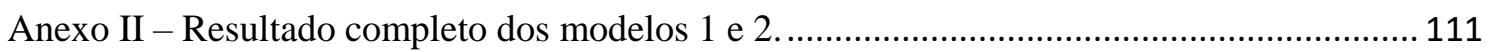





\title{
Resumo:
}

Este trabalho analisa os determinantes da eficiência dos municípios do Estado de São Paulo em prover serviços de saúde. Dois conjuntos de hipóteses foram testados. O primeiro, ligado à teoria da modernização, diz que a eficiência é determinada pelas condições sociais dos municípios, sendo que os municípios menores e mais pobres tenderiam a ser menos eficientes que os municípios grandes e ricos. $\mathrm{O}$ segundo conjunto de hipóteses diz respeito ao impacto das instituições fiscais. Segundo essa visão, as transferências intergovernamentais tenderiam a criar incentivos negativos para a eficiência local. A análise se mostrou claramente a favor das teorias institucionalistas. Como produto intermediário da análise, foi criado um indicador inédito da eficiência do setor público, mais abrangente e flexível que os usados até o momento pela literatura.

\begin{abstract}
:
This dissertation analyzes the determinants of the efficiency of local governments in the state of São Paulo in delivering health services. Two sets of hypotheses were tested. The first, linked to the modernization theory, says that efficiency is determined by the social development of municipalities, with smaller and poorer municipalities tending to be less efficient than large and rich municipalities. The second set of assumptions concerns the impact of fiscal institutions. According to this view, intergovernmental transfers would tend to create negative incentives for local efficiency. The analysis was clearly in favor of the institutionalist theories. An intermediate product of the analysis, an original indicator of public sector efficiency was created that is more comprehensive and flexible than those used so far in the literature.
\end{abstract}




\section{Capítulo 1 - Teorias sobre os determinantes da qualidade do governo.}

A eficiência do setor público é um assunto cadente tanto no debate público quanto no debate acadêmico. O contexto econômico atual aumenta cada vez mais a pressão por maior eficiência pública, devido às constantes pressões por maior controle fiscal e, ao mesmo tempo, por maior oferta de serviços públicos. Na área da saúde, em especial, o envelhecimento da população torna a necessidade de restrição fiscal permanente, dado que a demanda por serviços de saúde aumenta com o envelhecimento da população e a diminuição da população economicamente ativa diminui a oferta de recursos públicos. Frente a esse contexto, é cada vez mais importante descobrir as causas e entraves da produtividade pública, como forma de garantir que a população continue recebendo os serviços públicos nos próximos anos. Esse trabalho irá contribuir para o tema, explorando os determinantes da eficiência governamental na área da saúde, utilizando os municípios do Estado de São Paulo como um estudo de caso. Do ponto de vista metodológico, ele também irá propor uma grande inovação metodológica: um indicador inédito de eficiência pública na área da saúde.

Mas além da importância intrínseca da saúde pública e da busca por eficiência do setor público, esse trabalho também irá explorar outro tema, mais geral e abstrato: a busca pelo melhor arcabouço teórico para explicar o comportamento dos governos. Mais especificamente, iremos contrastar dois grandes sistemas teóricos com visões opostas sobre a natureza e os determinantes do desempenho do setor público: o determinismo sociológico e o institucionalismo. O determinismo sociológico afirma que são as estruturas sociais que determinam o comportamento governamental. Essa corrente pode vir com várias roupagens, como por exemplo, as abordagens marxista e culturalista. Nesse trabalho, iremos testar uma variante específica do determinismo sociológico: a chamada “teoria da modernização” (LIPSET, 1967). Essa visão argumenta que as sociedades mais "modernas" ou "dinâmicas" tendem a ter um desempenho melhor que as sociedades mais "tradicionais" ou "atrasadas". Segundo a teoria da modernização, os componentes da "modernidade" que fariam com que a atuação dos governos melhorasse seriam os efeitos 
de aglomeração, da riqueza, da escolaridade, da democracia e da cultura cívica. Esses fatores perfazem o ideal utópico de modernidade: uma sociedade rica, escolarizada, urbana e democrática. Essa teoria muitas vezes é utilizada para justificar uma visão negativa das pequenas cidades e dos estados pobres do país, que seriam supostamente mais "atrasados" e autoritários. Mais do que isso, essa visão tende a defender uma visão centralizadora das políticas públicas, onde políticos e burocratas oriundos dos centros "dinâmicos" controlassem o setor público das regiões "atrasadas", como forma de contornar as debilidades das elites locais. Essa visão é praticamente uma visão antiRousseauniana do Estado, exagerando as virtudes das sociedades urbanas, do capitalismo e da centralização estatal; menosprezando as virtudes das sociedades rurais e dos governos descentralizados, os preferidos de Rousseau (ROUSSEAU, 2010).

Outra visão totalmente diferente sobre como o governo funciona é a teoria institucionalista (HALL; TAYLOR, 2003; NORTH, 1990). Tal como o determinismo sociológico, o institucionalismo é um arcabouço teórico amplo, que permite um grande número de correntes teóricas distintas. Neste trabalho, abordamos a corrente chamada de "neoinstitucionalismo de escolha racional" (HALL; TAYLOR, 2003; TSEBELIS, 1998). Essa visão apresenta vários contrastes com a visão anterior. Em primeiro lugar, ela preserva alguma autonomia relativa do setor público. O governo não é determinado pela sociedade que o cerca, mas segue interesses próprios, determinados com relativa autonomia. Em segundo lugar, os membros do governo, assim como os demais indivíduos, são guiados por incentivos. Eles buscam maximizar seus interesses, que são relativamente conhecidos: os políticos querem se reeleger e o governo como um todo (incluindo os burocratas) quer aumentar seu orçamento. Nessa visão, as regras (ou seja, as instituições) cumprem um papel fundamental em moldar os interesses governamentais. Por exemplo, Weingast $(1995,2014)$ argumenta que se em determinado arcabouço institucional, a melhor forma dos governos locais manterem seu poder e ampliarem suas receitas é ampliar a base tributária local, incentivando a iniciativa privada, os governantes tenderão a incentivar o crescimento da economia local. Segundo o autor, esse seria o segredo por trás do desenvolvimento capitalista da Inglaterra no século XVIII, dos EUA no século XIX e da China nas últimas décadas. Por outro lado, se as regras deixam como opção mais vantajosa para os governos locais o apoio clientelista ao governo central, então, os governantes locais tenderão a se desinteressar pelo desenvolvimento local e passarão a se dedicar a construir relações fisiológicas com o núcleo do poder nacional. 
Esse foi o caminho trilhado pelos governos locais México durante a maior parte do século XX (Diaz-Cayeros, Magaloni, \& Weingast 2003). Independente de se a visão de Weingast está historicamente correta nesses casos específicos, o que eu gostaria de ressaltar é que sua explicação vai das instituições para o comportamento estatal, passando pelos incentivos governamentais. Essa visão se contrasta totalmente com a visão do determinismo sociológico, onde a explicação vai da sociedade para o governo, passando pela via econômica ou cultural. Essa dualidade permeia as hipóteses discutidas nesse trabalho.

Para testar a força relativa dessas abordagens para explicar a performance do setor público, eu testarei algumas hipóteses populares dentro dessas teorias gerais. Evidentemente, não estou colocando esses "macro sistemas" teóricos como um todo à prova, mas sim, repito, apenas algumas hipóteses populares dentro de cada corrente. Espero com isso contribuir para que os leitores formem, de forma indutiva, um panorama geral de qual sistema teórico possui mais partes que funcionam. No lado da teoria da modernização, testamos as hipóteses de que as cidades maiores, mais ricas e urbanizadas são mais eficientes. Do lado do institucionalismo, testamos a hipótese de que as regras de financiamento público determinam a eficiência governamental. Mais particularmente, testamos a hipótese de que os municípios cujos recursos são provenientes de impostos locais são mais eficientes que os municípios que se sustentam por transferências intergovernamentais. Se essa última hipótese estiver correta, o modelo brasileiro de financiamento dos municípios, fortemente baseado em transferências intergovernamentais, pode estar criando incentivos negativos para a eficiência do setor público local.

Os resultados dessa tese mostraram que a teoria da modernização possui um baixo poder explicativo para explicar a eficiência do setor público, com uma exceção: os efeitos de aglomeração. Mais que o tamanho da população, é a densidade populacional que tende a facilitar a provisão de serviços públicos. Já a população, a urbanização, a renda familiar per capita e a desigualdade social não estão correlacionadas com a qualidade do setor público, quando o efeito é controlado pelo padrão de financiamento municipal. Por outro lado, o tipo de financiamento público, determinado pelas regras Constitucionais e pela legislação vigente, possui um nítido papel explicativo na eficiência local. A análise mostrou que o gasto público possui um retorno marginal decrescente, ou seja, quanto mais se investe em saúde, menor o retorno por real gasto. Porém, a tendência declinante 
de retorno do gasto público é maior quando os recursos são obtidos por transferências intergovernamentais. Isso não quer dizer que o contexto social da cidade é irrelevante para eficiência governamental, mas seu papel principal é de potencializar o efeito das transferências. A análise mostrou que o efeito das transferências é mais negativo quando elas são destinadas a cidades pobres. A combinação de volumosas transferências per capita para comunidades muito carentes parece ser a combinação mais danosa para a eficiência.

Nesse primeiro capítulo, iremos delimitar a parte teórica da nossa análise, justificando as hipóteses empíricas utilizadas nesse trabalho. Nos próximos capítulos, detalho como foi criada variável dependente da análise: um indicador inédito de eficiência da provisão de serviços públicos de saúde. No Capítulo 4, testo empiricamente as hipóteses propostas neste capítulo para explicar a diferença de eficiência entre os municípios paulistas. Por fim, no Capítulo 5, existe uma pequena conclusão.

\section{1 - Centralização, descentralização e desenvolvimento político.}

Como mencionado acima, muitos autores tendem a atribuiu um comportamento mais "moderno" ou "dinâmico" aos grandes centros urbanos. Muitos estudos empíricos sobre a eficiência dos governos locais no Brasil corroboram essa visão (BOUERI; ROCHA; RODOPOULOS, 2015; GASPARINI; RAMOS, 2004; GODOY, 2014; MENDES; SOUSA, 2006; SOUSA; CRIBARI-NETO; STOSIC, 2005; VARELA; MARTINS; FÁVERO, 2012). Contudo, também é possível encontrar argumentos na literatura que vão em sentido oposto, defendendo que os governos descentralizados tendem a ser mais eficientes. De modo geral, podemos resumir os argumentos em dois grandes eixos: "problemas de escala" e "problemas de desenvolvimento político". Abaixo irei expor brevemente esses argumentos.

Muitos autores argumentam que as cidades pequenas tendem a ser ineficientes, devido a uma escala insuficiente de provisão de serviços ${ }^{1}$. Quais seriam os argumentos teóricos que levariam os pequenos municípios a ter uma escala ineficiente de provisão de serviços públicos? A primeira explicação (GASPARINI; RAMOS, 2004; MENDES;

\footnotetext{
${ }^{1}$ Argumento no Capítulo 2 e no Capítulo 4 de que esses resultados podem ser fruto de dados e métodos equivocados.
} 
MIRANDA; COSSÍO, 2008) seria relacionada ao custo fixo do setor público. Todo nível de governo possui um custo fixo mínimo, que é usado exclusivamente para manter o corpo dirigente estatal e não para a provisão de políticas públicas. Dentro das prefeituras, por exemplo, é preciso manter o gabinete do prefeito, o gabinete dos secretários, uma Câmara de Vereadores, etc. Quando o município é muito pequeno, uma parcela maior tende a ser gasta com esse custo fixo, deslocando recursos que poderiam ser utilizados para atividades finalísticas do governo. Evidentemente, essa visão considera que o custo dos governos locais é maior que sua contribuição para os serviços públicos. Ou pelo menos, se acredita que o mesmo trabalho poderia ser feito de maneira mais eficiente por burocratas ou políticos do nível central de governo. Outro argumento utilizado na literatura, diz que os pequenos municípios sofrem de falta de capacidade técnica, dado que seu corpo burocrático seria pouco qualificado. Isso aconteceria por dois motivos. Em primeiro lugar os funcionários mais qualificados tendem a preferir trabalhar para governos maiores (PRUD’HOMME, 1995). Em segundo lugar, equipes de trabalho menores tendem a ter menor especialização e, por consequência, menor capacidade administrativa. Outro argumento da "perda de escala" ressalta que muitos equipamentos e instalações físicas possuem ganho de escala (MENDES; SOUSA, 2006). Por exemplo, certos equipamentos sofisticados, como ressonância magnética ou tomografia computadorizada, são usados para diagnósticos de doenças raras. Se esses equipamentos foram instalados em comunidades pouco populosas, eles ficarão ociosos a maior parte do tempo. O uso de equipamentos de informática também segue a mesma lógica. Eles são caros de serem instalados, mas uma vez funcionando possuem uma grande capacidade de processar e guardar informação. Logo, são equipamentos que possuem forte ganho de escala. Por fim, existe os efeitos de aglomeração. Varela, Martins \& Fávero (2012) ressaltam que o atendimento de saúde é mais eficiente quando e população é concentrada. Isso evita o descolamento de equipes de saúde e dos próprios pacientes, gerando ganhos logísticos e administrativos. A concentração populacional e a urbanização facilitam o controle dos gestores públicos, dado que controlar um único grande estabelecimento de saúde é mais fácil que controlar vários pequenos estabelecimentos de saúde dispersos em uma grande região.

Por outro lado, existem argumentos de escala a favor da descentralização. Segundo essa visão, pequenos governos locais tendem a ter um conhecimento mais profundo das necessidades e dos recursos do território. Como consequência, eles têm 
melhores condições que o governo central para encontrar soluções locais para os problemas locais (OATES, 1999). Além disso, os preços dos insumos em grandes aglomerações urbanas, como o preço da terra e da mão de obra, tende a ser maior; o que tornam os custos do sistema de saúde maiores.

Um grupo diferente de argumentos diz respeito ao sistema político dos governos locais. Existe uma longa tradição nas ciências sociais brasileiras que identifica no setor público municipal e estadual, principalmente nos mais pobres e rurais, com os resquícios do atraso social e político (FURTADO, 1966; LAMBERT, 1959; LEAL, 1993; VIANA, $1987)^{2}$. Essa visão argumenta, algumas vezes de forma implícita, que as políticas públicas deveriam ser centralizadas, como forma de contornar as debilidades das elites locais. Segundo essa visão, os pequenos municípios seriam dominados por uma elite pequena e coesa (uma única família, por exemplo), sempre ávida em utilizar o governo em benefício próprio. As elites políticas locais ainda se comportariam como os “coronéis” da República Velha. Haveria, então, pouca concorrência eleitoral e, por isso, poucos incentivos para promover melhores políticas públicas (AVELAR; WALTER, 2008; CARVALHO, 2002; OTTMANN, 2006). Além disso, os eleitores dos pequenos municípios tenderiam a ser pouco demandantes do poder local, devido tanto aos baixos padrões históricos quanto devido à incapacidade de articulação própria da sociedade civil. Essa dificuldade política seria causada por questões sociológicas, como pobreza e baixa escolaridade da população. Este argumento é praticamente a reprodução do argumento da "teoria da modernização" (LIPSET, 1967) para o plano local. Pela teoria da modernização, o mero desenvolvimento econômico transformaria governos pobres, naturalmente autoritários, em governos democráticos. Isso ocorreria porque o desenvolvimento aumenta a proporção de eleitores das zonas urbanas e da classe média, que são mais escolarizados e demandantes que os eleitores pobres da zona rural. Se assumirmos que os mesmos mecanismos que levam a um governo democrático também influenciam positivamente a eficiência estatal, melhorando a qualidade da burocracia, por exemplo, assumiremos então que as sociedades mais desenvolvidas tendem a ter governos mais eficientes.

\footnotetext{
${ }^{2}$ Além dos trabalhos clássicos citados, podemos mencionar Carvalho (2002), Avelar and Lima (2000) e Avelar and Walter (2008). Entre autores estrangeiros, podemos destacar Mainwaring (2001) e Ottmann (2006).
} 


\subsection{1- Formalização das hipóteses sobre a teoria da modernização}

Podemos definir as principais hipóteses da teoria da modernização da seguinte forma:

Hipótese 1: quanto maior for a população da cidade, mais eficiente tenderá a ser o seu setor público.

Essa hipótese fala sobre os efeitos de escala. Basicamente, ela argumenta que existe ganho de escala na provisão de serviços públicos.

Hipótese 2: quanto maior for o desenvolvimento econômico da cidade, mais eficiente tenderá a ser seu setor público.

Essa hipótese é o núcleo da teoria da modernização, no que diz respeito à eficiência pública. Em nossa análise, utilizaremos a renda per capta das famílias como proxy do desenvolvimento local, uma vez que outras medidas, como o PIB, são mais ligadas ao valor agregado das empresas locais do que propriamente ao nível de desenvolvimento social local ${ }^{3}$. Contudo, para ser coerente com a visão sobre o "coronelismo" dos governos locais, poder-se-ia considerar que o que faz com que uma cidade seja ineficiente não é apenas a renda média, que pode ser influenciada pela presença de uma elite rica, mas sim a presença de eleitores pobres. Então, pode-se elaborar uma nova versão da Hipótese 2:

\footnotetext{
${ }^{3}$ Podemos pensar no caso, bem comum, de uma pequena cidade que possui apenas uma única grande empresa, situada nos limites da cidade. É possível o PIB per capita dessa cidade seja alto, mas não necessariamente seu desenvolvimento social, uma vez que grandes empresas frequentemente possuem poucos empregados e muitos deles sequer sejam moradores da cidade. Podemos pensar a situação oposta, das cidades dormitório, onde os moradores da cidade trabalhem nas regiões vizinhas. Em muitas cidades dormitório, o PIB per capita é, em geral, muito baixo, mas essa medida sub-representa o desenvolvimento social local.
} 
Hipótese 2a: o desenvolvimento econômico, combinado com a melhor distribuição de renda, gera governos mais eficientes.

Por fim, temos a hipótese que fala do ganho gerado pela concentração populacional. Essa hipótese argumenta que não é propriamente o desenvolvimento econômico que gera maior eficiência, mas uma de suas consequências: a concentração populacional e o aumento da urbanização.

Hipótese 3: quanto mais concentrada a população, maior a eficiência governamental.

Podemos resumir os argumentos da teoria da modernização através da figura 1.1. Os sinais positivos, “(+)", indicam que existe uma relação causal positiva entre um fenômeno e outro. Por exemplo, o aumento da população causa o aumento da eficiência (Hipótese 1). Repare que nesse esquema, as próprias relações causais podem sofrer a influência de outras relações causais. Podemos ver que a influência do desenvolvimento econômico é afetada pela desigualdade: quanto maior a igualdade social, maior a influência do desenvolvimento sobre a eficiência (Hipótese 2a).

\section{Figura 1.1 - Descrição esquemática das hipóteses da teoria da modernização}

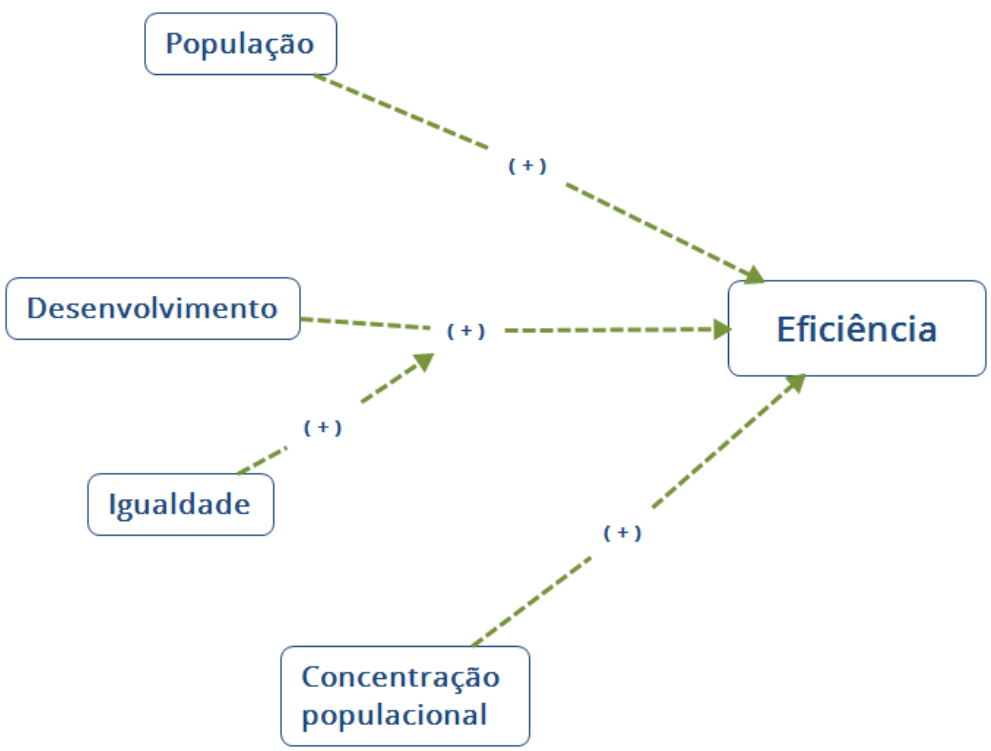




\subsection{2- O poder local à sombra do coronelismo}

A visão de que os governos dos municípios pequenos, pobres e rurais são dominados por uma oligarquia atrasada e autoritária foi imensamente influenciada pelos primeiros autores das ciências sociais no Brasil, notadamente pelos clássicos "Raízes do Brasil" de Sérgio Buarque de Hollanda (BUARQUE DE HOLANDA, 2004) e "Coronelismo, Enxada e Voto", de Victor Nunes Leal (LEAL, 1993). O primeiro livro faz uma análise da história do Brasil desde a colonização até os anos 30, enquanto o segundo livro se concentra sobretudo na República Velha. Apesar de serem obras já muito antigas, a influência de ambos os livros ainda pode ser sentida sobre a visão que se tem do setor público local.

Um ponto interessante para a presente tese, é que as duas teorias tratadas aqui, o determinismo sociológico e o institucionalismo, podem ser usadas para interpretar essas duas obras clássicas. A obra de Buarque, principalmente em sua primeira versão, professa de forma muito clara uma visão culturalista sobre a sociedade e o Estado (SCHLEGEL, 2017). Segundo o autor, as raízes ibéricas de nossa formação nacional tornariam as instituições democráticas inviáveis em solo nacional e a modernização social teria que vir através de um Estado central forte e autoritário. Deve-se ressaltar que Buarque alterou significativamente seu livro após a experiência do Estado Novo. Na segunda edição da obra, ele argumenta que por mais que a nossa formação "cordial", mais ligada a vínculos afetivos entre líderes e liderados que a instituições impessoais, seja um entrave à democracia, ainda assim devíamos construir instituições democráticas. A obra de Leal, por outro lado, foi uma verdadeira obra institucionalista avant la lettre. Ao contrário de muitas interpretações posteriores, que atribuíam o "coronelismo" apenas ao subdesenvolvimento da sociedade local (FURTADO, 2006; LAMBERT, 1959), Leal enxergava o fenômeno como um sistema de laços de lealdade que se criava de cima para baixo. O "pacto coronelista" começa com a construção de laços de lealdade entre os governadores de Estado e os líderes locais. Esse pacto fornecia os instrumentos necessários para que os líderes locais controlassem o poder dentro dos municípios. Os coronéis locais somente possuíam "moedas de troca políticas" por causa de sua relação com o governador. Essas "moedas de troca" seriam principalmente: (1) o acesso ao sistema policial e judiciário, (2) acesso a ajudas assistenciais, (3) acesso a serviços públicos básicos, como emissão de documentos e (4) verbas para obras no município. O 
sistema de segurança era, durante a República Velha, de responsabilidade estadual, pois era o governador de Estado que indicava o delegado e o juiz local. O líder político local, naturalmente, tinha influência sobre esses atores chave, podendo utiliza-los para proteger parceiros e atacar inimigos. Mas isso somente era possível por causa de seus laços com o governo estadual. É importante considerar que durante a República Velha, (como de certa forma ocorre ainda hoje) os municípios tinham muito pouca verba própria, sendo sua principal fonte de receita as transferências do governo estadual. Então, os serviços assistenciais e as obras públicas que os líderes locais podiam prover à população (e assim garantir seu poder) dependiam dos seus laços com os níveis superiores de governo. Não por acaso, Leal ressalta que os líderes locais não podiam suportar "o sacrifício da oposição" (LEAL, 1993, p. 33).

Toda a estrutura política narrada por Leal era sustentada por uma estrutura financeira e tributária particular. Como nos narra Ricardo Varsano (VARSANO, 1997), até o Estado Novo, a principal fonte de arrecadação do Estado brasileiro eram os tributos sobre o comércio exterior, ou seja, os impostos de importação e exportação. O imposto de importação, o principal imposto do país até os anos 30, era de atribuição federal. Isso garantia ao governo federal a maior parte das receitas públicas. O imposto de exportação era, até os anos 60, de atribuição estadual, o que garantia boa receita para os estados exportadores ricos, principalmente São Paulo, Minas, Bahia e o Distrito Federal (no Rio de Janeiro). Os demais estados, viviam, basicamente, de repasses do governo federal. Aos municípios cabiam os impostos sobre a propriedade territorial. No entanto, os impostos sobre a terra nunca tiveram grande arrecadação, devido a um sistema de registros de terras precário. Como consequência, os municípios viveram na maior parte da história do Brasil sobre grande dependência dos governos federal e estadual. Segundo o arranjo de poder narrado por Leal, era a dependência do Município em relação aos governos superiores, e não sua autonomia, que garantiram o coronelismo. Podemos pensar, por hipótese, que se os municípios tivessem tido uma verdadeira autonomia política e financeira desde a independência, sua estrutura política seria totalmente diferente. Nesse caso, é provável que a democratização política tivesse surgido antes, tal como ocorreu nos Estados Unidos. Robert Dahl (DAHL, 2005) nos narra a situação de New Haven, no Estado de Connecticut, onde a democracia surgiu inicialmente como uma competição entre oligarquias locais e gradualmente, durante os séculos XIX e XX, foi se espalhando para todas as classes sociais. Tal situação simplesmente não era possível no Brasil da 
República Velha, pois o pacto coronelista era entre o governador de Estado e um único grupo político local. Não era possível haver um pacto de lealdade entre o governador e dois grupos locais rivais, pois as elites políticas estaduais e municipais formavam um único corpo político. Apenas um grupo podia ser o representante "oficial” da situação estadual no município. Como o município dependia dos recursos do governo estadual, e a distribuição de transferências intergovernamentais era altamente discricionária, os municípios, além de não poderem suportar o ônus da oposição, também não podiam suportar o "sacrifício" de uma verdadeira competição política.

Apesar do coronelismo, enquanto organização social e política, ter sido gradualmente desmontando durante o século XX, em grande parte com a instituição do voto secreto e da Justiça eleitoral, o uso das transferências intergovernamentais continuou como uma forma do governo central controlar as elites locais e, por consequência, bloquear a competição política local. Durante os governos autoritários do Estado Novo e da ditadura militar, as bases próprias de arrecadação dos municípios foram severamente reduzidas e as transferências eram completamente controladas pelo governo central, que frequentemente impunha sua agenda política aos municípios. Assim, a dependência financeira do município foi um entrave à democratização local no Brasil. Existem evidências, sobre épocas bem mais recentes (durante o século XX), de que tal situação ocorreu de forma parecida no México (DIAZ-CAYEROS; MAGALONI; WEINGAST, 2003) e na Argentina (GERVASONI, 2010), onde o governo central teve discricionariedade para direcionar as transferências aos governos locais durante praticamente todo o século XX. Atualmente, no Brasil, apesar dos municípios continuarem altamente dependentes de recursos externos, a Constituição de 1988 reduziu fortemente o espaço para que as transferências fossem utilizadas pelos níveis superiores de governo para manipular a política local, através do estabelecimento de regras claras e rígidas de distribuição dos recursos. Assim, atualmente, os municípios estão relativamente protegidos contra o estrangulamento financeiro quando a oposição ganha as eleições. Contudo, ainda não podemos afirmar que as transferências não estejam influenciando de forma negativa os governos locais, reduzindo a eficiência das políticas públicas, ao reduzir os laços econômicos que ligam o governo local à sociedade local. Trataremos desse tema na próxima seção. 


\section{2- Modelo de federalismo fiscal}

Podemos definir como "federalismo fiscal" as regras que ordenam a distribuição de recursos e competências entre os diferentes níveis de governo em um sistema federativo ${ }^{4}$. Grande parte da literatura sobre o "federalismo fiscal" (Atkinson and Stiglitz 2015; Bosch, Espasa, and Mora 2012; Cossío 1998; Geys, Heinemann, and Kalb 2010; Oates 1999; Tibeout 1956; Weingast 2014) argumenta que os níveis subnacionais tenderão a ser mais eficientes se o setor público local for financiado pelos seus próprios eleitores. Quando os recursos arrecadados localmente são gastos em benefícios locais, a comunidade tem a correta percepção da relação custo/benefício dos serviços públicos, podendo determinar a quantidade de bens públicos que maximiza seu bem-estar. Inversamente, caso o nível local não seja financiado com os recursos locais, ocorre uma ineficiência decorrente da "assimetria de informação", pois os cidadãos perderão a capacidade de avaliar quanto custa seu governo. Como, nesse caso, quem financia os serviços públicos são os contribuintes de fora da jurisdição, os cidadãos locais passarão então a acreditar que os bens públicos custam menos do que realmente custam, fenômeno que ficou conhecido na literatura como "ilusão fiscal" (COURANT; GRAMLICH; RUBINFELD, 1978). A ilusão fiscal, originalmente, era vista apenas como uma distorção alocativa, pois ela faz com que os cidadãos demandem mais bens públicos do que o socialmente desejável ${ }^{5}$. Contudo, alguns autores, como Cossío (1998) e Geys et al, (2010), inspirados pela teoria de Niskanen (1971), de que o setor público é "maximizador de orçamento", também passaram a argumentar que a ilusão fiscal gera também uma distorção administrativa, pois os governos aproveitam a assimetria de informação para se apropriar privadamente de uma parte do orçamento. Basicamente, essa teoria diz que quando o governo pode aumentar seu orçamento sem precisar taxar seus eleitores, uma parte desse orçamento será apropriada pela elite governamental.

Por outro lado, as federações modernas raramente deixam de adotar mecanismos de transferências intergovernamentais. O principal motivo para isto é dar equidade ao gasto per capita dos governos subnacionais, permitindo que os cidadãos de todo o país tenham serviços públicos razoavelmente semelhantes. A completa autonomia dos

\footnotetext{
${ }^{4}$ Em alguns casos, pode-se analisar, pela mesma ótica, as relações entre os níveis de governo em países unitários.

${ }^{5}$ Os autores partem do pressuposto de que existe uma proporção de bens públicos e de bens privados que maximiza o bem-estar da comunidade. Quando existe a ilusão fiscal, a comunidade acredita que bens públicos são mais baratos do que realmente são, fazendo com que a demanda por bens públicos seja maior do que o socialmente ótimo.
} 
governos subnacionais pode levar a uma "corrida para baixo" (race to the bottom) na provisão de serviços, notadamente os voltados para a população mais pobre e vulnerável. Isso acontece porque se um governo subnacional cria benefícios sociais sem ser acompanhado pelos demais, ele atrai os pobres das regiões vizinhas, devido ao "magnetismo do welfare" (PETERSON, 1995; PETERSON; ROM, 1990). Nessa situação, manter os benefícios significa aumentar os impostos, afastando as empresas. Como consequência, em federações com grande autonomia local, a provisão de certos benefícios sociais por governos locais pode fazer com que a situação social local piore ao invés de melhorar.

Assim, existe um trade-off entre eficiência e equidade no sistema de financiamento dos níveis subnacionais. Por um lado, o financiamento dos níveis locais pelos próprios cidadãos tende a elevar a cobrança social e manter o governo austero. Por outro lado, a completa autonomia subnacional geraria uma corrida para baixo na provisão de serviços sociais, privando os cidadãos de direitos sociais básicos. Diante de tal dilema, as federações de todo o mundo procuraram desenvolver instituições que equilibrem eficiência e equidade nas relações intergovernamentais. Prado (2007) analisou detalhadamente os sistemas de redistribuição da Alemanha, Canadá, Ìndia e Austrália. Segundo o autor, essas federações desenvolveram mecanismos institucionais para evitar um comportamento rent-seeking dos governos locais, como incentivos à arrecadação própria, supervisão nacional sobre o desempenho local e acordos intergovernamentais sobre o uso dos recursos. Prado (2007) mostra, como exemplo, que na Austrália as transferências são decididas por mecanismos flexíveis, através de negociação anual entre os entes federativos no Poder Legislativo - bem diferente do Brasil, onde as regras são muito rígidas e estão inscritas na Constituição. Isso permite que o o governo federal exija contrapartidas pelos recursos enviados, como um padrão mínimo nos serviços públicos e complementação de recursos por parte do governo local (os chamados matching grants). No caso Austaliano existe uma câmara de especialistas, vinculada ao parlamento, que elabora um sistema de indicadores para a distribuição dos recursos segundo as necessidades e o desempenho de cada província. Na Alemanha, existe um complexo sistema de arenas de negociação intergovernamental para determinar a quantidade e o uso das transferências - que são substanciais no caso germânico. No Canadá, o "federalismo executivo" garante que as transferências sejam negociadas segundo contratos federativos entre o primeiro-ministro federal e os primeiros-ministros provinciais. Tais contratos se caracterizam pelo caráter flexível, sofrendo ajustes pontuais ano a ano. Segundo Prado 
(2007), devido às características próprias do sistemas de governo desses países, não existem evidências de que as transferências são utilizadas para fins clientelistas.

No caso brasileiro, o desejo dos constituintes de 1988 de criar um sistema de provisão de serviços públicos igualitário em território nacional levou a um grande aumento das transferências intergovernamentais, tanto para os estados quanto para os municípios (VARSANO, 1997). Contudo, o histórico de desconfiança entre os níveis de governo fez com que os legisladores criassem um sistema de transferências que são constitucionais, automáticas e incondicionadas, de modo a impedir que o governo federal use seu poder orçamentário para manipular a política local com fins clientelistas (MENDES; MIRANDA; COSIO, 2008; PRADO, 2007). Cerca de 70\% das transferências intergovernamentais no Brasil, o equivalentes a 5,87\% do PIB, são incondicionadas ${ }^{6}$.

As regras que regem as transferências também acabam criando algumas situações curiosas. Podermos ver isso olhando para três das principais fontes de transferências intergovernamentais que favorecem os municípios: o FPM, a cota-parte do ICMS e os royalties do petróleo. O Fundo de Participação dos Municípios (FPM), sustentado pelo governo federal, tende a fornecer um montante per capita maior quanto menor a população do município. Quando o município é muito pequeno ele tende a ter uma receita per capita altíssima. O caso mais icônico é Borá, no Estado de São Paulo. Esse município de 808 habitantes possui uma receita per capita de FPM de R $\$ 6.638,95$, enquanto a média do estado é R\$ 197,717 . Segundo Brollo et alli (2013), os municípios mais beneficiados pelo FPM tendem a ter mais casos de corrupção e prefeitos menos escolarizados. A cotaparte do ICMS, por outro lado, favorece os municípios que possuem grandes indústrias ${ }^{8}$. Os casos mais conhecidos em São Paulo são Paulínia, Cubatão e São Caetano do Sul. Os dois primeiros são sede de grandes refinarias de petróleo, enquanto o último é um importante polo automobilístico. Como uma parte do ICMS local é destinado à prefeitura, e esses três municípios não são muito populosos, eles acabam tendo uma altíssima arrecadação per capita. Existem casos menos extremos, mas que também merecem análise. Podemos comparar São José do Rio Preto e São José dos Campos, por exemplo. Apesar de ambos os municípios serem de médio porte, com 430 mil e 672 mil habitantes,

\footnotetext{
${ }^{6}$ Dados de 2013. Fonte: STN Finbra, elaboração própria.

${ }^{7}$ Dados de 2015.

${ }^{8} \mathrm{O}$ ICMS, Imposto sobre operações relativas à circulação de mercadorias e sobre prestações de serviços de transporte interestadual, intermunicipal e de comunicação, é um imposto sobre o valor agregado de competência estadual. Segundo a Constituição Federal, 25\% do ICMS deve ser repassado aos municípios. Desse montante, $75 \%$ deve ser repassado de acordo com o valor adicionado no território.
} 
respectivamente, a receita de de ICMS é muito diferente, $\mathrm{R} \$ 396,53$ e $\mathrm{R} \$ 952,31$ per capita, respectivamente. Abaixo mostraremos que o nível de eficiência dos dois municípios é consideravelmente diferente, sendo que São José do Rio Preto consegue ser mais eficiente que São José dos Campos, mesmo tendo menos receitas.

Por fim, podemos mencionar os royalties, principalmente os royalties do petróleo 9 . Durante os anos 2000, as receitas de royalties aumentaram consideravelmente, tanto por causa do aumento do preço internacional do petróleo quanto pela descoberta de novas jazidas no litoral brasileiro. Segundo Afonso \& Gobetti (2008), os recursos obtidos pelas prefeituras com royalties foram destinos sobretudo para aumentos de gastos com funcionalismo e com a Câmara dos Vereadores, dado que que os recursos com saúde, educação e gestão ambiental são iguais em prefeituras que recebem e que não recebem royalties. Ao que tudo indica, o caso dos royalties do petróleo repete em pequena escala a chamada "maldição dos recursos naturais". Sachs \& Warner (2001) e Auty (2007) mostraram que os países com abundância de recursos naturais apresentam taxas de crescimento inferiores aos relativamente desprovidos de tais recursos. Embora a explicação inicial para tal fenômeno fosse a "doença holandesa", um número crescente de estudos tem relacionado tal fato ao comportamento predatório das elites e à baixa qualidade das instituições (ATKINSON; HAMILTON, 2003; MEHLUM; MOENE; TORVIK, 2006). A teoria elaborada por Brollo et al. (2013), não por acaso chamada de "political resource curse" vai exatamente nesse sentido. Segundo esses autores, a alta renda do setor público torna mais vantajosa a entrada na política de indivíduos menos qualificados e mais dispostos a corrupção. Isso ocorre porque receitas elevadas abrem maior espaço para estratégias políticas que combinam um nível de provisão de serviços públicos que garante o sucesso eleitoral e, ao mesmo tempo, permite elevada extração de renda pessoal para os governantes.

Por fim, deve-se considerar que apesar do argumento normativo básico a favor das transferências intergovernamentais ser a ampliação da igualdade de serviços públicos, notadamente para a população de baixa renda, nenhuma fonte dessas três fontes de transferências aos municípios leva em conta explicitamente a desigualdade de renda ou qualquer critério de necessidade físcal ${ }^{10}$. No caso das transferências do ICMS, o critério

\footnotetext{
${ }^{9}$ Também existem royalties relacionados à exploração de recursos minerais e hídricos (hidrelétricas). Porém, os recursos dos royalties do petróleo são muito maiores que os demais.

${ }^{10}$ Deve-se ressaltar que o Fundeb (Fundo de Desenvolvimento da Educação Básica) e as transferências destinadas ao SUS levam em conta critérios de necessidade fiscal. No entanto, essas fontes de recursos são minoritárias em relação ao total de transferências.
} 
adotado chega a levar ao resultado contrário, ampliando os recursos de cidades ricas. No caso do FPM, pode-se observar que ele possui um efeito redistributivo global, ao privilegiar municípios pequenos, que são, na maioria dos casos, municípios pobres. Contudo, existem muitos casos individuais de municípios pequenos e ricos, mas a regra de distribuição do FPM não leva em conta esse fato. Quanto aos royalties, seu critério de distribuição simplesmente não é correlacionado com a renda do município, podendo beneficar igualmente (de forma de certa forma aleatória) comunidades ricas e pobres.

\subsection{1 - Um pequeno estudo comparado intermunicipal}

O efeito das transferências governamentais é de certa forma óbvio quando observamos casos extremos, como Ilhabela, Borá, e Paulínia, que possuem as maiores receitas de transferências per capita do Estado. Em 2015, esses municípios tiveram receita per capita de $\mathrm{R} \$ 13.961 .5, \mathrm{R} \$ 11.782 .09$ e $\mathrm{R} \$ 11.338 .96$, respectivamente, enquanto a receita média do Estado foi de $\mathrm{R} \$ 3.524 .48$. Não é de se espantar que esses municípios sejam, pouco eficientes. Contudo, gostaria de mostrar o efeito das transferências em dois casos menos intuitivos: São José do Rio Preto e São José dos Campos. Ambas as cidades (além de terem o nome do mesmo santo) também possuem algumas características em comum que as tornam interessantes para uma análise comparada. Elas são cidades de porte médio, respectivamente as $11^{\mathrm{a}}$ e a $7^{\mathrm{a}}$ maiores cidades do Estado, apresentando índices de urbanização e densidade populacional altos. Além disso, ambas são cidades ricas, com renda per capita acima da média do Estado, conforme podemos ver na tabela 1.2. As duas cidades ainda possuem uma característica em comum importante para nossos propósitos: uma receita per capita parecida. Contudo, existe uma diferença fundamental em relação ao perfil das receitas: São José do Rio Preto é uma cidade com receitas de transferências menor e com uma dependência menor que São José dos Campos. A cidade consegue compensar a menor quantidade de transferências, em relação a São José dos Campos, com um esforço tributário maior, algo que não é comum. Essa diferença no perfil do financiamento público de ambas as cidades se deve a diferenças com relação à economia de cada município. São José dos Campos é sede de grandes indústrias, o que resulta em grandes transferências de recursos para a cidade, via cota-parte do ICMS. São José dos Campos possui uma economia baseada em serviços e pequenos estabelecimentos industriais, o que resulta em uma quantidade de transferências relativamente baixa. 
Tabela 1.1 -

\begin{tabular}{|c|c|c|c|c|c|c|}
\hline Procedimento & Complexidade & $\begin{array}{l}\text { Número de } \\
\text { procedimentos } \\
\text { São José do } \\
\text { Rio Preto }\end{array}$ & $\begin{array}{l}\text { Número de } \\
\text { procedimentos } \\
\text { São José dos } \\
\text { Campos }\end{array}$ & $\begin{array}{l}\text { Procedimentos } \\
\text { per capita - } \\
\text { São José do } \\
\text { Rio Preto }\end{array}$ & $\begin{array}{l}\text { Procedimentos } \\
\text { per capita - } \\
\text { São José dos } \\
\text { Campos }\end{array}$ & $\begin{array}{l}\text { Procedimentos } \\
\text { per capita - } \\
\text { Estado }\end{array}$ \\
\hline Visita Domiciliar por Profissional de Nível Médio & Atenção Básica & 561.727 & 113.792 & 1,305 & 0,169 & 0,581 \\
\hline Consulta Medica em Atenção Básica & Atenção Básica & 377.904 & 330.312 & 0,878 & 0,491 & 0,395 \\
\hline Coleta de Material P/ Exame Laboratorial & Atenção Básica & 126.004 & 100.592 & 0,293 & 0,150 & 0,229 \\
\hline $\begin{array}{l}\text { Administração de Medicamentos em Atenção } \\
\text { Básica (por paciente) }\end{array}$ & Atenção Básica & 105.341 & 111.402 & 0,245 & 0,166 & 0,314 \\
\hline Glicemia Capilar & Atenção Básica & 90.449 & 163.515 & 0,210 & 0,243 & 0,116 \\
\hline $\begin{array}{l}\text { Consulta de Profissionais de Nível Superior na } \\
\text { Atenção Básica (Exceto Médico) }\end{array}$ & Atenção Básica & 152.908 & 144.569 & 0,355 & 0,215 & 0,162 \\
\hline Avaliação Antropométrica & Atenção Básica & 194.067 & 72.278 & 0,451 & 0,107 & 0,144 \\
\hline Inalação / Nebulização & Atenção Básica & 63.236 & 106.005 & 0,147 & 0,158 & 0,067 \\
\hline $\begin{array}{l}\text { Administração de Medicamentos na Atenção } \\
\text { Especializada. }\end{array}$ & Média & 372.083 & 477.257 & 0,865 & 0,710 & 0,259 \\
\hline $\begin{array}{l}\text { Atendimento Médico em Unidade de Pronto } \\
\text { Atendimento }\end{array}$ & Média & 164.065 & 541.127 & 0,381 & 0,805 & 0,270 \\
\hline Consulta Medica em Atenção Especializada & Média & 440.292 & 204.608 & 1,023 & 0,304 & 0,166 \\
\hline Hemograma Completo & Média & 147.448 & 100.721 & 0,343 & 0,150 & 0,119 \\
\hline Dosagem de Glicose & Média & 76.015 & 106.107 & 0,177 & 0,158 & 0,064 \\
\hline $\begin{array}{l}\text { Analise de Caracteres Físicos, Elementos e } \\
\text { Sedimento da Urina }\end{array}$ & Média & 76.251 & 85.132 & 0,177 & 0,127 & 0,072 \\
\hline Tomografia Computadorizada do Crânio & Alta & 789 & 4.578 & 0,00183 & 0,00681 & 0,00239 \\
\hline Ressonância Magnética de Coluna Lombo-Sacra & Alta & 385 & 911 & 0,00089 & 0,00135 & 0,00042 \\
\hline Ressonância Magnética de Crânio & Alta & 273 & 974 & 0,00063 & 0,00145 & 0,00038 \\
\hline
\end{tabular}


Tabela 1.2 -

Dados discais de São José do Rio Preto e de São José dos Campos

\begin{tabular}{|lccc|} 
& $\begin{array}{c}\text { São José do } \\
\text { Rio Preto }\end{array}$ & $\begin{array}{c}\text { São José dos } \\
\text { Campos }\end{array}$ & $\begin{array}{c}\text { Estado } \\
\text { População }\end{array}$ \\
430.312 & 672.556 & 43.035 .871 \\
\hline Renda per capita média & $\mathrm{R} \$ 978,49$ & $\mathrm{R} \$ 955,77$ & $\mathrm{R} \$ 852,65$ \\
\hline $\begin{array}{l}\text { Receita de transferências } \\
\text { per capita }\end{array}$ & $\mathrm{R} \$ 1334,49$ & $\mathrm{R} \$ 1827,31$ & $\mathrm{R} \$ 2599,55$ \\
\hline Receita total per capita & $\mathrm{R} \$ 3338.30$ & $\mathrm{R} \$ 3567,25$ & $\mathrm{R} \$ 3530,60$ \\
\hline Dependência financeira & $47,73 \%$ & $54,85 \%$ & $78,27 \%$ \\
\hline $\begin{array}{l}\text { Gasto per capita na função } \\
\text { saúde }\end{array}$ & $\mathrm{R} \$ 681,98$ & $\mathrm{R} \$ 858,55$ & $\mathrm{R} \$ 699,64$ \\
\hline
\end{tabular}

Como essa diferença de perfil se reflete na eficiência da provisão de saúde? Podemos ter uma ideia na tabela 1.1, que mostra a produção dos procedimentos de saúde mais comuns em atenção básica, média complexidade e alta complexidade. Apesar de São José do Rio Preto ter um gasto per capita em saúde cerca de $20 \%$ menor que São José dos Campos, a produção de serviços é maior em quase todos os casos. Apenas nos serviços de alta complexidade, atribuição que, a princípio, cabe ao governo do Estado, é que a produção per capita do São José dos Campos é sistematicamente maior. Assim, a população de São José do Rio Preto possui mais serviços públicos de saúde que a população de São José dos Campos, mesmo gastando menos recursos. Não podemos afirmar que o que diferencia as duas cidades seja o grau de desenvolvimento social, pois ambas as cidades são igualmente ricas e urbanas. Também não é factível argumentar que o que diferencia ambas é a capacidade técnica da burocracia. Em verdade, São José dos Campos é sede de grandes universidades públicas e privadas, privilégio que São José do Rio Preto não tem. O que explicar a diferença entre as duas cidades é o tipo de financiamento público. São José dos Campos obtém volumosos recursos de grandes empresas, como a Refinaria Henrique Lage, a Embraer, a General Motors e a Ericsson. Essas empresas recolhem impostos que foram cobrados de seus consumidores, que, em sua maioria, não são moradores da cidade de São José dos Campos. Porém, devido às regras de distribuição do ICMS, uma parte desses recursos fica com o município. Como consequência, a cidade consegue tributar consumidores de fora de sua jurisdição. Essa situação é cômoda para o governo local e para os próprios moradores, que são "desonarados" de terem que financiar os serviços locais com a renda local. Contudo, essa situação "cômoda" pode estar gerando incentivos negativos para o uso dos recursos 
públicos. Em governos onde cada serviço local precisa ser financiado com impostos locais, situação mais próxima à realidade de São José do Rio Preto, o governo e os próprios cidadãos parecem se preocupar muito mais com a qualidade do governo.

\subsection{2- Formalização da hipótese sobre a influência do financiamento público}

Os argumentos levantados acima apontam dois mecanismos causais diferentes para a influência das transferências intergovernamentais sobre a eficiência local. Podemos sintetizar esses argumentos da seguinte forma:

Hipótese 4: quanto maior for o montante de transferências destinadas aos governos locais, menor será sua eficiência.

A Hipótese 4 argumenta que os recursos que não são provenientes da comunidade local, ou seja, foram obtidos de contribuintes que não são eleitores, tenderiam a ser mau utilizados. A base para esse argumento é a assimetria de informação sobre o custo do setor público que existe entre a elite estatal e a população, que tende a ser maior quando os recursos públicos não foram arrecadados pela via tributária. Por outro lado, o argumento levantado por Brollo et al. (2013) e outros que argumentam as transferências causam efeitos análogos à "maldição dos recursos naturais" pode ser resumida da seguinte forma:

Hipótese 5: quanto mais abundantes os recursos estatais menor tende a ser a eficiência pública.

A Hipótese 5 fala que os recursos estatais tendem a ser mal utilizados quando eles são abundantes. Para diferenciar essa hipótese das questões relacionadas à escala das políticas públicas, sempre mensuraremos a abundância utilizando a receita pública per capita, e não a receita pública total. Contudo, essa hipótese precisa de qualificação. Os recursos seriam abundantes em relação à o que? Podemos pensar em dois referenciais para determinar a "abundância" dos recursos: 
Hipótese 5a: quanto mais abundantes os recursos estatais per capita em relação à média dos demais governos de mesmo nível (estadual, municipal, etc), menor tende a ser a eficiência pública.

A Hipótese 5a diz que quanto maior for a receita de recursos de um município em relação à média dos demais, menor será sua eficiência. Essa hipótese não é diferente da hipótese de que existe uma relação linear inversa entre receita per capita e eficiência. Podemos dizer, usando a linguagem econômica, que o gasto público possui retorno marginal decrescente: cada recurso adicional produz menos por unidade que o recurso anterior. Assim, as transferências não diminuiriam a eficiência porque são recursos externos, mas sim porque são recursos a mais. Essa hipótese é difícil de separar da Hipótese 4. Inclusive, a metodologia proposta no trabalho de Brollo et al. (2013) não consegue distinguir a Hipótese 4 da Hipótese 5a. Brollo observou que quando os municípios recebiam transferências adicionais, havia mais casos de corrupção e os prefeitos eram menos escolarizados. Contudo, não é possível, por essa metodologia, separar o efeito do aumento das transferências do efeito do aumento de recursos. Porém, o presente trabalho resolveu esse problema utilizando modelos interativos. Iremos interagir o nível de dependência financeira com o montante de recursos per capita. Assim, podemos separa o efeito do mero aumento de recursos (que pode ser por via de transferências ou não) do efeito do aumento de transferências.

Outra forma de interpretar a "abundância" de recursos é a seguinte:

Hipótese 5b: quanto mais abundantes os recursos estatais per capita em relação à sociedade civil local, menor tende a ser a eficiência pública.

Essa hipótese argumenta que o que causa a perda de eficiência é o desbalanceamento entre as receitas públicas locais e a renda privada local. A afluência de renda pública em sociedades pobres tenderia a incentivar a elite local a desenvolver uma relação parasitária com o setor público. Essa hipótese é coerente com o estudo de Gervasoni (2010), sobre a influência das transferências constitucionais na Argentina. De certa forma, essa hipótese é uma mescla das teorias institucionalista e da teoria da modernização. A presença de um governo rico em uma comunidade pobre favorece um comportamento predatório da elite 
política. Assim, os recursos abundantes não seriam necessariamente danosos, caso a sociedade civil seja também rica. Abaixo iremos explorar essa possibilidade, também utilizando modelos interativos.

Podemos descrever esquematicamente as hipóteses acima através da figura 1.2. Repare que existe um efeito negativo direto do aumento da receita pública sobre a eficiência (Hipótese 5a). Igualmente, existe um efeito direto da dependência financeira ${ }^{11}$ sobre a eficiência. Porém, o esquema mostra que a dependência reforça o efeito negativo da abundância de recursos e a abundância de recursos reforça o efeito das transferências (Hipótese 4). Esse efeito interativo é a forma que encontramos de separar o efeito das transferências do efeito do mero aumento de recursos. Caso apenas colocássemos o montante de transferências em nosso modelo, não seria possível distinguir as hipóteses Hipótese 4 e Hipótese 5a. Porém, podemos distinguir tal efeito com modelos interativos. Caso a Hipótese 4 seja verdadeira, mas não a Hipótese 5a, apenas as receitas de transferências seriam danosas para a eficiência, mas não as receitas próprias. Nesse caso, a receita total somente diminuiria a eficiência caso estivesse combinada com a dependência. Ou seja, uma dependência alta é condição necessária para que a receita pública tenha um papel negativo na eficiência. Caso a Hipótese 5a seja verdadeira, mas não a Hipótese 4, então não haveria efeito interativo entre receita e dependência. Nessa possibilidade, qualquer aumento de receita, seja ele de transferências ou não, teria o mesmo efeito na eficiência. Por fim, segundo a Hipótese 5b, a renda privada das famílias tende a diminuir o efeito da abundância de recursos. Assim, governos ricos seriam eficientes, caso a população seja rica também.

\footnotetext{
${ }^{11}$ A dependência financeira é igual ao montante de transferências correntes sobre a receita total (receita de transferências/receita total). Na amostra, ela varia entre $40 \%$ e $100 \%$.
} 
Figura 1.2 - Descrição esquemática das hipóteses do federalismo fiscal.

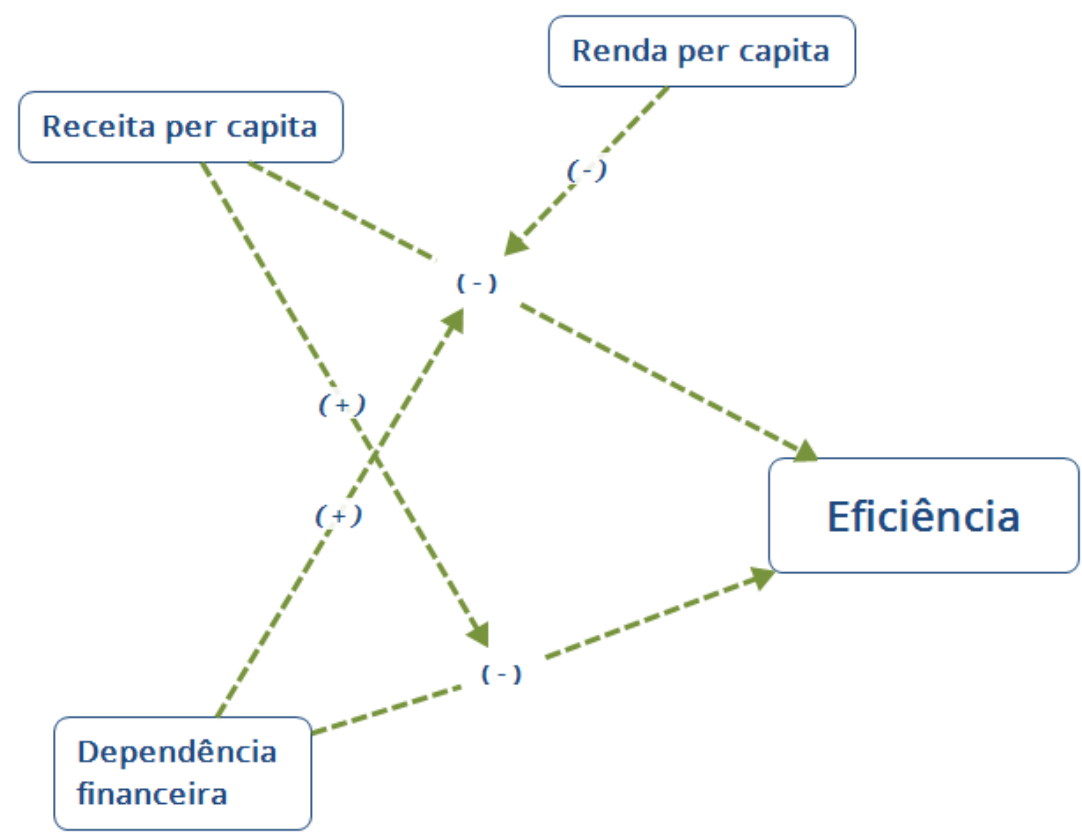

Antes de passar ao próximo tópico, gostaria de ressaltar que as características socioeconômicas das cidades (fundamentais para a teoria da modernização) e o montante de transferências constitucionais (hipótese institucionalista abordada aqui) são fenômenos altamente correlacionados. Isso se deve ao fato de que no Brasil, como em grande parte das federações, os municípios pequenos e pobres tendem a ser mais dependentes de recursos externos que os municípios grandes e ricos. Isso pode ser visto no gráfico abaixo, que descreve a proporção de receitas próprias e de transferências em diferentes faixas populacionais.

Podemos ver que quanto maior o município, menor tende a ser as transferências per capita, em média. Casos como esses são propícios a sofrer de "viés de variável omitida", caso uma das variáveis esteja ausente. Por exemplo, admitindo, por hipótese, que as cidades menores recebem mais transferências, mas somente as transferências influenciam na eficiência governamental, se apenas colocarmos a população na análise, e não as transferências, irá parecer que a população está influenciando a eficiência, quando esse efeito é, na verdade, causado pelas transferências. É exatamente isso que ocorre em muitos estudos atuais sobre eficiência do setor público local no Brasil. Todos os estudos sobre eficiência pública municipal que esta pesquisa encontrou incluem a população 
como variável de análise, mas pouquíssimos analisam as transferências ${ }^{12}$. Por outro lado, a proposição de que as transferências possuem efeito negativo na eficiência local é estabelecida na literatura internacional, mas ainda é pouco testada empiricamente com casos brasileiros. Esse trabalho pretende preencher essas lacunas.

Figura - 1.3

Dependência financeira dos municípios do Estado de São Paulo (2015)

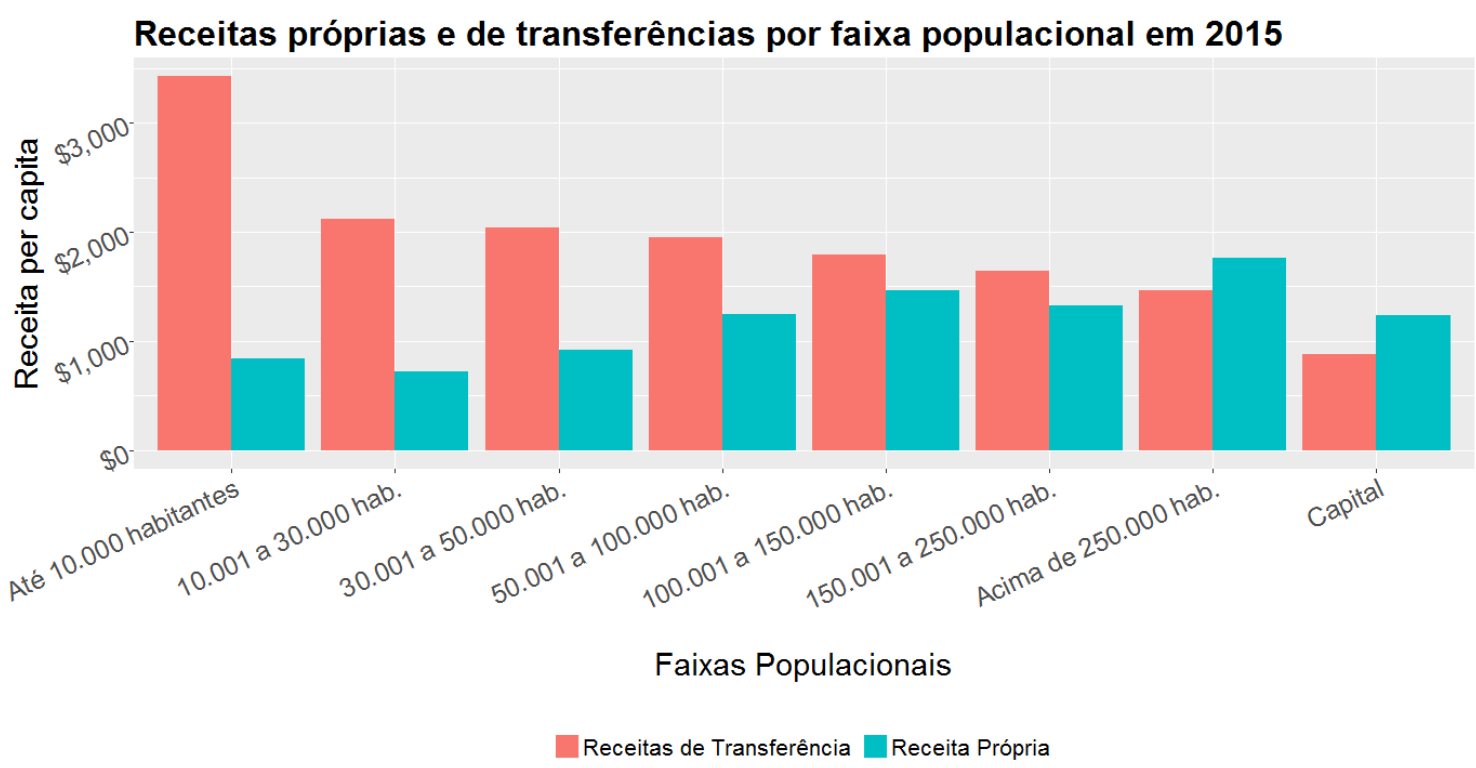

1.3 - O caso de análise: os Municípios do Estado de São Paulo

Neste trabalho, iremos utilizar um indicador inédito de eficiência para medir o desempenho dos municípios do Estado de São Paulo na provisão de saúde pública. A metodologia criada para esse estudo acabou se demonstrando tão flexível, que ela pode

\footnotetext{
${ }^{12}$ Até onde pudemos constatar, apenas Furtado (2012) e Sampaio De Sousa \& Stošić (2005) analisaram o papel das transferências intergovernamentais na eficiência municipal. Contudo, em ambos os casos, não foram incluídas todas as transferências na análise. Furtado analisou apenas o FPM. Sampaio et ali analisou apenas os royalties do petróleo. Nenhum trabalho estudou o efeito das transferências do ICMS, mesmo sendo essa a maior transferência intergovernamental do país. Também, os estudos citados não separa o efeito das transferências do efeito do montante de recursos, ou seja, não se distingue a Hipótese 4 da Hipótese 5, como nós fazemos aqui.
} 
ser utilizada para analisar a eficiência da provisão de saúde de qualquer nível federativo. Também é possível, com a mesma metodologia, fazer análises micro, medindo a eficiência de estabelecimentos de saúde individuais - desde que existam dados financeiros desagregados. Contudo, vale justificar a escolha da análise ao nível municipal e também do Estado de São Paulo.

Apesar do objeto teórico de o estudo ser a eficiência do setor público como um todo, este estudo tratará apenas de governos municipais. Isso acontece por duas razões: (1) os governos municipais são em maior número e são mais variados, facilitando o uso de métodos estatísticos para testar as hipóteses levantadas aqui, e (2) eles são menores e mais fáceis de serem estudados. Ou seja, apesar de ser possível fazer um estudo interessante sobre os governos estaduais, tanto fatores estatísticos (número e variabilidade de casos) quanto técnicos (menor complexidade dos casos), me induziram a focar apenas nos governo municipais. A escolha de São Paulo se deve à fácil disponibilidade de informações, devido aos detalhados bancos de dados do Tribunal de Contas do Estado ${ }^{13}$ e da Fundação Seade ${ }^{14}$. Algumas características do Estado também o tornam atraente para a análise. São Paulo é o estado mais populoso e o mais rico da federação brasileira, contendo por volta de $20 \%$ da população e $40 \%$ do PIB nacional. O Estado está em segundo lugar no número total de municípios do país, com 645 municípios. Além disso, São Paulo é um estado relativamente uniforme quanto à geografia. A maior parte da heterogeneidade municipal no Estado pode ser modelada com variáveis disponíveis, como o tamanho da população e os graus de urbanização e desenvolvimento econômico. Analisar o todo Brasil nos obrigaria a modelar a influência de condições adversas, como os municípios da região amazônica ou do semiárido no Nordeste, o que poderia criar ruídos na análise. Contudo, a metodologia proposta neste trabalho poderá ser facilmente replicada em outras amostras.

\footnotetext{
${ }^{13} \mathrm{O}$ TCE-SP recolhe anualmente informações sobre as finanças municipais através do sistema AUDESP, que tem mais informações que a Secretaria do Tesouro Nacional-STN, fonte mais comum dos dados sobre finanças públicas municipais. Os dados do Município de São Paulo foram retirados diretamente do site da secretaria de finanças.

${ }^{14}$ A Fundação Estadual de Análise de Dados, Seade, possui projeções populacionais discriminando entre população urbana e rural e também por idade. Ao nível federal, no site do IBGE, as taxas de envelhecimento e de urbanização apenas estão disponíveis nos anos do censo demográfico e apenas o total da população possui projeções para todos os anos.
} 


\section{4 - O conceito de eficiência na gestão pública}

Uma pergunta fundamental para responder as questões levantadas neste trabalho é justamente, “o que é eficiência?”. Essa pergunta pode ser escorregadia, pois a eficiência é vista de formas muito diferente por diferentes abordagens econômicas. Além disso, conceitos próximos, mas não iguais, como produtividade, eficácia e efetividade podem ser confundidos com a eficiência. Essa seção visa dar maior clareza conceitual ao tema ${ }^{15}$, algo fundamental para a compressão dos próximos capítulos, que visam justamente apresentar a medida empírica de eficiência usada nesse trabalho.

A economia do setor público pode ser entendida como um ciclo, onde o Estado retira recursos da sociedade, através de impostos e outros meios, e os transformam em produtos e serviços para a sociedade. Os serviços públicos podem impactar a sociedade, gerando "resultados". Em um ciclo ideal, o resultado das políticas públicas gera um processo de desenvolvimento social que amplia a quantidade de insumos disponíveis para o setor público no ciclo seguinte. A figura 1.4 mostra esquematicamente o fluxo de insumos e produtos na gestão pública ${ }^{16}$.

Figura 1.4: modelo circular do setor público

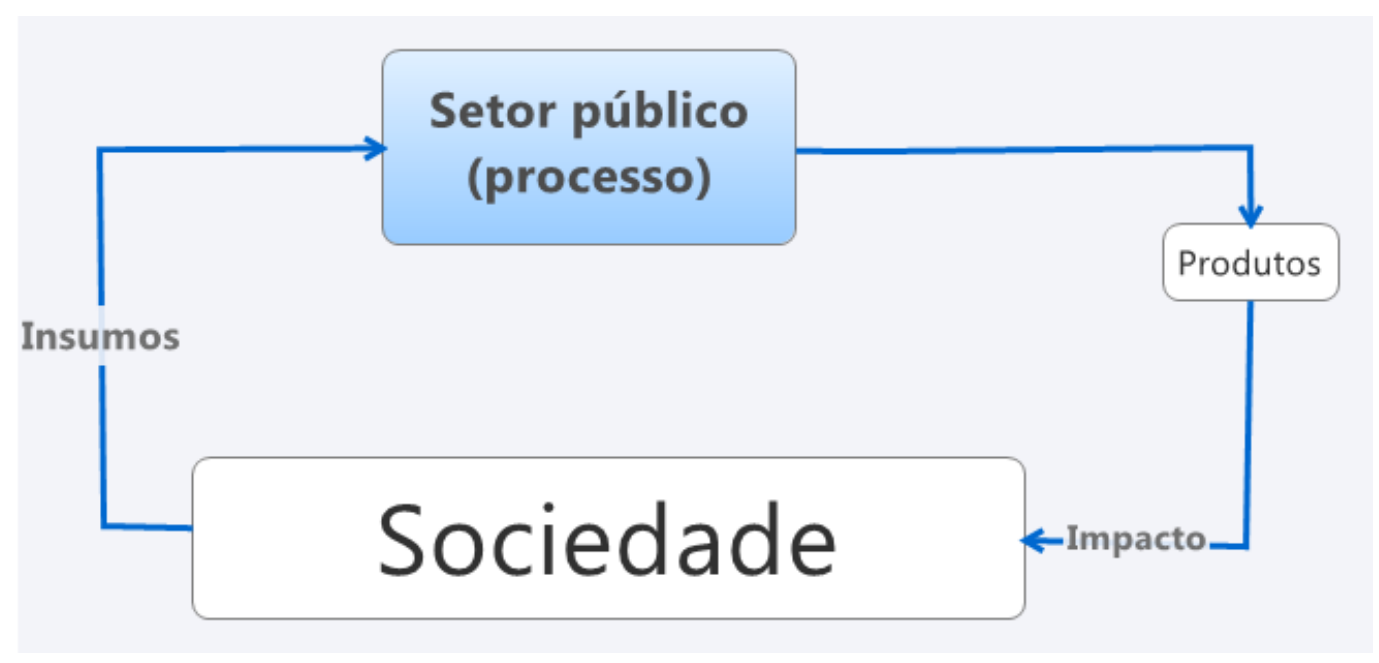

\footnotetext{
${ }^{15}$ As principais referências para essa seção são Coelli et al. (2005), Dunleavy and Carrera (2013) e Greene (2008).

${ }^{16}$ O fluxograma é livremente baseado em Easton (1965).
} 
A capacidade de uma política pública gerar um impacto positivo na sociedade é chamada de "efetividade". A capacidade dos produtos individuais gerarem um impacto positivo é chamado de "eficácia" e, por fim, a produtividade do setor público pode ser definida como uma a relação entre insumos e produtos.

$$
\text { Índice de produtividade }=\frac{\text { produtos }}{\text { insumos }}
$$

No setor privado, a produtividade foi utilizada inicialmente na engenharia, sobretudo para mensurar o desempenho de máquinas e equipamentos (FARRELL, 1957). Um exemplo da aplicação desse conceito é a produtividade dos carros, onde o produto é o número de quilômetros rodados e o insumo é a quantidade de combustível consumido. Quanto maior a quantidade de quilômetros rodados por litro de combustível, maior é a produtividade do veículo. Toda a dificuldade surge quando se utilizam múltiplos insumos ou se produzem múltiplos produtos, obrigando o analista a criar um sistema de ponderação para criar um índice agregado de produção e um índice agregado de insumos. Nesse trabalho, enfrentaremos esse desafio através de um indicador inovador de produção de serviços em saúde, descrito no Capítulo 2 e do método de Fronteiras Estocásticas, descrito no Capítulo 3, abaixo.

A produtividade é um indicador absoluto, onde cada organização é mensurada individualmente. Por outro lado, a eficiência, conceito frequentemente confundido com a produtividade, é um índice relativo, pois indica se a organização está na fronteira tecnológica de produção, quando comparada a outras organizações similares (Coelli, Rao, $\&$ Battese, 2005, cap. 1 e 2). A figura 1.5 esclarece esse conceito. Nessa figura cada ponto representa uma organização, os eixos horizontal e vertical representam o gasto de insumos e a produção, respectivamente. A linha $\mathbf{F}^{\prime}$ representa a fronteira das possibilidades de produção, dada a tecnologia disponível. Podemos ver que as organizações $\mathbf{C}$ e $\mathbf{B}$ estão na fronteira de produção, demonstrando que são eficientes. Por outro lado, a organização A não está na fronteira, demonstrando que ela pode aumentar a produção, mantida a quantidade de insumos empregada (se igualando a B), ou diminuir os insumos, mantida constante a produção (se igualando a C). Assim, a organização A é considerada ineficiente. 
Figura 1.5 - A fronteira das possibilidades de produção

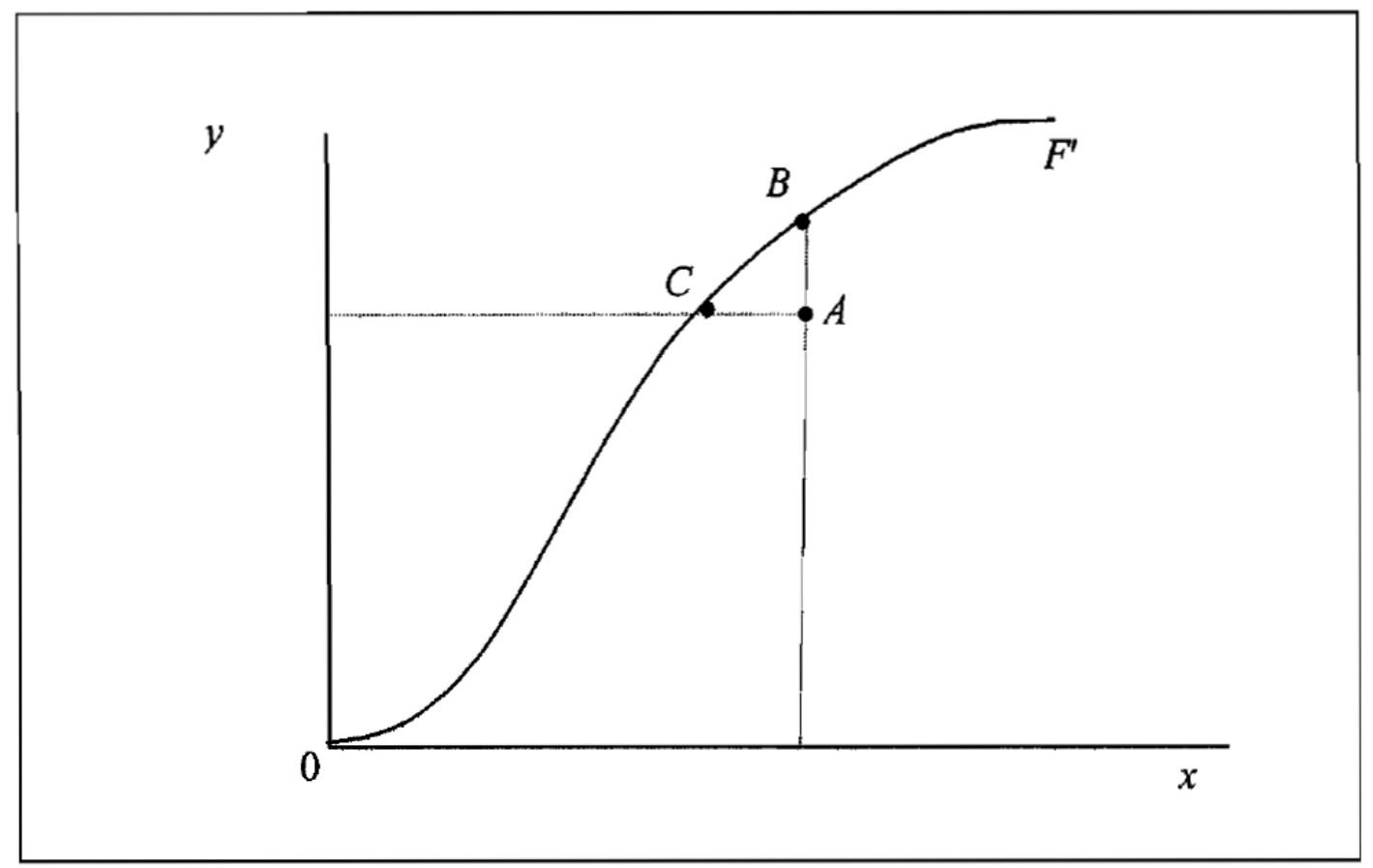

A medida de ineficiência de uma organização é sua distância em relação à fronteira de produção. Assim, no exemplo acima, as organizações C e B possuem ineficiência igual à zero, enquanto a organização A possui uma ineficiência maior que zero. Muitos estudos, por clareza de exposição, utilizam um índice de eficiência (e não de ineficiência), onde as organizações eficientes possuem um valor entre zero e um. Ambas as medidas são equivalentes umas às outras e podem ser usadas intercambiavelmente. No caso de setores produtivos que se utilizam de mais de um produto ou mais de um insumo, a fronteira de produção possui mais de duas dimensões. Se a fronteira possui mais de três dimensões, já não pode mais ser presentadas em gráficos. Contudo, as distâncias que determinam o índice de (in)eficiência ainda também podem ser medidas usando técnicas comuns de cálculo.

Nos estudos sobre a eficiência, raramente determina-se uma fronteira de produção $a$ priori, mas sim a partir da distribuição dos dados. As organizações mais produtivas da amostra constituem a fronteira e as organizações menos produtivas são ineficientes em relação a essa fronteira. No nosso caso, iremos analisar a eficiência municipal na provisão de saúde, portanto cada sistema municipal de saúde será considerado uma organização 
diferente, onde os sistemas mais eficientes serão considerados na fronteira de produção. Assim, os municípios não terão um índice de eficiência absoluto, mas sim relativo aos demais municípios. É importante considerar que não estamos realizando uma comparação entre os setores público e privado. A fronteira de produção será estimada a partir da produtividade observada dos municípios, portanto, um município somente serão considerados (in)eficientes quando comparado aos outros municípios.

Assim, podemos ver que a noção de produtividade e de eficiência não é difícil de ser conceituada. Por outro lado, esses conceitos são bem complexos de serem operacionalizados em estudos empíricos. Os próximos dois capítulos visam criar uma medida de eficiência municipal em saúde, de forma a nos permitir explorar possíveis explicações para o desempenho governamental. O próximo capítulo irá definir as variáveis de insumos e produtos utilizadas em nossa análise. No capítulo seguinte, explicaremos como calculamos a fronteira de eficiência e as medidas de eficiência de cada município. No Capítulo 4, iremos analisar as hipóteses explicativas da eficiência elaboradas acima. 


\section{Capítulo 2 - Um novo indicador de eficiência dos gastos públicos em saúde.}

Nos últimos anos, vários estudos criaram indicadores de eficiência da provisão de serviços públicos de saúde ${ }^{17}$. Tais indicadores são fundamentais para podermos encontrar os diferentes mecanismos que fazem com que o Estado seja mais ou menos eficiente. Sem uma mensuração confiável da eficiência da pública de saúde, as afirmações que este ou aquele fator leva a um aumento (ou diminuição) da eficiência estatal não podem ser adequadamente verificadas.

Porém, a mensuração do desempenho do setor público não é um exercício trivial. As medidas existentes ainda pecam por falta de precisão e de consistência. Frente a esse contexto, o presente trabalho irá propor um novo indicador de mensuração da eficiência da saúde pública. O foco desse trabalho é analisar a provisão de saúde pública ao nível municipal, mas o indicador criado pode ser estendido aos outros níveis de governo. A medida proposta rompe com duas estratégias comuns da literatura, que são consideradas frágeis. Em primeiro lugar, muitos estudos utilizam os gastos nas subfunções de saúde (normalmente "atenção básica" ou "assistência hospitalar e ambulatorial") como proxy de mensuração dos insumos de saúde. Usando dados detalhados do Tribunal de Contas Estadual do Estado de São Paulo, podemos ver que os municípios não seguem uma metodologia uniforme de classificação do gasto nas subfunções, introduzindo erros de mensuração que não podem ser facilmente corrigidos. Para corrigir esse problema, o indicador proposto utiliza a função de gasto em saúde e não as subfunções.

Em segundo lugar, os estudos não criam um indicador abrangente da produção municipal em saúde, mas se baseiam em proxies de produção. Essas proxies podem ser a seleção arbitrária de alguns procedimentos médicos realizados pelos municípios ou indicadores de disponibilidade de recursos, como número de leitos de internação ou de médicos contratados. Essas estratégias são problemáticas, pois (1) a seleção arbitrária de proxies de produção deixa a medida altamente dependente das escolhas arbitrárias do analista e (2) a presença de certos recursos não garante que eles estejam sendo usados

\footnotetext{
${ }^{17}$ Caliari, Ruiz, Maria, \& Oliveira (2009); Cavalcante (2013); Faria, Jannuzzi, \& Silva (2008); Furtado (2012); Gasparini \& Ramos (2004); Godoy (2014); Mattos, Rocha, Novaes, Arvate, \& Orellano (2010); Motta \& Moreira (2009); Varela et al. (2012); Sampaio De Sousa \& Stošić (2005).
} 
para aumentar a provisão de saúde pública. Além disso, os indicadores de saúde utilizados na análise não possuem nenhuma ponderação de qualidade ou complexidade dos procedimentos realizados. Essa prática pode levar ao risco de tratar procedimentos de saúde caros e baratos como se fossem coisas iguais. Para corrigir esses problemas, o presente estudo criou uma metodologia inédita de mensuração da produção pública de saúde. Nessa metodologia, praticamente todos os procedimentos de saúde realizados pelos municípios (ou qualquer outro nível de governo) entram na análise, desobrigando o analista a fazer uma seleção arbitrária de proxies de produção. Os preços do setor privado são utilizados como ponderadores dos custos dos serviços públicos de saúde. Isso permite reduzir a lista de milhares de procedimentos de saúde realizados pelo setor público em uma pequena lista de indicadores agregados produção.

O indicador proposto por esse trabalho se destaca por ser mais preciso e flexível do que os empregados atualmente. Podemos utiliza-lo para analisar a eficiência tanto dos governos municipais (foco desse trabalho), quantos dos governos estaduais ou do nível federal. É possível, inclusive, comparar os níveis federativos entre si. O indicador proposto pode ainda ser utilizado em nível micro, mensurando a eficiência de hospitais e unidades básicas de saúde individuais, desde que existam dados orçamentários separados para cada unidade.

O presente capítulo está dividido da seguinte forma. Na seção seguinte iremos propor um indicador de insumo da produção em saúde. Na seção seguinte, proporemos um conjunto inédito de indicadores mensuração da produção municipal em saúde. Por fim, iremos propor um indicador de preço dos insumos. Esses três conjuntos serão usados para mensurar a eficiência municipal, nos próximos capítulos.

\section{1 - Indicador de insumo em saúde}

A eficiência técnica de qualquer organização, seja do setor público ou do setor privado, se refere à maximização dos produtos fornecidos dada uma disponibilidade de insumos e uma fronteira de produção (COELLI et al., 2005; GREENE, 2008) ${ }^{18}$. Assim, a

\footnotetext{
${ }^{18} \mathrm{O}$ indicador proposto nesse texto se refere exclusivamente à eficiência da provisão de saúde pública. Não abordaremos a eficácia ou efetividade da produção de saúde. Ou seja, não exploraremos nesse trabalho o quanto os serviços de saúde contribuem para melhorar os indicadores sociais, como, por exemplo, a expectativa de vida ou mortalidade infantil. Para avaliar esses fatores, teríamos que criar uma
} 
escolha mais fundamental de qualquer análise de eficiência é quais indicadores de insumos e produtos ${ }^{19}$ serão empregadas na análise. Tal decisão é ainda mais importante em estudos que envolvem o setor público, dado que existe pouca clareza conceitual sobre quais são os “inputs" e "outputs" do governo ${ }^{20}$. Nessa primeira seção do texto, vou propor um indicador de insumo em saúde.

O indicador de insumo proposto nesse trabalho será o gasto na função "saúde". Infelizmente, não existem dados suficientes para avaliar o uso de recursos não monetários, como a disponibilidade de infraestrutura instalada, por exemplo. Existem duas estratégias na literatura para se mensurar a eficiência da saúde: fazer uma análise ampla de toda a produção municipal em saúde ou fazer uma análise mais focada, de apenas um nível de produção, normalmente a atenção básica ou a atenção hospitalar. $\mathrm{Na}$ estratégia de análise ampla, o indicador de insumo normalmente utilizado é o gasto público na função "saúde" 21 . Na estratégia da análise focada, o indicador de insumo é o gasto em uma subfunção típica da área da saúde, normalmente a subfunção "Atenção básica" ou a subfunção "Atenção Hospitalar e Ambulatorial"22. Infelizmente, veremos abaixo que não existe uniformidade quanto à classificação das subfunções de gasto em saúde, o que compromete o resultado dos estudos que utilizam a estratégia focada em um nível de produção. Assim, somente é possível, atualmente, realizar a análise mais ampla, que envolve toda a produção em saúde. Usaremos os municípios do Estado de São Paulo para demonstrar esse ponto.

Até onde esta pesquisa pode averiguar, a totalidade dos estudos brasileiros sobre o desempenho do setor público trabalham com os dados fornecidos pela Secretaria do Tesouro Nacional (STN), através da pesquisa FINBRA - Finanças do Brasil. Apesar dessa pesquisa ser muito rica; dada sua amplitude (envolve todo o território nacional), sua uniformidade metodológica e sua periodicidade anual; ela possui uma importante limitação: não é possível enxergar as interseções entre as classificações de despesa. Não

estratégia para isolar a influência do setor público de outros fatores intervenientes, como as condições econômicas, a demografia e a imigração. Também teríamos que modelar a interação entre as diferentes políticas públicas e seu efeito ao longo do tempo. Esses desafios estão além da proposta desse trabalho.

${ }^{19}$ Neste texto, usaremos os termos "produto", "serviços", "output" e "produção" como sinônimos.

${ }^{20}$ Por exemplo, muitos acreditam que "impessoalidade", "segurança jurídica" ou "regras claras" são produtos que o setor público deve prover. Mas se isso é verdade, como medir essa "produção"? Esse trabalhou preferiu restringir a análise apenas àqueles produtos mensuráveis.

${ }^{21}$ Os trabalhos que utilizam a estratégia de análise ampla são: Caliari et al. (2009), Cavalcante (2013), Godoy (2014), Mattos et al. (2010).

${ }^{22}$ Os trabalhos que utilizam a estratégia de análise focada são: Furtado (2012) e Varela et al. (2012). 
podemos, por exemplo, verificar como os estados ou municípios classificam as subfunções de gasto dentro de cada função. Também não podemos fazer intersecções entre classificações de elemento e de função. Por exemplo, podemos saber o quanto um município gastou com pessoal e o quanto ele gastou com saúde, mas não podemos saber o quanto ele gastou com pessoal na saúde. Contudo, esse tipo de análise pode ser feita utilizando os dados do sistema AUDESP (Auditoria Eletrônica de Órgãos Públicos), do Tribunal de Contas do Estado de São Paulo (apenas para o Estado de São Paulo) ${ }^{23}$.

O enorme detalhamento do sistema AUDESP permite observar algumas anomalias nos dados, muitas delas fundamentais para a análise de eficiência. Podemos ver na tabela 2.1 que muitos municípios possuem uma quantidade elevada de gastos que são ao mesmo tempo da função saúde e da subfunção "administração geral" (coluna b). O cruzamento dos dados entre subfunção e elemento mostra que esses dados se referem ao pagamento de pessoal (coluna c) ${ }^{24}$. Podemos citar como exemplo o município de Campinas, o terceiro maior do Estado, que declarou em 2015 38,47\% dos gastos da função saúde na subfunção "Administração Geral”. Praticamente toda a folha de pagamentos da saúde foi classificada na subfunção "Administração Geral” e não nas subfunções típicas de saúde.

Qual a consequência para a análise da eficiência dessa anomalia nos dados? Os estudos que utilizam o gasto nas subfunções típicas de saúde (atenção básica e assistência hospitalar) como indicador de insumo acabam por subreportar o gasto com saúde. Nesses estudos, os municípios que classificam parte dos gastos de saúde na subfunção "administração geral" acabam por parecer mais eficientes do que os municípios que não adotam essa prática. Por uma mera divergência de classificação contábil (a omissão do gasto com pessoal nas subfunções típicas de saúde) o município "ganha" eficiência aos olhos da análise. Podemos ver isso comparando os municípios de Franca e Campinas em

\footnotetext{
${ }^{23} \mathrm{O}$ grau de detalhamento do sistema AUDESP é muito maior que o do FINBRA. Para se ter uma ideia, apenas a tabela para descrever as despesas da cidade de Campinas-SP, no ano de 2015, possui 23 colunas e 119.495 linhas, enquanto no FINBRA-STN a mesma cidade-ano é descrita em uma única linha, com pouco mais de 100 colunas. Os dados consolidados do sistema AUDESP podem ser acessados em http://transparencia.tce.sp.gov.br/municipios-csv

${ }^{24}$ A contabilidade pública segue a lógica do orçamento matricial, onde uma subfunção pode estar atrelada tanto a funções típicas quanto a funções atípicas. É permitido, e conceitualmente válido, que subfunções típicas da função "administração" estejam classificadas na função "saúde". Um exemplo seria o gasto com o planejamento e administração da secretaria municipal de saúde. Contudo, em termos contábeis, é um erro conceitual classificar o gasto com os funcionários da área fim (como o salário de médicos e enfermeiras) na subfunção "administração geral". No entanto, parece ser essa a prática de muitos municípios.
} 


\begin{tabular}{|l|c|c|c|c|c|}
\hline \multicolumn{5}{|c|}{ Tabela 2.1 - Detalhamento do gasto municipal em saúde } \\
\hline Município & Ano & $\begin{array}{c}\text { Gasto na } \\
\text { função saúde } \\
\text { sobre gasto } \\
\text { total } \\
\text { (a) }\end{array}$ & $\begin{array}{c}\text { Porcentagem do } \\
\text { gasto em adm. } \\
\text { geral em (a) } \\
\text { (b) }\end{array}$ & $\begin{array}{c}\text { Porcentagem do } \\
\text { gasto com } \\
\text { pessoal em (b) } \\
\text { (c) }\end{array}$ & $\begin{array}{c}\text { Porcentagem } \\
\text { do gasto com } \\
\text { pessoal em } \\
\text { Atenção } \\
\text { Básica }\end{array}$ \\
\hline Bauru & 2015 & $19,98 \%$ & $74,36 \%$ & $72,76 \%$ & $0,00 \%$ \\
\hline Campinas & 2015 & $29,03 \%$ & $38,47 \%$ & $78,64 \%$ & $15,22 \%$ \\
\hline $\begin{array}{l}\text { Ferraz de } \\
\text { Vasconcelos }\end{array}$ & 2015 & $13,78 \%$ & $80,15 \%$ & $87,52 \%$ & $0,00 \%$ \\
\hline Franca & 2015 & $29,17 \%$ & $0,00 \%$ & $0,00 \%$ & $62,70 \%$ \\
\hline Limeira & 2015 & $23,71 \%$ & $26,26 \%$ & $72,77 \%$ & $36,40 \%$ \\
\hline Osasco & 2015 & $27,47 \%$ & $67,15 \%$ & $84,16 \%$ & $0,00 \%$ \\
\hline Piracicaba & 2015 & $25,49 \%$ & $55,31 \%$ & $81,32 \%$ & $0,00 \%$ \\
\hline Santo André & 2015 & $20,70 \%$ & $32,13 \%$ & $77,46 \%$ & $3,40 \%$ \\
\hline São Carlos & 2015 & $29,11 \%$ & $27,11 \%$ & $91,86 \%$ & $57,03 \%$ \\
\hline Tatuí & 2015 & $28,46 \%$ & $73,22 \%$ & $60,38 \%$ & $0,00 \%$ \\
\hline
\end{tabular}

2015. Enquanto Campinas declarou 15,22\% do gasto de atenção básica como pessoal, Franca declarou $62,70 \%$. Essa diferença é grande demais para se referir a diferenças técnicas na provisão dos serviços, provavelmente se referindo a divergências de classificação. Como consequência, Campinas gastou $6,41 \%$ do orçamento da saúde com atenção básica, quanto Franca gastou 36,09\%.

\section{Gráfico 2.1 -}

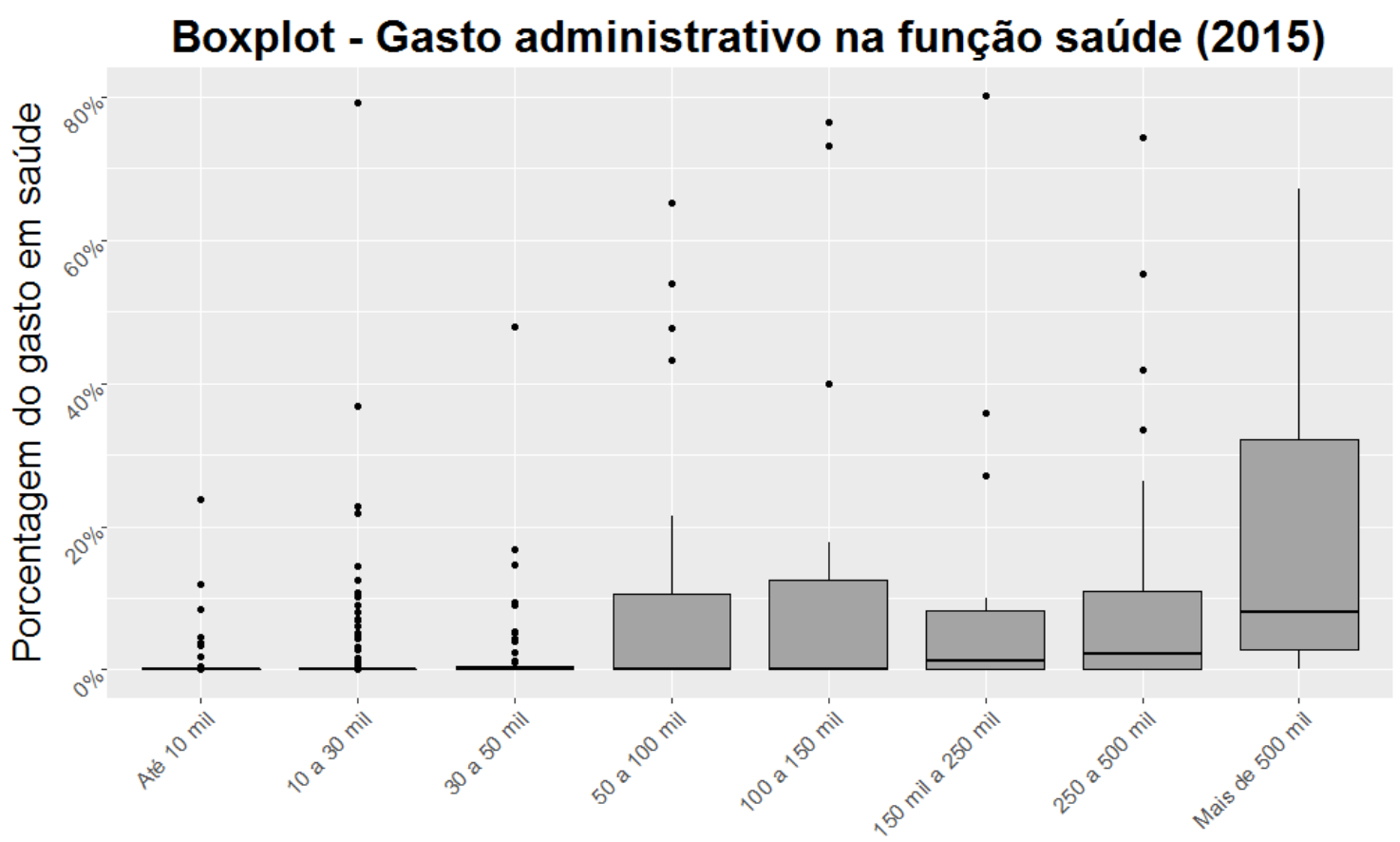

Faixas populacionais 
A solução padrão para erros de classificação como esse é excluir os municípios que apresentam anomalias dos nados. Contudo, essa não é uma solução conveniente nesse caso. Infelizmente, a inclusão de gastos na subfunção "administração geral" dentro da função saúde é comum entre municípios do Estado, notadamente nos maiores municípios, como mostra o gráfico 2.1. O mesmo ocorre com Limeira (26\% do gasto com saúde está classificado na subfunção de administração geral), São Carlos (27\%), Santo André (32\%), Piracicaba (55\%), Osasco (67\%), Bauru (74\%) e Ferraz de Vasconcelos (80\%) ${ }^{25}$. Excluir esses municípios levaria à exclusão de muitos municípios médios e grandes na amostra, sendo que são nesses municípios onde vive a maior parte da população do Estado.

Outra anomalia encontrada foi a divisão entre os gastos nas funções "Atenção Básica" e "Assistência Hospitalar e Ambulatorial". É de se esperar que os municípios menores concentrem seus gastos em Atenção Básica, enquanto municípios maiores, por serem centros regionais, gastem mais em serviços de saúde mais complexos, como gastos hospitalares. Contudo, podemos ver no gráfico 2.2, que a proporção mediana de gastos em atenção hospitalar é a mesma nos municípios de 50 a 100 mil habitantes e nos municípios de mais de 500 mil habitantes. Além disto, a variação nas proporções é muito alta. Mesmo em municípios pequenos, na faixa dos 10 mil a 30 mil habitantes, existem municípios que reportam $100 \%$ dos gastos em saúde em assistência hospitalar e $0 \%$ em atenção básica. Esse comportamento é estranho mesmo em municípios de tamanho médio. Por exemplo, Sorocaba e São Caetano do Sul, reportam a quase totalidade dos seus gastos em atenção hospitalar (92,37\% e 92,32\%, respectivamente), e muitíssimo pouco em atenção básica.

Não está claro o motivo desse comportamento errático das subfunções. Contudo, uma boa hipótese é que os gestores municipais classifiquem todos os gastos realizados em hospitais ou estabelecimentos similares como "assistência ambulatorial e hospitalar" e todos os gastos em unidades básicas de saúde como gastos em "atenção básica", independentemente dos procedimentos $\operatorname{adotados}^{26}$. Essa postura torna as classificações

\footnotetext{
25 Todos os dados se referem ao ano de 2015. Contudo, o padrão se refere em todos os anos.

${ }^{26}$ Essa hipótese também explicaria porque os maiores municípios reportam os gastos com pessoal na subfunção "administração geral". Como muitos profissionais atuam tanto em hospitais quanto em unidades básicas de saúde, os gestores municipais acabam classificando os salários desses profissionais como gastos administrativos. Já nos municípios menores, como, muitas vezes, há apenas um estabelecimento de saúde, não há necessidade de se utilizar tal subterfúgio. Por outro lado, se o único estabelecimento de saúde do município for um hospital (ou pelo menos os gestores locais enxergarem assim), todo o gasto local em saúde será de atenção hospitalar.
} 
de despesa não comparáveis com as classificações de procedimentos médicos realizados, pois um hospital também pode fazer atendimentos de atenção básica (como consultas) da mesma forma que unidades básicas de saúde podem realizar alguns procedimentos de média complexidade (como exames de sangue). O ideal seria separar a contabilidade de cada unidade prestadora de saúde entre o gasto com procedimentos de atenção básica e o gasto com procedimentos de média e alta complexidade. No entanto, essa diferenciação requer que a contabilidade pública tenha um nível de complexidade que ela ainda não consegue atingir. Novamente, a consequência desses erros de mensuração é "premiar" a eficiência dos municípios que sub-reportam o gasto em uma ou outra subfunção de gasto, fazendo com que eles pareçam ser mais eficientes do que realmente são.

\section{Gráfico 2.2 -}

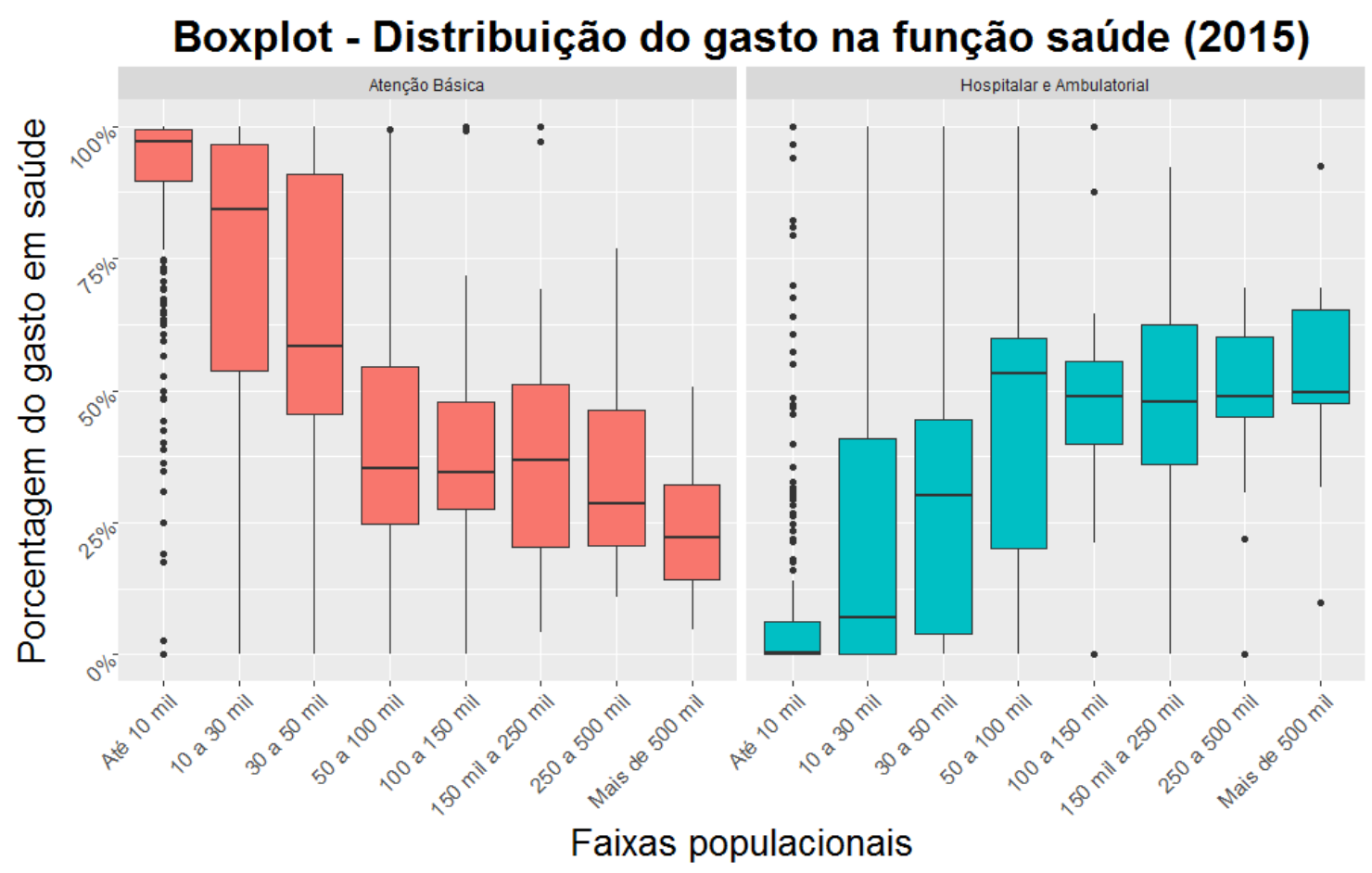

Temos que lembrar que não existe determinação legal sobre como deve ser classificado os gastos entre as subfunções. Desse modo, tanto no caso da saúde quanto em qualquer área de política, utilizar subfunções do gasto público na análise é extremamente arriscado. Uma forma de análise menos arriscada é utilizar a função de gasto em saúde e não as subfunções. Ao contrário das subfunções, existem determinações 
legais de gasto mínimo em saúde ${ }^{27}$. Além disso, espera-se que a divergência contábil sobre o que é gasto em saúde seja menor do que a divergência de o que é gasto nas subfunções. Evidentemente que é mais complexo analisar o gasto em saúde como um todo e não apenas em um nível de provisão, como a atenção básica. Abaixo apresento uma metodologia para lidar com esse problema.

Por fim, utilizaremos em nossa análise apenas os gastos correntes, e não os gastos de capital, seguindo o exemplo de Kalb (2010). Utilizar os gastos de capital puniria os municípios que estão realizando investimentos, fazendo-os parecerem menos eficientes do que são.

\section{2 - Indicador de produção em saúde}

Na literatura, existem três tipos de indicadores de produção em saúde. O primeiro utiliza a disponibilidade de insumos como indicador de produção. São exemplos desse tipo de indicador: o número de médicos contratados, o número de leitos disponíveis ou o número de famílias cadastradas no Programa Saúde da Família (CALIARI et al., 2009; CAVALCANTE, 2013; GASPARINI; RAMOS, 2004). Contudo, esse tipo de abordagem confunde insumos e produtos. Não podemos afirmar que os médicos contratados estão de fato atendendo a população, que os leitos estão sendo usados ou mesmo que as famílias cadastradas no PSF estão sendo acompanhadas. Por isso, não usaremos esse tipo de indicador.

Um segundo grupo de indicadores de produção em saúde utiliza indicadores sociais de saúde, como expectativa de vida ao nascer, mortalidade hospitalar ou IDH, como medida de produção em saúde (GODOY, 2014; MATTOS; ROCHA; ARVATE, 2011; MOTTA; MOREIRA, 2009) ${ }^{28}$. Contudo, os indicadores sociais de saúde são influenciados por muitos fatores além da qualidade do sistema público de saúde. Existe a influência da renda da população, do aumento da educação, da imigração, da provisão de serviços privados e mesmo da interação entre as diferentes políticas públicas e entre os

\footnotetext{
27 Segundo a Emenda Constitucional 29/2000, os municípios devem gastar pelo menos 15\% de seu orçamento em saúde pública. Cabe às Câmaras de Vereadores e ao Tribunal de Contas responsável fiscalizar o cumprimento dessa regra.

${ }^{28}$ Analises desse tipo poderiam ser melhor descritas como análises de "custo-efetividade" do que análises propriamente análises de eficiência (TREVISAN; VAN BELLEN, 2008).
} 
diferentes níveis federativos. Além disso, as ações de curto prazo do setor público muitas vezes levam muitos anos para se traduzirem em melhores (ou piores) indicadores sociais. Por exemplo, a melhoria da educação básica este ano irá impactar a mortalidade infantil quando as crianças de hoje forem mães e pais, daqui a vários anos. Assim, é muito mais difícil modelar o efeito independente dos serviços públicos sobre os indicadores sociais. Apesar de esses indicadores serem os mais relevantes do ponto de vista social, eles não são convenientes para o estudo que está sendo aqui proposto, pois nosso objetivo é avaliar a qualidade do governo, do governo municipal em particular, e não a dinâmica social como um todo. Assim, não utilizaremos este tipo de indicador.

Por fim, um terceiro grupo de indicadores de produção utiliza os procedimentos de saúde realizados (consultas, exames, cirurgias, etc) pelos municípios como indicadores de produção (Furtado 2012; Varela, Martins, and Fávero 2012). No site do Departamento de Informática do Ministério da Saúde (DATASUS) existe uma extensa relação de procedimentos realizados pelos Estados e Municípios, em elevado grau de detalhe. Porém, o enorme detalhamento desses bancos de dados gera um problema para a análise, pois existem mais de 5000 procedimentos de saúde listados. Dada a impossibilidade de inserir tantos procedimentos nos modelos de mensuração de eficiência, parte da literatura brasileira utilizou a estratégia de restringir a análise à atenção básica, pois existem apenas cerca de 100 procedimentos classificados neste nível de complexidade. Frente a esse reduzido conjunto de procedimentos, não é difícil para os analistas selecionar os procedimentos mais relevantes e agregar procedimentos parecidos, criando um conjunto de indicadores de produção que seja pequeno o suficiente para ser utilizado com as metodologias existentes de mensuração da eficiência. Com isso, surgem os indicadores de output encontrados na literatura, como "número de consultas médicas", "procedimentos odontológicos”, “ações de enfermagem”, “procedimentos de profissionais de nível médio", etc.

Esse tipo de estratégia, apesar de mais adequada que as anteriores para nosso propósito, apresenta pelo menos outros três problemas. O primeiro é que esses estudos utilizam o gasto na subfunção "atenção básica" como indicador de insumo, resultando nas inconsistências mencionadas na seção anterior. O segundo problema é que o critério de agregação de diferentes procedimentos individuas em indicadores de output é arbitrário. Por fim, não existe diferenciação de complexidade ou qualidade dos procedimentos dentro de cada categoria. Os procedimentos complexos ou simples dentro 
de uma mesma categoria contam igualmente. Por exemplo, dentro da categoria "procedimentos odontológicos" há os serviços "Consulta odontológica inicial” e o serviço "implante ortodôntico". Obviamente que esses procedimentos possuem custos diferentes e não podem ser contados igualmente.

Frente a isso, esse trabalho irá propor uma abordagem completamente nova. Em primeiro lugar, nos focaremos nos produtos ofertados pelos governos, isto é, os procedimentos de saúde. Eles, ao contrário dos indicadores sociais, são influenciados pela ação de curto prazo dos gestores públicos, sendo um bom indicador da qualidade do governo. Em segundo lugar, esse trabalho não focará nem na atenção básica nem na atenção hospitalar, mas sim em toda a produção de saúde realizada pelos municípios. Contudo, essa estratégia leva a alguns desafios metodológicos: como reduzir os milhares procedimentos realizados pelos municípios em um número de indicadores de produção em saúde que seja pequeno o suficiente para permitir o uso de técnicas de aferição da eficiência? Como diferenciar procedimentos de complexidade distintas? Para resolver essas questões, este trabalho propõe uma metodologia inédita de mensuração da produção municipal em saúde pública, utilizando o valor dos honorários pagos pelo setor privado.

A saúde privada possui uma tabela própria de procedimentos médicos e odontológicos: a tabela TUSS (Terminologia Unificada da Saúde Suplementar). Essa tabela foi criada originalmente pela Associação Médica Brasileira e foi posteriormente adotada (com algumas modificações) pela Agência Nacional de Saúde Suplementar como classificação oficial dos procedimentos de saúde privada. A terminologia da tabela TUSS não é exatamente a mesma da lista de procedimentos do SUS, mas é possível estabelecer uma correspondência entre as duas listas de procedimentos ${ }^{29}$. As seguradoras privadas de saúde (os convênios), utilizam a tabela TUSS para determinar a remuneração dos médicos e demais profissionais de saúde que são seus fornecedores. Neste trabalho, usaremos essas tabelas de honorários como ponderadores de custo dos procedimentos. Partiremos do pressuposto que o preço de mercado pago aos fornecedores é uma boa proxie da complexidade dos procedimentos realizados.

Podemos formalizar o indicador de eficiência do município através da seguinte medida:

\footnotetext{
${ }^{29}$ A correspondência entre as duas tabelas foi obtida junto à Agência Nacional de Saúde Suplementar, mediante requisição pela lei de acesso a informação.
} 


$$
\theta_{i}=\frac{\sum_{k=1}^{m} q_{k, i} p_{k}}{C_{i}}
$$

Onde,

$\theta_{i}$ é a eficiência o município $i$.

$C_{i}$ é o indicador de gasto em saúde do município i.

$q_{k, i}$ é a quantidade produzida do procedimento $k$ pela rede municipal de saúde i.

$p_{k}$ é o preço do procedimento $k$ segundo a tabela de honorários paga pelo setor privado.

Caso conseguíssemos um valor referencial padronizado no setor privado, $p_{k}$, para cada procedimento realizado pelo setor público, o termo $\theta_{i}$ nos daria diretamente o valor da eficiência municipal, sem a necessidade de usarmos técnicas mais sofisticadas de aferição da eficiência. Nesse caso, o valor de $\theta_{i}$ seria igual a 1 quando o município consegue produzir seus serviços de saúde com os mesmos valores referenciais que o setor privado (em média); $\theta_{i}$ seria menor que 1 se o município produz de forma mais cara que o setor privado e maior que 1 se o setor público produz de forma mais barata que o setor privado.

Infelizmente, ainda não conseguimos chegar ao indicador agregado de produção exposto na equação 2.1, e por isso ainda precisamos de técnicas mais sofisticadas. Isso ocorre por dois motivos: (a) existem muitos procedimentos fornecidos pelo setor público que não são fornecidos pelo setor privado ${ }^{30} \mathrm{e}(\mathrm{b})$ os procedimentos fornecidos pelo setor privado não estão padronizados em uma lista única. Não conseguimos encontrar um convênio privado que forneça procedimentos médicos e odontológicos, por exemplo. Podemos conseguir separadamente valores referenciais médicos e odontológicos, mas não podemos simplesmente juntar as listas, dado que elas foram criadas por critérios diferentes. Então, precisamos agregar separadamente cada tipo de procedimento, de acordo com cada tipo de ponderador (procedimentos médicos, de acordo com listas de honorários médicos, procedimentos odontológicos de acordo com a lista de honorários odontológicos, etc). Para que possamos somar os diferentes tipos de procedimentos, que

30 O contrário também é verdadeiro: vários procedimentos fornecidos pelo setor privado não são fornecidos pelo setor público. Contudo, esse fato não é relevante para a presente análise. 
foram ponderados por diferentes critérios, precisamos de um "ponderador dos ponderadores", da seguinte forma:

$$
\begin{aligned}
& \theta_{i}^{*}=\frac{\sum_{j=1}^{l} \beta_{j} y_{j, i}}{C_{i}} \\
& y_{j, i}=\sum_{k=1}^{m} q_{k, i} p_{k}
\end{aligned}
$$

Onde,

$y_{j, i}$ é o valor agregado da lista $j$. Repare que ele é igual ao numerador do lado direito da equação 2.1.

$\beta_{j}$ é um ponderador do peso dos item da lista $j$.

Nessa formulação, existem $l$ listas de produtos que são ponderadas por $\beta_{j}$ para formar o indicador agregado de produção. Nesse trabalho, propomos encontrar o valor dos parâmetros $\beta_{j}$ a partir da própria distribuição dos dados, utilizando análise de fronteiras estocásticas (stochastic frontier analysis - SFA). Também é possível utilizar a análise envoltória dos dados (DEA) ou Free Disposal Hull (FDH), mas o método SFA foi preferido por ser um método estocástico, e não determinístico. Isso permite que o modelo lide melhor com ruídos derivados de erros de mensuração, que são inevitáveis em dados gerados descentralizadamente por centenas de municípios.

Podemos observar como essa metodologia é operacionalizada através da tabela 2.2. Ela mostra valores hipotéticos de produção de um município. A primeira coluna mostra os procedimentos fornecidos. As segunda e a terceira colunas mostram o tipo e a quantidade ofertada de procedimentos. A quarta coluna mostra o preço que o procedimento tem no setor privado. A quinta coluna é simplesmente a multiplicação da terceira e quarta colunas. Abaixo da tabela estão os indicadores agregados de produção do município segundo seu tipo. São esses valores que entrarão no modelo como indicadores de produção agregada do município. 
Tabela 2.2 - Exemplo de criação de indicadores de produção em saúde.

\begin{tabular}{|c|c|c|c|c|}
\hline Procedimentos & Tipo & $\mathbf{N}$ & $\begin{array}{c}\text { Valor de } \\
\text { Ponderação }\end{array}$ & $\begin{array}{c}\text { Total } \\
\text { Ponderado }\end{array}$ \\
\hline Consulta médica & $\begin{array}{l}\text { Serviços } \\
\text { médicos }\end{array}$ & 10 & 90 & 900 \\
\hline Mamografia & $\begin{array}{l}\text { Serviços } \\
\text { médicos }\end{array}$ & 5 & 225 & 1125 \\
\hline Traqueostomia & $\begin{array}{l}\text { Serviços } \\
\text { médicos }\end{array}$ & 3 & 400 & 1200 \\
\hline Consulta odontológica & $\begin{array}{c}\text { Serviços } \\
\text { odontológicos }\end{array}$ & 8 & 80 & 640 \\
\hline Aplicação de selante & $\begin{array}{c}\text { Serviços } \\
\text { odontológicos }\end{array}$ & 5 & 120 & 600 \\
\hline Atendimento de denuncias & $\begin{array}{l}\text { Vigilância } \\
\text { Sanitária }\end{array}$ & 4 & 1 & 4 \\
\hline $\begin{array}{l}\text { Coleta de água para } \\
\text { análise }\end{array}$ & $\begin{array}{l}\text { Vigilância } \\
\text { Sanitária }\end{array}$ & 5 & 1 & 5 \\
\hline \multicolumn{4}{|c|}{ Produção total de serviços médicos: } & 3225 \\
\hline \multicolumn{4}{|c|}{ Produção total de serviços Odontológicos: } & 1240 \\
\hline \multicolumn{4}{|c|}{ Produção total de serviços de Vigilância Sanitária: } & 9 \\
\hline
\end{tabular}

Após consultar as principais tabelas de honorários médicos disponíveis, este trabalho optou por usar a tabela da SulAmerica Seguros, dado que ela é a que cobre o maior número de procedimentos médico-hospitalares (a média dos serviços). No caso dos serviços de odontologia, a tabela utilizada foi a CBHPO, Classificação Brasileira Hierarquizada de Procedimentos Odontológicos, divulgada pelas associações de classe odontológicas $^{31}$. Os procedimentos de enfermagem foram ponderados pelos preços referenciais indicados pelo Conselho Regional de Enfermagem do Distrito Federal (COREN-DF). Os procedimentos encontrados nessas três tabelas cobrem 59,11\% dos procedimentos realizados pelos municípios paulistas entre 2009 e 2012. Para podermos avaliar os procedimentos que não possuem equivalência na tabela TUSS, utilizaremos os valores referenciais de remuneração dos procedimentos de média e alta complexidade do SUS. Por fim, recorreremos ao procedimento adotado em outros estudos, de contar os procedimentos realizados sem qualquer ponderação de preço ou complexidade, apenas em serviços que não são fornecidos pelo setor privado e também não possuem valores referenciais no SUS. Esses procedimentos são: de atenção psicosocial, prevenção em saúde, atendimento domiciliar e vigilância sanitária. É importante considerar que mesmo

\footnotetext{
${ }^{31}$ http://cbhpo.com.br/
} 
os procedimentos sem ponderação interna (onde todos contam igualmente dentro da categoria) terão um valor de ponderação geral da categoria, determinado a posteriori pelo método SFA. A tabela 2.3 resume os indicadores de produção escolhidos e os respectivos ponderadores.

Tabela 2.3 - Descrição dos indicadores de produção em saúde

\begin{tabular}{|c|c|c|c|}
\hline Indicador de produção & Ponderador & $\begin{array}{c}\text { Número de } \\
\text { procedimentos* }\end{array}$ & $\begin{array}{l}\text { Produção } \\
(\%)^{* * *}\end{array}$ \\
\hline Serviços médicos & $\begin{array}{l}\text { Honorários } \\
\text { médicos }\end{array}$ & 2622 & $52,87 \%$ \\
\hline Serviços Odontológicos & Tabela CBHPO & 56 & $5,34 \%$ \\
\hline Serviços de Enfermagem & $\begin{array}{c}\text { Serviços } \\
\text { profissionais } \\
\text { COREN-DF }\end{array}$ & 12 & $0,90 \%$ \\
\hline Saúde pública & Sigtap SUS (2015) & 1403 & $20,22 \%$ \\
\hline $\begin{array}{l}\text { Procedimentos de atenção } \\
\text { Psicosocial. }\end{array}$ & Nenhum & 27 & $0,24 \%$ \\
\hline $\begin{array}{l}\text { Procedimentos de prevenção em } \\
\text { saúde. }\end{array}$ & Nenhum & 9 & $5,62 \%$ \\
\hline $\begin{array}{l}\text { Procedimentos de atendimento } \\
\text { domiciliar e saúde da família }\end{array}$ & Nenhum & 12 & $13,62 \%$ \\
\hline $\begin{array}{l}\text { Procedimentos de vigilância } \\
\text { Sanitária }\end{array}$ & Nenhum & 68 & $1,4 \%$ \\
\hline Total & & 4281 & $100 \%$ \\
\hline
\end{tabular}

* - O valor se refere ao número de procedimentos da tabela Sigtap SUS em cada categoria. ** - O valor se refere à porcentagem de procedimentos de saúde realizados pelos municípios do Estado de São Paulo entre 2009 e 2015.

\subsection{1 - A população como indicador de produção}

Em nossa análise, o indicador de insumo e todos os indicadores de produção foram divididos pela população. Assim, não inserirmos no modelo o gasto total na função saúde, mas sim o gasto per capita. Igualmente, não inserimos a produção médica total, mas a produção médica per capita; assim como todos os demais indicadores da tabela Erro! Fonte de referência não encontrada. per capita. Como consequência, nosso modelo não analisa propriamente a eficiência municipal na provisão de serviços, mas a eficiência na provisão de serviços per capita. Essa medida torna a interpretação dos dados mais 
simples: os municípios mais eficientes são aqueles que conseguem produzir mais serviços por habitante dado certo nível de despesa por habitante. Muito provavelmente, essa é a primeira ideia que vem à mente dos analistas quando pensam em eficiência governamental. Raramente pensamos na produtividade do setor público como um todo (e não na produtividade por habitante).

Contudo, essa medida tem uma consequência pouco intuitiva: ela é equivalente a inserir a população como um indicador de produção (FIREBAUGH; GIBBS, 1985, 1986). Isso pode ser visto no exemplo abaixo. Se temos o modelo:

$$
\mathrm{y}=\beta_{0}+\beta_{1} x+\beta_{2} z+v_{i, t}
$$

Dividindo todos os termos por $z$, temos:

$$
\begin{gathered}
\frac{\mathrm{y}}{z}=\frac{\beta_{0}}{z}+\frac{\beta_{1} x}{z}+\frac{\beta_{2} z}{z}+\frac{v_{i, t}}{z}= \\
\beta_{0} \frac{1}{z}+\beta_{1} \frac{x_{1}}{z}+\beta_{2}+\frac{v_{i, t}}{z}
\end{gathered}
$$

Caso $\beta_{0}=0^{32}$, então temos:

$$
\frac{\mathrm{y}}{Z}=\beta_{2}+\beta_{1} \frac{x_{1}}{z}+\frac{v_{i, t}}{Z}
$$

\footnotetext{
${ }^{32}$ Esse pressuposto, no nosso caso, é equivalente a admitir que a equação 2.5 tem intercepto igual a zero. Em casos onde a variável z é a população, esse pressuposto é razoável. Significa que se não houver serviços de saúde e a população for igual a zero, o gasto público em saúde também será igual a zero. Contudo, caso quisermos testar esse pressuposto, podemos inserir o inverso da população $(1 / z)$ dentro do modelo, para poder captar a influência de $\beta_{0}$.
} 
Assim, no modelo em razão (ratio model), o coeficiente da fronteira, $\beta_{1}$, continua o mesmo, embora o erro e o intercepto do modelo sejam alterados. Testes preliminares (não mostrados) mostram que tanto o uso dos dados per capita quanto a inclusão da população como indicador de produção melhoram fortemente o ajuste a qualidade dos modelos e diminuem a heterocedasticidade dos erros. Quando a população não é inserida no modelo de produção, a eficiência municipal é fortemente correlacionada com a população, de modo invertido. Essa acentuada perda de escala contradiz os estudos prévios da literatura e mesmo a análise com dados descritivos, que serão mostrados na seção Erro! Fonte de referência não encontrada.. Contudo, a pergunta mais importante neste caso é: a inclusão da população como indicador de produção é válida do ponto de vista teórico? Em minha opinião a resposta é sim. Incluir a população como indicador de produção é equivalente a admitir que existe um custo fixo por habitante. Esse custo fixo é uma proxy para uma série de serviços não capitados pelos outros indicadores de produção. Podemos citar os serviços administrativos ligados à saúde, como a realização de cadastros e a emissão de documentos. Também podemos citar atividades de vigilância sanitária e vigilância epidemiológica que não são discriminados nos indicadores de produção. Além disso, existe um custo fixo por paciente que os indicadores de quantidade de serviços realizados não conseguem captar, como o custo de fazer o diagnóstico do paciente ou entender suas condições de vida, por exemplo. Assim, o número de pacientes (e não apenas o número de serviços) deve ser levado em conta nos custos da saúde.

\section{3 - Indicadores de preço dos insumos em saúde}

A análise dos determinantes da eficiência municipal pode ser muito melhorada com bons indicadores de preços dos insumos de produção. Esse tipo de indicador ajuda a isolar o efeito de algumas variáveis explicativas que serão utilizadas no Capítulo 4. Algumas dessas variáveis estão fortemente correlacionadas com o preço da mão-de-obra. Podemos citar a urbanização e a renda. Cidades rurais e pobres tendem a ter salários mais baixos, barateando o custo de produção de todos os serviços, incluindo os serviços de saúde. Desconsiderar o preço dos insumos pode confundir a nossa variável de interesse, a eficiência técnica governamental, com a facilidade com que os governos têm de comprar insumos no mercado. 
Nesta análise, iremos usar informações sobre um insumo fundamental: os salários dos trabalhadores da saúde. Utilizaremos os dados da RAIS (Registro Anual das Informações Sociais), do ministério do trabalho. Essa base de dados contém o registro de todos os empregados do setor formal da economia ${ }^{33}$. Dessa base, retiramos informação apenas sobre os salários dos trabalhadores da saúde do setor privado, de modo a obter uma proxy do custo local da mão-de-obra. Utilizar o custo dos trabalhadores do setor público resultaria em endogeneidade do modelo, uma vez que os salários fazem parte do nosso indicador de insumo: o gasto do setor público. Além disso, o ideal é que diferenças salariais entre o setor público e o setor privado fossem captadas pelo nosso indicador de ineficiência, algo que não seria possível se colocássemos os salários dos funcionários públicos em nossa fronteira de produção. Utilizaremos quatro variáveis de preço dos insumos: o salário médio dos médicos, o salário dos demais profissionais de saúde de nível superior, os salários dos profissionais de saúde de nível médio e o salário médio dos profissionais administrativos de nível médio que trabalham em estabelecimentos de saúde.

Em muitas cidades pequenas, existe um número muito pequeno de vínculos de trabalho formais na área da saúde, insuficientes para uma estimativa confiável do valor dos salários. Para resolver esse problema, utilizamos duas estratégias: usar informações da região do município e usar informações do Estado como um todo. Em primeiro lugar, retiramos informação de outros municípios similares da região ${ }^{34}$. O valor de cada insumo em um município será igual à média ponderada dos vínculos de trabalho da região em municípios semelhantes. O peso de cada vínculo irá depender da distância em relação ao município de referência. Para vínculos de trabalho do próprio município de referência, o valor de ponderação será igual a 1. Para os demais municípios da região, o valor de ponderação será igual ao inverso da raiz da distância. A "distância” nesse caso é a quantidade de minutos que se leva para se deslocar de carro entre um município e outro ${ }^{35}$. Usar o tempo de deslocamento como indicador de distância nos ajuda a estimar melhor o grau de conexão entre os municípios, uma vez que municípios que estejam conectados por boas vias de transporte tendem a ser mais parecidos que municípios que estão

\footnotetext{
${ }^{33}$ Infelizmente, a base não contém registros de profissionais liberais, autônomos e trabalhadores não registrados.

${ }^{34} \mathrm{~A}$ região do município compreende todas as cidades cujo centroide da área urbana está a menos de 100 quilômetros do centroide da área urbana do município de referência. A posição pontual dos municípios em nossa análise é sempre o centroide da área urbana.

35 Informação retirada do site Google Maps.
} 
geograficamente próximos, mas isolados por barreiras naturais ou vias de transporte precárias. Os municípios foram divididos em sete categorias, de acordo com a população ${ }^{36}$. Apenas municípios de uma mesma categoria foram comparados entre si.

Mesmo assim, houve regiões com um número muito baixo de vínculos. Em alguns casos, não há nenhum médico registrado formalmente na região, dado que é extremamente comum que os médicos que atuam no setor privado sejam profissionais liberais e não assalariados. Para resolver esse problema, utilizamos um indicador bayesiano. Basicamente, consideramos que o melhor valor estimado para um insumo é o valor médio para aquele tipo de município no Estado como um todo no ano. Podemos descrever o indicador pela seguinte equação:

$$
w_{p, i, t}=\frac{30 \bar{s}_{p, c, t}+\sum_{v=1}^{V} \frac{1}{\sqrt{d_{j}}} s_{v, p, j, t}}{30+V \frac{1}{\sqrt{d_{j}}}}
$$

Onde $w_{p, i, t}$ é o preço do insumo $p$, no município $i$, no ano $t ; \bar{s}_{p, c, t}$ é a média do mesmo insumo na categoria de municípios $c$ (na qual $i$ faz parte) no Estado todo naquele ano; $d_{j}$ é a distância do município $j$ (que está na região de $i$ ) ao município $i$ (caso $j=i$, o valor de $d_{j}$ é 1$) ; s_{v, p, j, t}$ é o salário por hora do vínculo de trabalho $v$ dentro do município $j$, ano t e $V$ é o total de vínculos de trabalhos dentro da região do município $i$ que são da categoria $c$ no ano $t$. Caso o valor ponderado da região do município for menor que 30, a maior parte do indicador será composta pela média da categoria no Estado $\left(\bar{s}_{p, c, t}\right)$. A medida que o número de vínculos observados na região aumenta, o peso da média do Estado no cálculo do indicador diminui e o valor da região aumenta. Com isso, os municípios com poucas observações tenderão a ter indicadores de insumos próximos à média do Estado dentro de sua categoria, enquanto os municípios com mais observações poderão, a depender dos dados, se distanciar da média estadual do ano.

\footnotetext{
${ }^{36}$ Municípios com menos de 20 mil, 50 mil, 100 mil, 250 mil, 500 mil, 1 milhão e mais de 1 milhão de habitantes.
} 


\section{4 - Correção de erros de mensuração e outliers}

Os dados utilizados em nossos indicadores de produção estão sujeitos a erros de mensuração e, em alguns casos, esses erros criam outliers nos dados. Isso se deve ao fato de estarmos usando registros administrativos que foram gerados de forma descentralizada por cada secretaria municipal de saúde. Esse tipo de dado não apresenta o mesmo rigor metodológico dos dados gerados por órgãos especializados de estatística. Podemos citar alguns casos curiosos em nossa amostra. O município de Monte Alegre do Sul (SP) realizou entre 300 e 1200 vezes por mês o procedimento "0201020041 - COLETA DE MATERIAL P/ EXAME LABORATORIAL" no ano de 2010. A exceção foi o mês de novembro do mesmo ano, onde a produção subiu para 921.746 (!) serviços produzidos, cerca de 120 vezes a população do município, de 7600 habitantes. No ano seguinte, a produção sobe para algo entre 1500 e 2000 procedimentos por mês, mas novamente existe um mês (agosto) onde há o registro de com 251.886 ocorrências, 32 vezes a população da cidade. Esse tipo de registro anômalo não ocorre apenas em pequenos municípios. No município de Campinas (SP) um dos maiores municípios do país, o procedimento "0202080048 - BACILOSCOPIA DIRETA P/ BAAR TUBERCULOSE (DIAGNÓSTICA)" teve uma produção mensal entre 500 e 2000 procedimentos mensais no ano de 2010. Porém, em novembro, a produção registrada foi excepcionalmente alta, de 349.847 ocorrências. Em todo o restante do período analisado, não há nenhum outro mês onde Campinas registrou mais de 2000 exames mensais de mesmo tipo. Assim, claramente, esses valores são frutos de erros de mensuração, como erros de digitação, por exemplo.

Gráfico 2.3 - Produção de serviços médicos per capita (com outliers) 

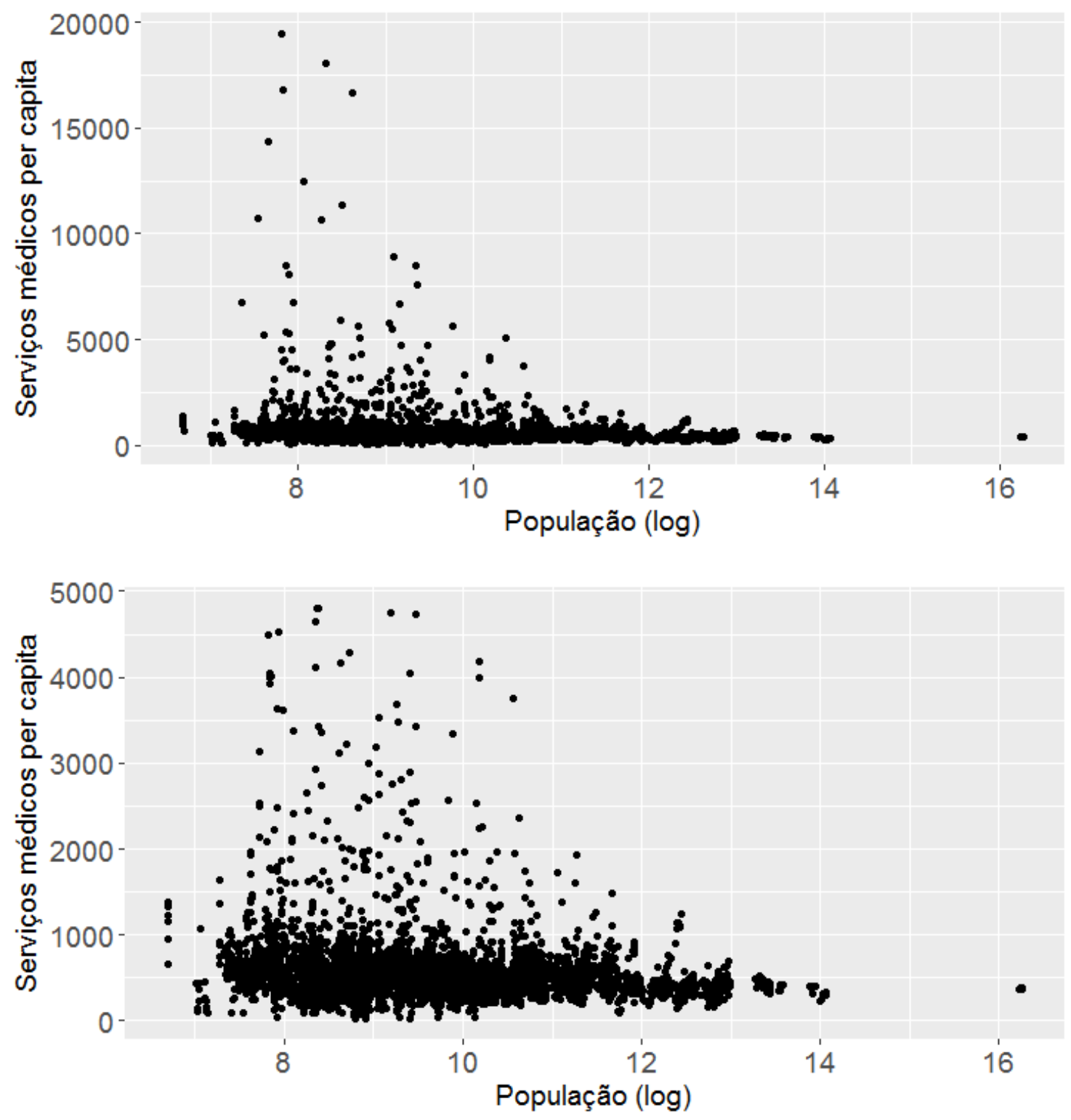

Esses erros provocam anomalias nos dados, como podemos ver no gráfico 2.3, abaixo. O quadro superior mostra a produção de serviços médicos per capita na amostra, de acordo com a população do município. O quadro inferior do gráfico mostra a mesma informação, mas apenas nos municípios com produção per capita abaixo de $\mathrm{R} \$ 5000$ per capita. Podemos ver que, especialmente nos pequenos municípios, existem alguns casos

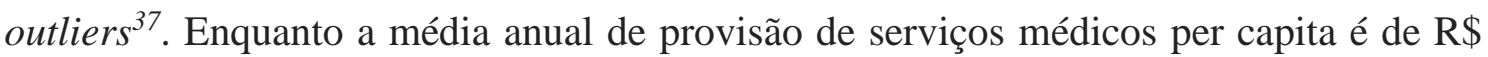

\footnotetext{
${ }^{37}$ Apesar dos erros de mensuração também ocorrem em municípios de grande porte, eles não são tão visíveis pela produção agregada. Quando existe a inserção equivocada de um zero a mais (50 procedimentos viram 500, por exemplo) a produção per capita de um pequeno município pode disparar, mas o mesmo erro pode parecer invisível em um município grande.
} 
629, existem 9 cidades-ano que produzem mais de $\mathrm{R} \$ 10.000$ por ano (Alfredo Marcondes-2010, Arapeí-2011, Monções-2011, São José do Barreiro-2012, Mesópolis2013, Pedranópolis-2013, Salmourão-2013, Poloni-2015 e Sebastianópolis do Sul-2015).

A presença de outliers nos dados foi reconhecida na literatura, mas ainda não existe uma formula padrão para lidar com eles. Os procedimentos para lidar com os erros de mensuração na amostra variam desde técnicas simples, como retirar os dados que obviamente são outliers (VARELA; MARTINS; FÁVERO, 2012) ou retirar observações que estão a certo número de desvios-padrão da média (GODOY, 2014) até procedimentos complexos, como bootstrap-Jacknife (SAMPAIO DE SOUSA; CRIBARI-NETO; STOSIC, 2005) ou DataCloud (ROCHA et al., 2016). Este trabalho optou por uma solução alternativa, que retirou a grande maioria dos dados anômalos de uma forma muito simples. Todas as técnicas mencionadas anteriormente não aproveitaram o fato de que os dados estão dispostos de forma mensal, mas para a maior parte das análises os agregam de forma anual. Em quase todos os casos, a maior parte das anomalias ocorre em poucos procedimentos, onde os valores de um ou dois meses apresentam um quantitativo anômalo, enquanto todo o restante da série apresenta valores próximos aos esperados. Assim, esses meses discrepantes podem ser retirados da amostra, deixando apenas os meses com dados “normais". Então, este trabalho, ao invés de utilizar a produção anual total de cada município, utilizou a "média aparada mensal" anualizada (ou seja, multiplicada por doze). Escolhemos excluir os dois meses com maior valor e os dois meses com menor valor de cada ano. Assim, nos casos mencionados acima, os meses com produção outlier foram excluídos da amostra. Esse procedimento tem a grande vantagem de não excluir os municípios-ano desviantes, mas sim de corrigir os dados, preservando o tamanho da amostra. Podemos ver no gráfico 2.4 como fica a produção médica per capita dos municípios quando utilizamos a média aparada, ao invés da produção agregada anual. O quadro inferior do gráfico 2.4 mostra apenas os municípios com produção per capita inferior a $\mathrm{R} \$ 5000$ per capita. 


\section{Gráfico 2.4 - Produção de serviços médicos per capita (sem outliers)}
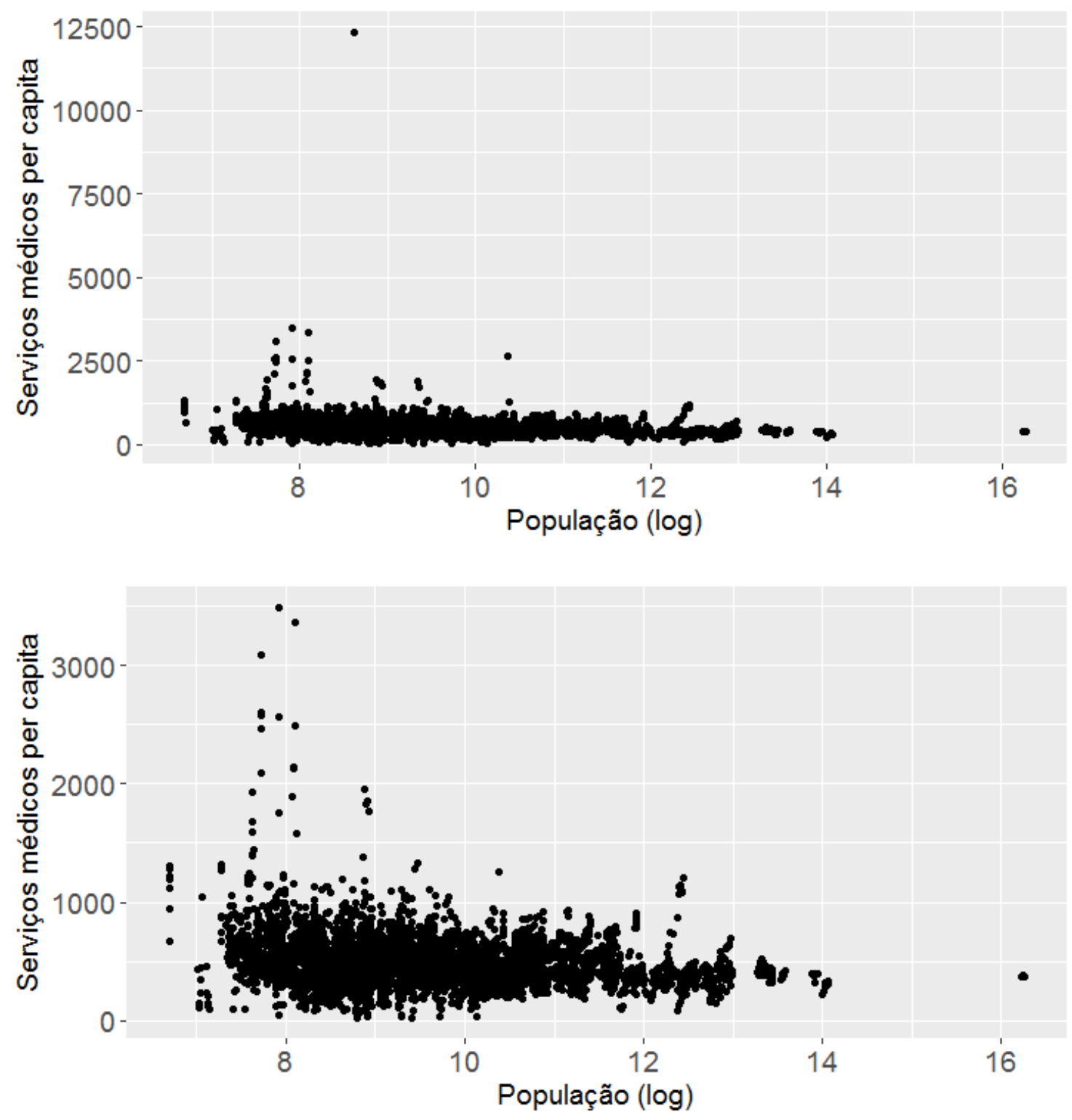

Podemos ver que no gráfico 2.4, a produção dos municípios fica muito mais concentrada em torno da média quando usamos a média mensal aparada. Caso consideremos outliers os municípios que possuem, nos valores antes do tratamento, mais de três desvios-padrão da média, existem 56 municípios-ano com valores de produção médica outlier na amostra. Esse número cai para apenas 3 após o tratamento. Mesmo assim, ainda existem alguns casos difíceis, pois existem alguns municípios onde os valores de muitos meses estão acima do esperado. Por exemplo, o município de Serra Negra (SP) possui valores muito acima do esperado em quase todos os meses, durante todo o período. Há claro indício de manipulação dos dados, pois muitos procedimentos 
possuem quantitativos de produção mensal que acabam em zero (200, 500, 1000, etc). Esse problema é diferente, e provavelmente mais grave, que o mero erro involuntário de mensuração. Então, como controle adicional, foram incluídos mais três procedimentos de eliminação de dados anormais: (1) foram excluídos da amostra todos os municípios-ano que possuem uma relação de produção médica sobre real gasto em saúde maior que 2 ou menor que 0,1 , (2) foi excluído todos os municípios-ano que possuem uma relação de serviços odontológicos sobre real gasto em saúde maior que 1 ou menor que 0,05 e (3) foi excluído todo município com mais de dois anos excluídos da amostra. Assim, nossa amostra deixa muita margem para municípios realmente eficientes, mas exclui casos muito suspeitos. Abaixo, na tabela 2.4, podemos comparar os dados da produção médica em saúde antes e depois dos tratamentos de correção dos outliers.

Tabela 2.4 - Resultado da correção de outliers.

\begin{tabular}{|lccccc|}
\hline \multicolumn{1}{|c}{ Variável } & Média & $\begin{array}{c}\text { Desvio- } \\
\text { Padrão }\end{array}$ & Mínimo & Máximo & $\begin{array}{c}\text { Tamanho } \\
\text { da amostra }\end{array}$ \\
\hline Amostra Original & 628,75 & 853,68 & 18,20 & $19.475,58$ & 4.513 \\
\hline Amostra com média aparada & 507,02 & 292,12 & 18,34 & $12.341,06$ & 4.513 \\
\hline $\begin{array}{l}\text { Amostra com tratamento } \\
\text { completo }\end{array}$ & 516,03 & 204,60 & 63,28 & 1.958 .46 & 4.383 \\
\hline
\end{tabular}

Qual a consequência para a análise desses procedimentos de correção dos erros de mensuração e dos outliers? A primeira consequência é um melhor ajuste dos modelos, dado que há menos "ruído" nos dados. Esse melhor ajuste diminui a variância dos parâmetros e, como consequência, os erros padrões de cada coeficiente. Com isso, há maior probabilidade de se encontrar uma relação estatisticamente significativa, evitando o erro de tipo 2. Uma segunda consequência é que os modelos de máxima verossimilhança levam menos tempo para convergir, tornando a análise computacionalmente menos $\operatorname{custosa}^{38}$. Supreendentemente, a redução dos outliers não altera as conclusões substantivas desse estudo, uma vez que as conclusões do modelo de eficiência (equação

\footnotetext{
${ }^{38}$ Como os modelos de Análise de Fronteira Estocástica são complexos e nossa amostra é relativamente grande, a análise é computacionalmente custosa. Alguns modelos demoram até três horas para serem calculados. Em alguns casos, o ruído dos dados simplesmente impede que os modelos cheguem a uma conclusão. Assim, qualquer tratamento que melhore a qualidade dos dados ou a especificação dos modelos é altamente relevante.
} 
3.15) não são significativamente alteradas na amostra com e sem tratamento ${ }^{39}$. Esse fato é um forte indício de que os erros de mensuração na amostra estão distribuídos, em sua maioria, de forma aleatória e, portanto, não atrapalham os padrões sistemáticos da eficiência municipal.

\section{5 - Análise preliminar dos dados}

Nesta seção, iremos começar a explorar os indicadores propostos acima de forma gráfica, ainda a análise de fronteiras estocásticas, que será apresentada no - A análise de eficiência por Fronteiras Estocásticas.Capítulo 3. Como veremos, a mera exposição dos dados nos ajuda tanto a adiantar muitas conclusões que serão discutidas mais à frente quanto a descobrir a forma funcional adequada das variáveis. Nessa análise preliminar, utilizaremos a provisão de serviços médicos (sem discriminar por tipo de produção ou complexidade dos serviços) como proxy da produção municipal em saúde. Como a maior parte da produção municipal em saúde é de serviços médicos, acredito que essa é a melhor variável para uma análise preliminar nos dados.

No gráfico 2.5, podemos ver a produção de serviços médicos per capita sobre o logaritmo natural da população. Ao contrário do que advogaria um defensor da teoria da modernização, a produção médica é bem distribuída entre os diferentes tipos de municípios. No gráfico 2.5 a linha azul representa a correlação linear entre os parâmetros do eixo vertical e do eixo horizontal, enquanto a linha vermelha representa a um modelo não-paramétrico (smooth), que se ajusta gradualmente em cada posição do gráfico. Podemos ver pela linha azul que a correlação entre a população e os serviços per capita é zero, ou seja, os cidadãos das pequenas cidades recebem praticamente a mesma quantidade de serviços médicos per capita que os cidadãos das grandes cidades. É importante considerar que estamos analisando apenas os serviços públicos municipais. Caso incluíssemos os serviços privados de saúde e os serviços públicos estaduais, certamente o gráfico seria mais favorável às grandes cidades. De toda forma, esse gráfico refuta algumas visões extremamente pessimistas quanto aos pequenos municípios.

\footnotetext{
${ }^{39}$ Não serão mostrados os resultados dos modelos com outliers, mas eles podem ser enviados, mediante requisição ao autor.
} 


\section{Gráfico 2.5 -Serviços médicos per capita sobre a população}

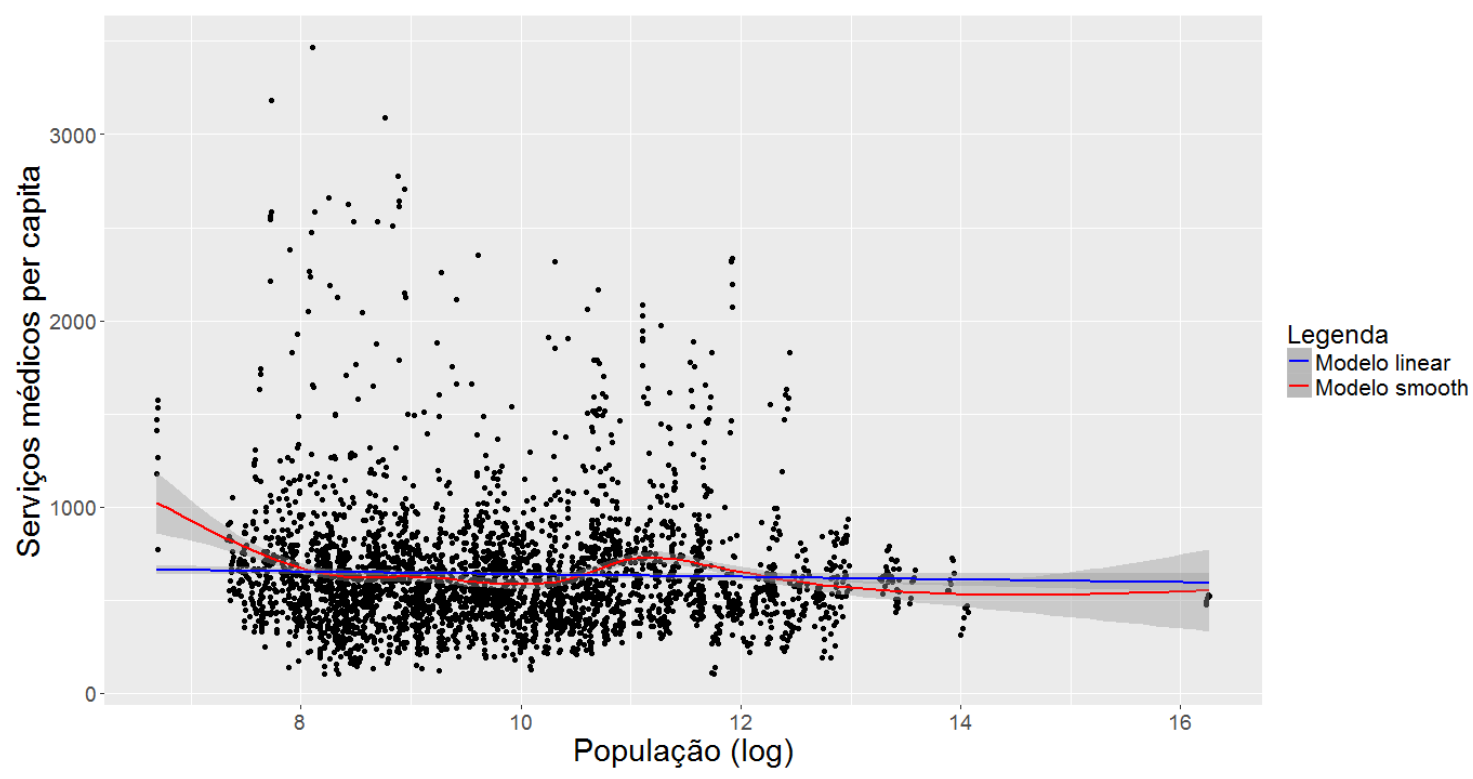

O gráfico 2.6 mostra a distribuição dos insumos, ou seja, do gasto per capita na função saúde, sobre a população. Podemos ver que os municípios muito pequenos possuem um gasto per capita elevado, devido à influência do FPM. Contudo a quantidade por habitante logo cai para próximo da média, se mantendo praticamente constante a partir daí e somente voltando a aumentar nos maiores municípios (mais de $400 \mathrm{mil}$ habitantes). O gráfico fica mais fácil de ser interpretado se lembrarmos de que os municípios com população igual a log de 8 possuem por volta de 3 mil habitantes, o log de 10 é por volta de 22 mil, o log de 12 é 162 mil habitantes e o $\log$ de 14 é 1 milhão e duzentos mil habitantes. 


\section{Gráfico 2.6 - Gastos com saúde per capita sobre a população}

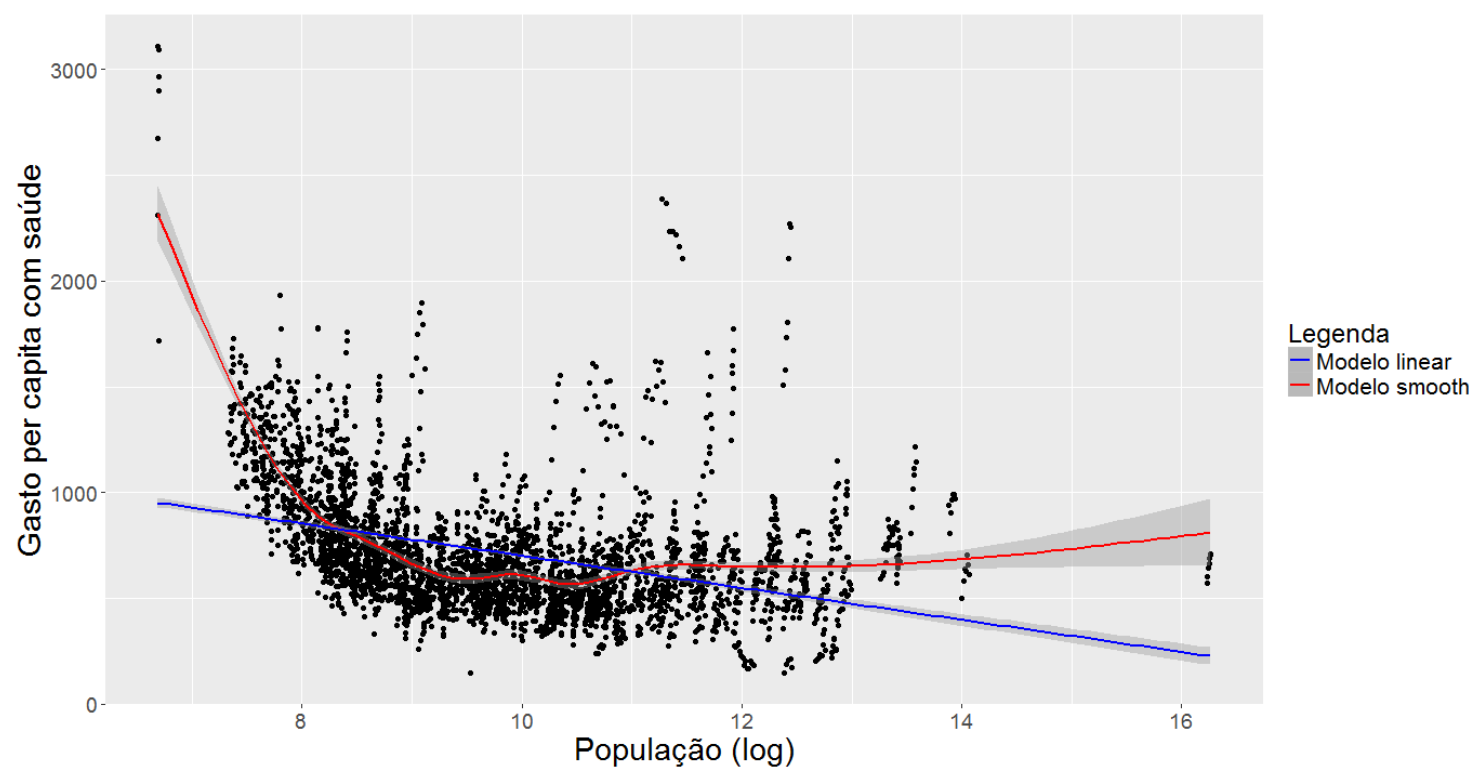

Gráfico 2.7 - Pseudo-Eficiência médica sobre a população

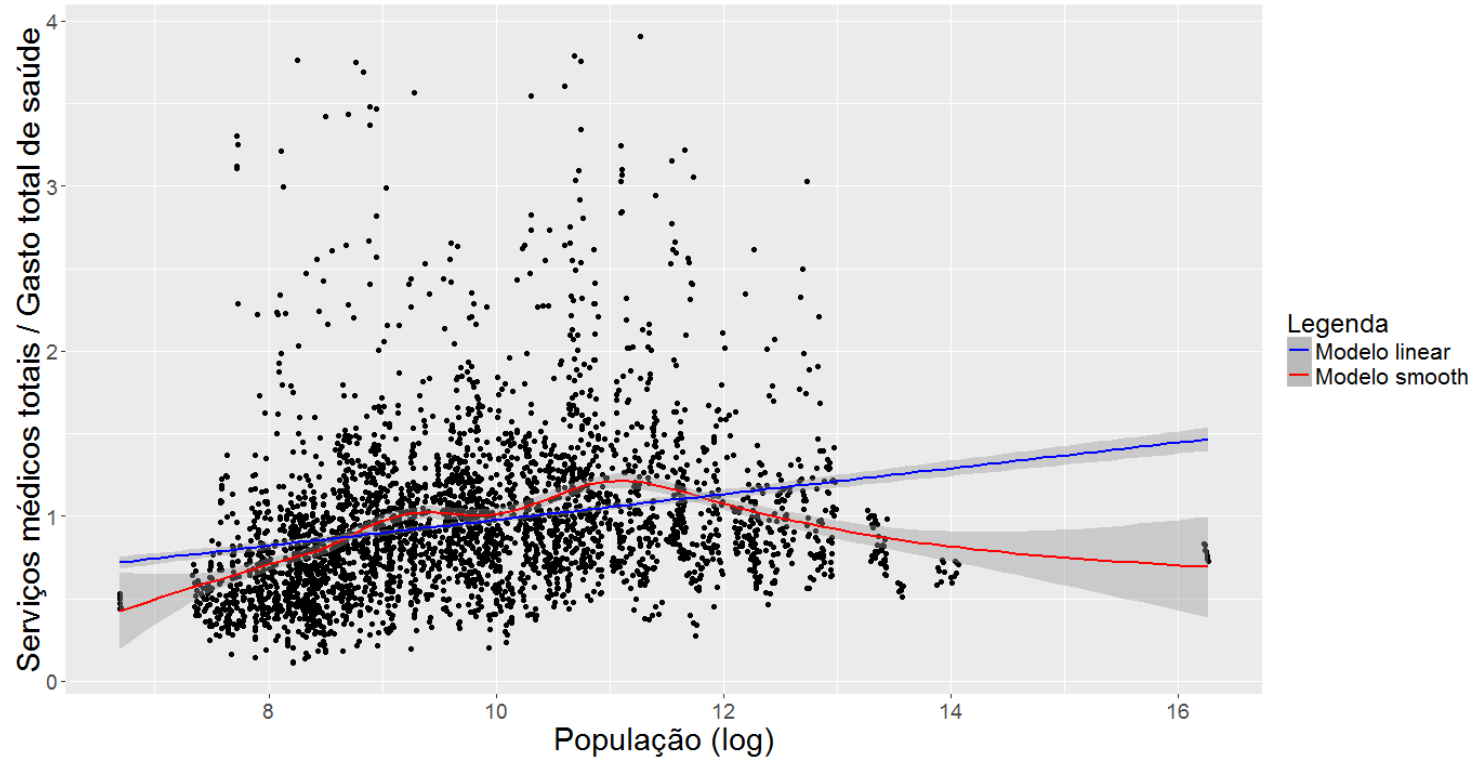

O gráfico 2.7 analisa o que eu chamei de "pseudo-eficiência" médica, que é simplesmente o indicador de produção em serviços médicos sobre o gasto total em saúde. Podemos ver que o modelo linear mostra um ganho de escala ao longo da distribuição, mas o modelo não-paramétrico mostra que existe uma função quadrática, onde a eficiência cresce até cerca de log de 11,2 (por volta de 70 mil habitantes) e cai a partir daí. Assim, os dados corroboram a hipótese de que existe um ganho de escala na provisão municipal de saúde, mas apenas quando os municípios são muito pequenos. O a pseudo- 
eficiência máxima ocorre em um patamar surpreendentemente baixo, sendo que a partir daí, ocorre uma diminuição da eficiência. Assim, o gráfico 3 tende a fortalecer mais as hipóteses que advogam a favor da descentralização do que as teorias centralizadoras.

\section{Gráfico 2.8 - Pseudo-Eficiência médica sobre a transferências per capita}
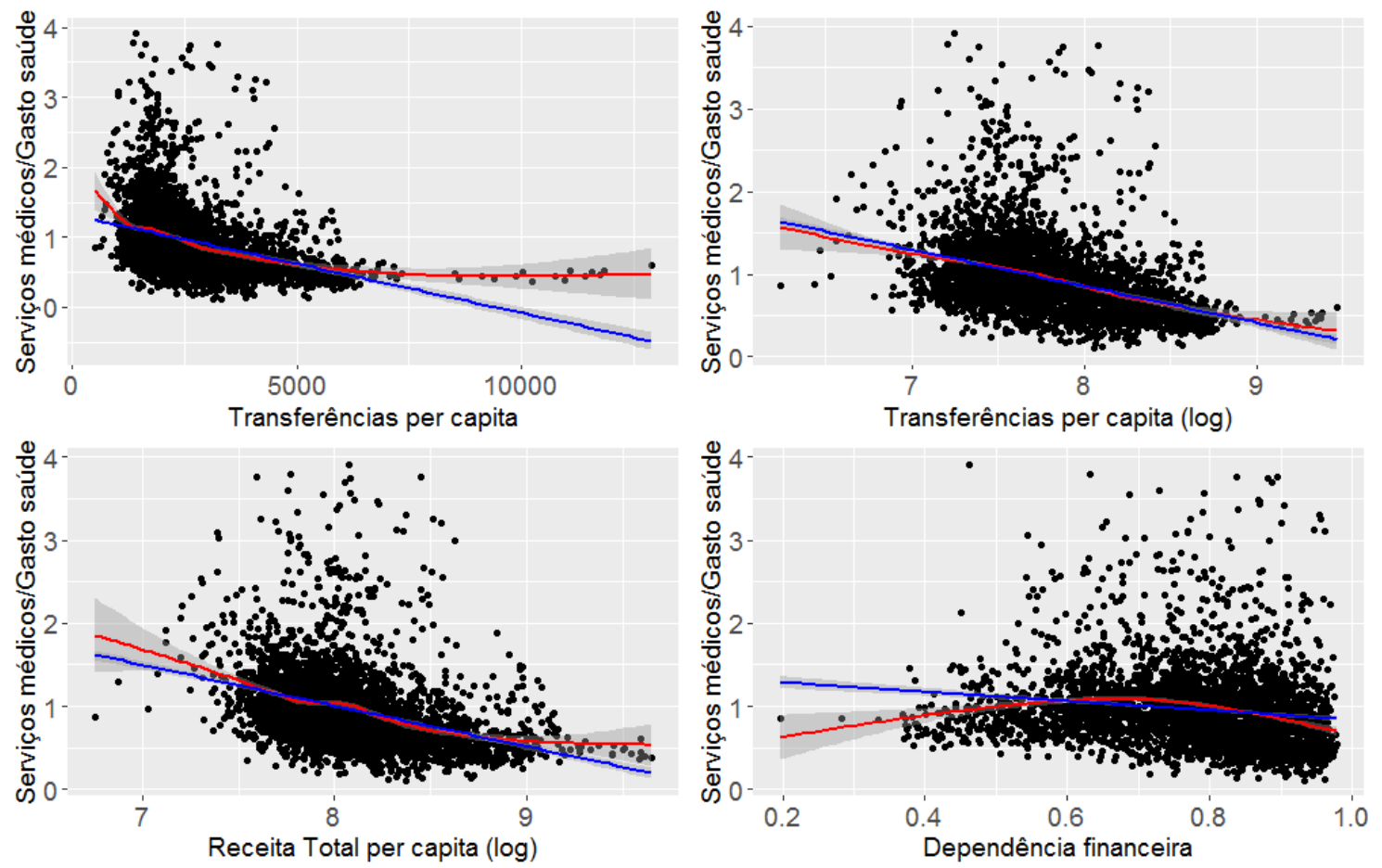

No gráfico 2.8 podemos ver a correlação entre a pseudo-eficiência médica, as transferências per capita, a receita total per capita e a dependência financeira. Na parte superior esquerda, podemos ver a relação entre a pseudo-eficiência médica e as transferências per capita em nível. Na parte superior direita, há a relação entre as mesmas duas variáveis, mas as transferências estão em logarítimo. Ambos os gráficos mostram que existe uma forte correlação negativa entre transferências e eficiência. Contudo, o ajuste do modelo linear é melhor no segundo caso. Assim, temos tanto evidências de que as transferências afetam negativamente a eficiência da provisão de saúde quanto que essa relação é marginalmente decrescente, informação que usaremos em nossos modelos abaixo. A correlação entre receitas totais e eficiência é muito parecida com a relação entre transferências e eficiência. Como mencionamos, é muito difícil separar o efeito da receita total do efeito das transferências, uma vez que quase todos os municípios que apresentam elevada receita per capita também possuem elevadas transferências per capita. Por fim, 
na parte inferior direita está a correlação entre dependência financeira e pseudoeficiência. Podemos ver que a correlação vai ao encontro da literatura, ou seja, os municípios mais dependentes tendem a ser menos eficientes que os municípios menos dependentes.

\section{Gráfico 2.9 - Pseudo-Eficiência médica, renda e escolaridade}
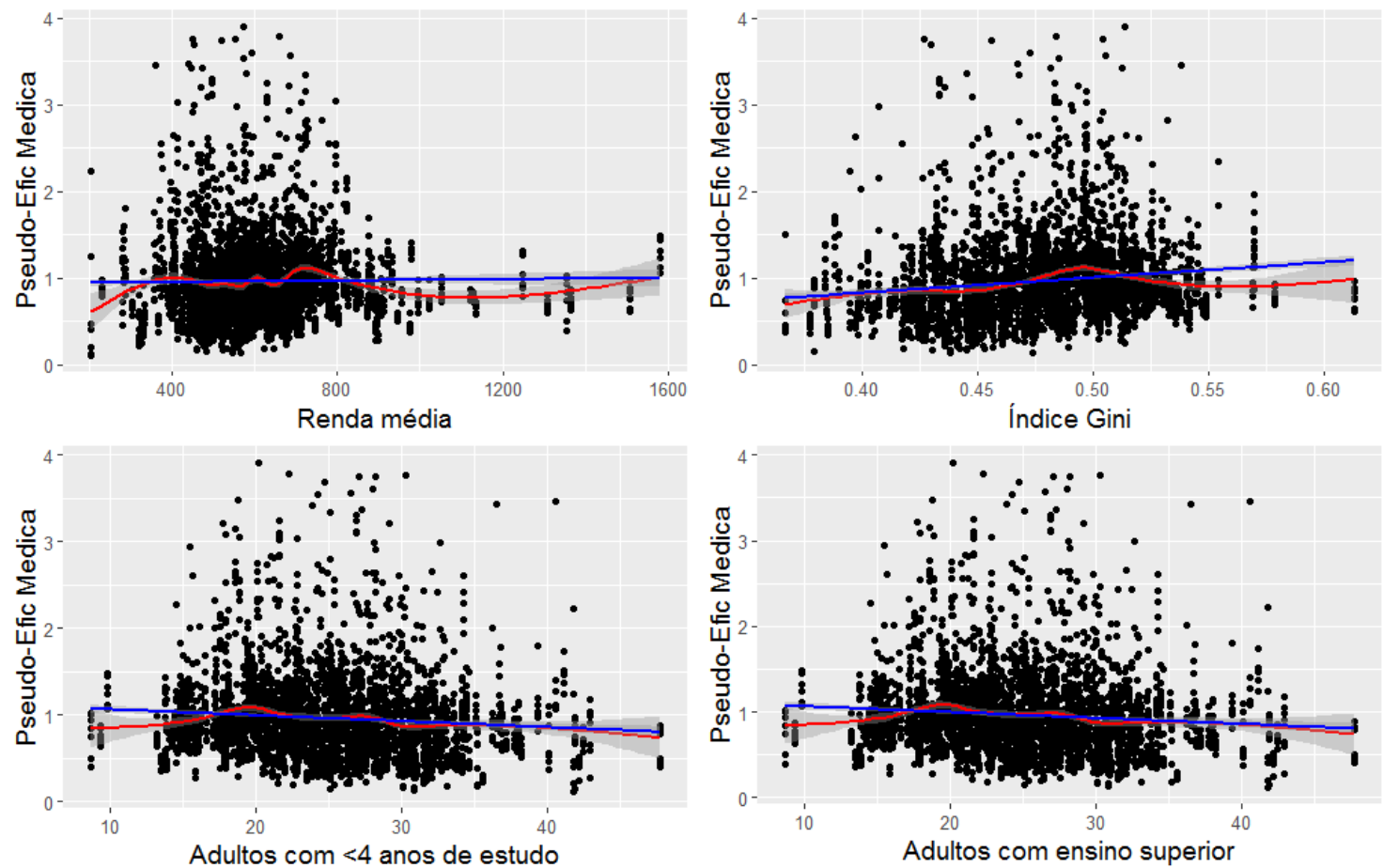

Por fim, o gráfico 2.9 mostra a relação entre renda, distribuição de renda, escolaridade, e pseudo-eficiência médica. No canto superior, à esquerda, há a correlação entre renda a pseudo-eficiência média. Na parte superior à direita, há a correlação entre desigualdade de renda municipal, medida pelo indicador Gini, e pseudo-eficiência. Nos dois quadros da parte inferior há a correlação entre a pseudo-eficiência e a proporção de adultos com menos de quatro anos de estudo e com nível superior, respectivamente. Podemos ver que nas quatro variáveis de desenvolvimento social utilizadas aqui, a princípio, não há correlação clara com a eficiência governamental. Contudo, temos que observar que todas essas variáveis explicativas estão correlacionadas entre si. Assim, precisamos utilizar um modelo estatístico mais sofisticado para podermos tirar conclusões mais robustas. Esse é o objetivo das próximas seções. 


\section{Capítulo 3 - A análise de eficiência por Fronteiras Estocásticas.}

Neste trabalho, mensuraremos a fronteira de produção e o índice de eficiência de cada município utilizando análise de fronteiras estocásticas (Stochastic Frontier Analysis, SFA, Aigner, Lovell \& Schmidt, 1977; Meeusen \& Broeck, 1977). A SFA é um método paramétrico e estocástico de aferição da eficiência, ou seja, ele necessita de uma forma funcional definida a priori pelo analista, mas, por outro lado, incorpora componentes aleatórios na determinação da eficiência. A SFA apresenta algumas vantagens em relação às metodologias deterministas (como a análise envoltória de dados, DEA, por exemplo), pois as variáveis utilizadas para mensurar os insumos e produtos do setor público local estão sujeitos a erros de mensuração e a choques exógenos aleatórios. Ao contrário das metodologias deterministas, as metodologias estocásticas lidam melhor com "ruídos" nos dados ${ }^{40}$. Outra vantagem da SFA para os propósitos desse trabalho, é que nela a análise das variáveis de controle relacionadas aos escores de eficiência é mais direta e natural que nos estudos em envolvem a DEA. A SFA permite estimar a eficiência das organizações e a influência de variâncias ambientais em um único modelo, evitando problemas típicos da análise em dois estágios.

Este capítulo visa apresentar os principais conceitos da SFA e, ao mesmo tempo, justificar as escolhas metodológicas desse trabalho. Não iremos descrever extensamente os detalhes da metodologia, pois essas informações se encontram amplamente disponíveis em livros-texto sobre o tema (COELLI et al., 2005; GREENE, 2008; KUMBHAKAR; LOVELL, 2003; KUMBHAKAR; WANG; HORNCASTLE, 2014). Particularmente, não serão apresentadas as funções de máxima verossimilhança de cada modelo explicado mencionado, apenas a sua forma funcional.

Além de explicar a metodologia SFA, esse capítulo tem outra função: justificar a escolha da forma funcional da função de custo utilizada nesse trabalho. Como mencionado, a SFA, ao contrário da DEA, é um método paramétrico, ou seja, exige que

\footnotetext{
${ }^{40}$ Contudo, a diferença entre a DEA e a SFA nesse quesito tem caído nos últimos anos, uma vez que o método proposto por Simar \& Wilson (2007) incorpora componentes da análise estocástica dentro da DEA.
} 
o analista crie uma forma funcional a priori da fronteira de produção. Como esse trabalho se utiliza de dados inéditos, não existe uma forma funcional consolidada na literatura de economia da saúde pública. Para sanar essa lacuna, na parte final desse capítulo eu avalio diferentes modelos de fronteira de custos de saúde e justifico a forma funcional.

\section{1 - Conceitos básicos da SFA}

O desenho básico da SFA parte de uma série de pressupostos simples sobre a organização da produção. Podemos estender a equação 1.1 para pensar que em uma situação de um único insumo (o gasto público) e vários produtos de saúde, da seguinte forma $^{41}$ :

$$
T E_{i}=\frac{f\left(y_{1}, \ldots, y_{m}, \beta_{1}, \ldots, \beta_{m}\right)}{C_{i}} e^{v_{i}}
$$

Onde $f\left(y_{1}, \ldots, y_{m}, \beta_{1}, \ldots, \beta_{m}\right)$ é uma função contendo dois vetores: o vetor $y$, que é um vetor de produtos fornecidos pela organização $i$, e o vetor $\beta$, que são o conjunto de parâmetros que define a tecnologia produtiva de fronteira. A variável $C_{i}$ é o custo total da organização (insumo). Nessa formulação, a tecnologia disponível (representada pelos valores betas) é comum a todas as organizações. Contudo, cada organização possui um nível de eficiência técnica próprio $\left(T E_{i}\right)$, que, junto com a disponibilidade de insumos, determinará o índice agregado de produção da organização $i$. O indicador $T E_{i}$ varia entre 1 (no caso de uma organização que se situa na fronteira de produção) e zero (no caso de uma organização com produção nula). O parâmetro $e^{v_{i}}$ representa o erro de mensuração nos parâmetros betas. Sem ele, o modelo se tornaria uma fronteira determinista, dado que estamos pressupondo que os parâmetros betas representam exatamente a fronteira produtivas. Mas como estamos estimando o modelo com um com a variável de erro, o modelo se torna uma fronteira probabilística ou "fronteira estocástica".

\footnotetext{
${ }^{41} \mathrm{Na}$ análise, as funções que possuem um único produto e vários insumos são chamadas de "funções de produção". Já as funções que possuem um insumo e vários produtos são chamadas de "funções de custo". Neste trabalho, como em quase todos que abordam a eficiência do setor público, utilizaremos uma função de custo.
} 
Caso considerarmos a função $f\left(y_{1}, \ldots, y_{m}, \beta_{1}, \ldots, \beta_{n}\right)$ uma simples função linerar Cobb-Douglas ${ }^{42}$, então podemos reescrever a equação 3.2 da seguinte forma:

$$
C_{i}=\beta_{0} y_{1, i}^{\beta_{1}} y_{2, i}^{\beta_{2}} \ldots y_{m, i}^{\beta_{m}} * e^{v_{i}} * T E_{i}
$$

Partindo do pressuposto de que $T E_{i}=\frac{1}{e^{\mu}}$ e reorganizando os termos da equação, podemos criar um modelo econométrico para a estimação da eficiência técnica com a seguinte forma ${ }^{43}$ :

$$
\begin{gathered}
T E_{i}=\frac{1}{e^{\mu}} \\
\ln C=\beta_{0}+\beta_{1} \ln y_{1, i}+\beta_{2} \ln y_{2, i}+\ldots+\beta_{m} \ln y+v_{i}+\mu_{i}
\end{gathered}
$$

Onde $\mu_{i}$ é um indicador de eficiência técnica e $v_{i}$ é o erro do modelo.

Existem duas grandes dificuldades matemáticas para se estimar esse modelo: (a) calcular a fronteira das possibilidades de produção (os parâmetros beta) e (b) separar o erro aleatório $(v)$ e do componente de eficiência $(\mu)$. Greene (1980) mostrou que o método dos mínimos quadrados ordinários, MQO, pode calcular corretamente os parâmetros da fronteira. A única exceção é o intercepto, que é enviesado para baixo, dado que $\mu$ sempre possui valor negativo e $\varepsilon_{i}$ precisa ter média zero. Por outro lado, Jondrow et all (1982) e Bauer (1987) mostraram que é possível calcular tanto os parâmetros corretos da fronteira quanto os demais valores necessários $\left(v_{i}, \mu_{i}, \operatorname{Var}\left(v_{i}\right)\right.$ e $\left.\operatorname{Var}\left(\mu_{i}\right)\right)$ utilizando máxima verossimilhança. Apenas precisamos assumir uma distribuição para o termo $v$ e outra distribuição para o termo $\mu$. O erro aleatório, $v$, normalmente é assumido como tendo uma distribuição normal. O termo de ineficiência, $\mu$, pode assumir as distribuições meianormal, normal-truncada, Normal-Exponencial e Normal-Gama. Neste trabalho, iremos

\footnotetext{
${ }^{42}$ A função de produção Cobb-Douglas pode ser definida como uma relação de produção onde o output $(Y)$ e os inputs $\left(I_{i}\right)$ estão na forma logarítmica, representando retorno marginal decrescente. A função de produção Cobb-Douglas pode ser escrita como a $\ln (Y)=\beta_{0}+\sum_{i} \beta_{i} \ln \left(I_{i}\right)$, sendo que os betas representam os coeficientes do modelo. É possível fazer uma função de custo Cobb-Douglas, invertendo os termos da equação, $\ln (I)=\beta_{0}+\sum_{i} \beta_{i} \ln \left(Y_{i}\right)$.

${ }^{43}$ Lembrando que, pelas propriedades dos logaritmos, $y_{1, i}^{\beta_{1}} y_{2, i}^{\beta_{2}}=\beta_{1} \ln y_{1, i}+\beta_{2} \ln y_{2, i}$.
} 
assumir que o termo $\mu$ tem distribuição normal-truncada, mas estudos recentes mostram que as diferentes distribuições levam a resultados parecidos (GREENE, 2008).

Assim, a função de custo de nossa fronteira estocástica possui a seguinte forma:

$$
\begin{gathered}
\ln C_{i}=\beta_{0}+\sum_{j=1}^{s} \beta_{j} \ln y_{j, i}+\varepsilon_{i} \\
\varepsilon_{i}=v_{i}+\mu_{i} \\
v_{i} \sim N\left(0, \sigma_{v}^{2}\right) \\
\mu_{i} \sim N^{+}\left(\mu, \sigma_{\mu}^{2}\right)
\end{gathered}
$$

Onde,

$C_{i}$ é o custo da rede municipal de saúde $i$, no nosso caso, é o gasto na função saúde do município $i$.

$\varepsilon_{i}$ é o erro da equação de fronteira. Ele é a soma de um erro aleatório e da eficiência do município $i$.

$y_{j, i}$ é o indicador de produção $j$ de $i$,

$v_{i}$ é o erro do modelo e

$\mu_{i}$ é um indicador de ineficiência $i$.

\section{2 - Extensões do método SFA}

\subsection{1 - Dados em painel}

Recentemente, os estudos SFA têm evoluído muito para a análise de dados em painel (Parmeter \& Kumbhakar, 2014, cap 7). Os dados em painel possuem pelo menos três grandes vantagens. Em primeiro lugar, é possível analisar a tendência temporal da eficiência, mostrando ganhos ou perdas tecnológicas na fronteira de produção. Em segundo lugar, os dados em painel permitem reduzir a incerteza dos modelos, uma vez que cada unidade é observada em vários pontos no tempo, reduzindo o efeito de choques 
aleatórios (como erros de mensuração). Por fim, os dados em painel permitem separar entre eficiência persistente e transitória. Contudo, neste trabalho nos ateremos apenas à eficiência persistente, ou seja, aquela que não varia dentro do período observado. Nosso foco na (in)eficiência persistente se dá dois motivos. Em primeiro lugar, os argumentos teóricos levantados no Capítulo 1, dizem mais respeito à ineficiência duradoura que a ineficiência transitória, ou seja, estamos mais interessados em explicar porque alguns municípios são mais ineficientes que outros na média do que saber o que fez com que alguns municípios se tornassem mais ou menos ineficientes de um ano para outro. Em segundo lugar, a maior parte das variáveis explicativas levantadas no tópico anterior (população, transferências intergovernamentais, etc) variam pouco no tempo, por isso são melhor capitadas pela ineficiência persistente dos modelos de eficiência (BADUNENKO; KUMBHAKAR, 2016).

Os modelos em painel permitem analisar a tendência temporal da eficiência, ou seja, se as organizações estão se tornando mais (ou menos) produtivas ao longo do tempo. Em termos matemáticos, isso equivale a criar uma função específica para o termo $\mu_{i, t}$, da seguinte forma:

$$
\begin{gathered}
\ln C_{i, t}=\beta_{0}+\sum_{j=1}^{s} \beta_{j} \ln y_{j, i, t}+v_{i, t}+\mu_{i, t} \\
\mu_{i, t}=G(t) \mu_{i} \\
\mu_{i} \sim N^{+}\left(\mu, \sigma_{\mu}^{2}\right) \\
v_{i} \sim N\left(0, \sigma_{v}^{2}\right)
\end{gathered}
$$

Onde,

$G(t)$ é a função que modela a influência da variável de tempo, $t$.

Existem várias opções de funções temporais (para uma revisão, ver Kumbhakar, Wang, and Horncastle, 2014, cap 10), mas para nossos propósitos não é conveniente construir modelos temporais complexos, dado que temos apenas sete anos na amostra. Podemos pressupor ou que não existe variação tecnológica no período, ou então que o 
tempo possui uma relação linear com eficiência, diminuindo ou aumentando a uma taxa constante. Neste caso, a função $G(t)$ seria:

$$
G(t)=\exp \left[\gamma\left(t-t_{\text {min }}\right)\right]
$$

Onde,

$t$ é a variável de tempo.

$t_{\text {min }}$ é o início do período.

$\gamma$ é o parâmetro de crescimento da ineficiência.

Abaixo iremos contrastar o modelo de evolução linear da fronteira de produção, com a o esse modelo de eficiência invariável no tempo, ou seja, onde $G(t)=1$. O modelo invariante no tempo apresenta a grande vantagem de ser mais fácil de calcular, mas, por outro lado, pode parecer infactível, a depender da evolução tecnológica do período.

\subsection{2 - Variáveis explicativas da eficiência}

Uma grande vantagem da análise SFA é que ela permite analisar a influência de variáveis explicativas ao mesmo tempo que calcula a eficiência de cada organização. Assim, se evita adotar a chamada "análise em dois estágios", onde se usa um modelo para calcular a eficiência da organização e, então, se utiliza a eficiência estimada como variável dependente de um modelo de mínimos quadrados ordinários. Tal estratégia é frequentemente utilizada em análises que se utilizam de metodologias não estocásticas de mensuração, como a Data Envelopmente Analisys. Contudo, Battese \& Coelli (1995), Wang \& Schmidt (2002) e Simar \& Wilson (2007) mostraram que essa estratégia de análise pode levar a resultados enviesados, pois no primeiro estágio, se calcula a eficiência partindo do pressuposto de que o valor estimado do erro é zero $\left(E\left[v_{i}\right]=0\right)$. Quando o indicador de eficiência é utilizado como variável dependente de outro modelo, esse pressuposto é invalidado.

Huang and Liu (1994) e Battese \& Coelli (1995) desenvolveram uma metodologia para calcular a eficiência das organizações e ao mesmo tempo analisar quais variáveis 
explicativas estão correlacionadas com esse índice de eficiência ${ }^{44}$. Então, o modelo teria a seguinte forma:

$$
\begin{gathered}
\ln C_{i, t}=\beta_{0}+\sum_{j=1}^{s} \beta_{j} \ln y_{j, i, t}+v_{i, t}+\mu_{i} \\
\mu_{i}=\delta_{0}+\sum_{k=1}^{K} \delta_{k} z_{k, i} \\
\mu_{i} \sim N^{+}\left(\mu, \sigma_{\mu}^{2}\right) \\
v_{i} \sim N\left(0, \sigma_{v}^{2}\right)
\end{gathered}
$$

Onde,

$z_{k, i}$ é uma variável exógena explicativa $k$

$\delta_{k}$ é o parâmetro do modelo explicativo da ineficiência.

Como todos os parâmetros são calculados na mesma função de máxima verossimilhança, o pressuposto de valor esperado dos erros igual a zero permanece válido. Neste trabalho, a equação 3.15 é de especial importância, pois é ela que mostrará a relação entre as variáveis dependentes e independentes, validando ou não as relações causais explanadas no Capítulo 1.

Antes de passar ao próximo tópico, é importante ressaltar que nosso modelo considera toda heterogeneidade como ineficiência persistente, ou seja, todos os fatores que fazem com que um município seja mais ou menos eficiente são considerados ineficiência persistente. Fatores que estão além do controle dos gestores, como características do território ou pouca disponibilidade de mão-de-obra qualificada, por exemplo, estão incluídas no termo $\mu_{i}$. Contudo, podemos controlar parte do efeito da heterogeneidade municipal sobre a eficiência utilizando variáveis de controle. Assim, a inclusão de variáveis pode "isolar" a qualidade do gestor público de outros fatores que não estão sob sua responsabilidade.

\footnotetext{
${ }^{44}$ A implementação em STATA do código que combina os modelos SFA em painel e os modelos que avaliam a influência de variáveis exógenas foi feita por Kumbhakar, Wang, \& Horncastle (2014, cap 10).
} 


\subsection{3 - Heterocedasticidade}

Segundo discutido por Kumbhakar \& Lovell (2003, cap 3.4), ignorar a heterocedasticidade é mais problemático em modelos SFA que em modelos clássicos lineares. Em modelos de fronteiras estocásticas, omitir a heterocedasticidade quando ela está presente no modelo populacional não somente leva à perda de eficiência das medidas, mas também leva a estimadores inconsistente. Contudo, é possível criar uma modelagem específica para a heterocedasticidade, eliminando esse viés. Assim, iremos utilizar as mesmas variáveis $z$ para o modelo explicativo para também modelar a heterocedasticidade.

$$
v_{i, t} \sim N\left(0, \mathrm{H}\left(\gamma_{i} z_{i}\right)\right)
$$

\section{3 - Escolha entre diferentes modelos de fronteira de eficiência}

Segundo Lai \& Huang (2010), a maior parte dos trabalhos escolhe que utilizam SFA escolhe o modelo da fronteira de produção de uma forma arbitrária e pouco justificada. Muitas vezes, modelos alternativos sequer são considerados e comparados. Esse trabalho irá, então, seguir um caminho distinto, contrastando diferentes modelos e escolhendo aquele que melhor se ajusta aos dados e à teoria de análise.

Existem três critérios para a formação de uma fronteira de custos de saúde, utilizando os indicadores de produção em saúde descritos no Capítulo 2. Em primeiro lugar, podemos explorar melhor as informações disponibilizadas no DATASUS, desagregando os indicadores de produção em saúde mencionados no Capítulo 2 em novos subconjuntos. Os bancos de dados do Ministério da Saúde dividem os procedimentos realizados pelos municípios segundo o tipo de produção (ambulatorial ou hospitalar) e o segundo o nível de complexidade do procedimento (atenção básica, média complexidade e alta complexidade). Por exemplo, poderíamos dividir a produção médica com equivalência no setor privado (serviços médicos) em 6 categorias: (1) serviços 
médicos ambulatoriais de atenção básica, (2) serviços médicos hospitalares de atenção básica, (3) serviços médicos ambulatoriais de média complexidade, (4) serviços médicos hospitalares de média complexidade, etc. Nem todos os grupos podem ser divididos em 6 categorias, pois existem alguns grupos inexistentes. Todos os procedimentos de atenção psicossocial possuem a mesma complexidade, por exemplo ${ }^{45}$. Essa desagregação pode ser útil para captar custos ocultos em nossos indicadores de produção. Por exemplo, os procedimentos hospitalares tendem a ser realizados em pacientes mais graves que os procedimentos ambulatoriais, por isso, podem ter custos maiores. Os modelos utilizados também se tornam mais robustos contra eventuais ganhos ou perdas de eficiência decorrentes da especialização na provisão de procedimentos de alta ou baixa complexidade. Nesse trabalho, testaremos a adequação de três tipos de agregação dos procedimentos: uma agregação concisa, uma agregação média e uma agregação completa. A agregação concisa é simplesmente as oito categorias básicas descritas na tabela 2.3. A agregação média equivale à agregação concisa, mas com os indicadores de serviços médicos, serviços de enfermagem, serviços odontológicos, e serviços médicos ponderados pelos valores do SUS desagregados em produção ambulatorial e produção hospitalar. A agregação completa desagrega todos os procedimentos de acordo com o tipo de produção e com a complexidade dos procedimentos, resultando em 22 categorias. Também seria possível criar uma agregação que desagregasse os procedimentos por complexidade, mas não por tipo de produção, mas testes preliminares mostraram que essa opção traz resultados muito parecidos com a desagregação média, mas com ajuste pior. O principal trade-off entre os tipos de agregação é entre o melhor ajuste aos dados e o aumento do número de variáveis. Mais variáveis normalmente levam a um melhor ajuste do modelo aos dados, mas por outro lado aumenta o custo computacional do modelo. As descrição das variáveis utilizadas em cada agregação se encontram no Anexo I.

\footnotetext{
45 Os procedimentos com complexidade "NA - Não se aplica", são muito pouco frequentes, por isso foram agregados aos procedimentos de média complexidade. Houve apenas uma exceção que continuou como categoria separada: os procedimentos ambulatoriais sem equivalência no setor privado (ou seja, ponderados pelo valor de referência do SUS). Esse subconjunto se mostrou frequente e muito significativo na análise. Neste conjunto estão os famosos gastos com transporte de pacientes, onde as prefeituras enviam seus moradores para serem atendidos em outras cidades. Os procedimentos odontológicos de alta complexidade são também muito raros, por isso foram agregados aos procedimentos de média complexidade. O mesmo acontece com os procedimentos psicossociais hospitalares, que foram agregados aos procedimentos ambulatoriais.
} 


\begin{tabular}{|c|c|c|}
\hline \multicolumn{3}{|c|}{ Tabela 3.1 - Critérios para função de custo em saúde pública municipal } \\
\hline Agregação & Forma Funcional & Ajuste temporal \\
\hline Concisa & Coob-Douglas & Invariante \\
\hline Média & Quadrática & Variação linear \\
\hline Completa & Translog & \\
\hline
\end{tabular}

O segundo critério para a criação de modelos é a forma funcional das variáveis. Existem três formas funcionais na literatura: a função Coob-Douglas, a função Quadrática e a Função Translog. A função Coob-Douglas equivale ao modelo "log-log" dos modelos de regressão clássicos, mas as variáveis não estão em funções quadráticas nem interagidas entre si. Na função quadrática, por outro lado, cada variável aparece duas vezes, uma em nível e outra elevada ao quadrado. Na função Translog, a mais flexível de todas, as variáveis estão todas interagidas umas com as outras em pares. Elas, inclusive, estão interagidas consigo mesmo, formando termos quadráticos. A tabela $\mathbf{3 . 2}$ descreve as fórmulas funcionais.

\begin{tabular}{|c|c|}
\hline \multicolumn{2}{|c|}{ Tabela 3.2 - formulas funcionais. } \\
\hline Função & Formula \\
\hline $\begin{array}{c}\text { Coob- } \\
\text { Douglas }\end{array}$ & $\ln C_{i}=\beta_{0}+\sum_{j=1}^{s} \beta_{j} \ln y_{j, i}+v_{i}+\mu_{i}$ \\
\hline Quadrática & $\ln C_{i}=\beta_{0}+\sum_{j=1}^{s} \beta_{j} \ln y_{j, i}+\sum_{j=1}^{s} \beta_{j} \ln y_{j, i}^{2}+v_{i}+\mu_{i}$ \\
\hline Translog & $\ln C_{i}=\beta_{0}+\sum_{j=1}^{s} \beta_{j} \ln y_{j, i}+\frac{1}{2} \sum_{j=1}^{s} \sum_{k=1}^{s} \beta_{j, k} \ln y_{j, i} \ln y_{k, i}+v_{i}+\mu_{i}$ \\
\hline
\end{tabular}

Novamente, temos uma trade-off entre melhor adequação aos dados e aumento do número dos parâmetros. Particularmente, a função Translog pode se tornar muito complexa caso for combinada com uma agregação média ou completa. Para se ter uma ideia, a função translog com a agregação média possui 66 variáveis. A função translog com a agregação completa possui incríveis 237 variáveis. Funções complexas em 
modelos de máxima verossimilhança são difíceis de calcular. De fato, os modelos translog com agregações média e completa não chegaram a uma convergência.

Por fim, podemos inserir modelos de variação no tempo. Iremos testar a possibilidade de variação tecnológica na fronteira de produção durante o período, para cima ou para baixo. Usaremos o modelo proposto por Battese \& Coelli (1992) e S. C. Kumbhakar and Wang (2005), conforme mostra a equação 3.13.

Usaremos a seguinte estratégia para escolher entre os diferentes modelos: quando o modelo estiver aninhado, utilizaremos o "likelihood ratio test of inefficiency". Quando o modelo não estiver aninhado, utilizaremos os indicadores propostos por Lai \& Huang (2010). O likelihood ratio test of inefficiency, pode ser descrito pela seguinte equação:

$$
-2\left[L\left(H_{0}\right)-L\left(H_{1}\right)\right]
$$

Onde,

$L\left(H_{0}\right)$ é o log-likelihood de um modelo restrito (com menos parâmetros).

$L\left(H_{1}\right)$ é o log-likelihood de um modelo irrestrito (com mais parâmetros).

Esse teste permite saber se o modelo com menos parâmetros possui um ajuste significativamente menor que um modelo com mais parâmetros. Ele permite escolher entre as diferentes formas funcionais (Coob-Douglas, Quadrática e Translog) e entre os modelos de eficiência invariante no tempo e variante no tempo. Por outro lado, ele não pode ser utilizado para modelos que não estão aninhados, como é o caso das diferentes formas de agregação dos serviços em indicadores de produção municipal em saúde. Nesses casos Lai \& Huang (2010) recomenda que os modelos sejam escolhidos por três critérios: o indicador AIC (Akaike information criterion), o BIC (bayesian information criterion) e Vuong Test. Primeiramente, iremos testar todos os modelos aninhados para verificar qual o "melhor" dentro de cada agregação. Posteriormente iremos aplicar os outros testes para verificar qual dos modelos não aninhados iremos escolher.

Para testar os modelos de análise, utilizamos uma "versão de teste" dos modelos, um pouco mais simples que o modelo final, utilizado no Capítulo 4. Esse modelo é 
homocedástico, ou seja, não possui uma função modelando o termo de erro, tal como descrito na seção 3.2.3. Ele contém todas as variáveis explicativas da eficiência, tal como descritas na seção 4.1, mas não modelos interativos. Essas medidas foram necessárias, pois a inclusão heterocedasticidade e de variáveis interagidas aumenta a colinearidade entre as variáveis, tornando o custo computacional dos modelos muito alto. As informações básicas dos modelos testados estão na tabela 3.3 .

Tabela 3.3 - Performance das funções de custo em saúde

\begin{tabular}{|c|c|c|c|c|c|c|c|}
\hline Nome modelo & Agregação & função & $\begin{array}{l}\text { Var. } \\
\text { tempo }\end{array}$ & Il & df & AIC & BIC \\
\hline Coob-Douglas Completa & Completa & CoobDouglas & não & $2.964,14$ & 32 & $-5.864,27$ & $-5.659,94$ \\
\hline Coob-Douglas Concisa & Concisa & CoobDouglas & não & $2.851,72$ & 17 & $-5.669,44$ & $-5.560,89$ \\
\hline Coob-Douglas Média & Média & CoobDouglas & não & $2.920,20$ & 21 & $-5.798,40$ & $-5.664,30$ \\
\hline Quadrática Completa & Completa & Quadrática & não & $3.046,50$ & 55 & $-5.983,00$ & $-5.631,80$ \\
\hline Quadrática Concisa & Concisa & Quadrática & não & $2.926,89$ & 25 & $-5.803,79$ & $-5.644,15$ \\
\hline Quadrática Média & Média & Quadrática & não & $2.968,11$ & 33 & $-5.870,23$ & $-5.659,51$ \\
\hline Translog Concisa & Concisa & Translog & não & $2.950,30$ & 53 & $-5.794,59$ & $-5.456,16$ \\
\hline Translog Média & Média & Translog & não & \multicolumn{4}{|c|}{ Não convergiu. } \\
\hline Translog Completa & Completa & Translog & não & \multicolumn{4}{|c|}{ Não convergiu. } \\
\hline $\begin{array}{l}\text { TV Coob-Douglas } \\
\text { Completa }\end{array}$ & Completa & CoobDouglas & $\operatorname{sim}$ & $2.964,17$ & 33 & $-5.862,33$ & $-5.651,61$ \\
\hline TV Coob-Douglas Concisa & Concisa & CoobDouglas & $\operatorname{sim}$ & $2.852,30$ & 18 & $-5.668,60$ & $-5.553,66$ \\
\hline TV Coob-Douglas Média & Média & CoobDouglas & $\operatorname{sim}$ & $2.920,20$ & 22 & $-5.796,40$ & $-5.655,92$ \\
\hline TV Quadrática Completa & Completa & Quadrática & $\operatorname{sim}$ & $3.046,63$ & 56 & $-5.981,25$ & $-5.623,66$ \\
\hline TV Quadrática Concisa & Concisa & Quadrática & $\operatorname{sim}$ & $2.927,67$ & 26 & $-5.803,34$ & $-5.637,32$ \\
\hline TV Quadrática Média & Média & Quadrática & $\operatorname{sim}$ & $2.968,27$ & 34 & $-5.868,54$ & $-5.651,44$ \\
\hline TV Translog Concisa & Concisa & Translog & $\operatorname{sim}$ & $2.950,89$ & 54 & $-5.793,78$ & $-5.448,96$ \\
\hline TV Translog Média & Média & Translog & $\operatorname{sim}$ & \multicolumn{4}{|c|}{ Não convergiu. } \\
\hline TV Translog Completa & Completa & Translog & $\operatorname{sim}$ & \multicolumn{4}{|c|}{ Não convergiu. } \\
\hline
\end{tabular}

Obs: Var. tempo = Variação temporal; 11 = log-likelihood; $\mathrm{df}=$ graus de liberdade.

Podemos observar pela tabela 3.3 que os modelos translog com agregação média e completa (com e sem variação temporal) não convergiram, devido ao grande número de parâmetros a serem calculados. Conforme o esperado, os modelos com mais variáveis tiveram um ajuste melhor, como pode ser observado pela correlação positiva entre os graus de liberdade (que neste caso é igual ao número de parâmetros) e o log-likelihood 
dos modelos e o indicador AIC. O indicador BIC tende a privilegiar modelos com menos parâmetros, por isso nem sempre a função com mais parâmetros possui o melhor $\mathrm{BIC}^{46}$. Na tabela 3.5 podemos ver o resultado do comparação de pares entre os modelos que convergiram. Somente foram comparados modelos aninhados (que possuem a mesma agregação). Podemos observar que em cada grupo, a função com mais parâmetros sempre teve desempenho melhor. No caso da agregação concisa, a função translog mostrou melhor ajuste aos dados. No caso das agregações média e completa, a função quadrática teve desempenho melhor. Curiosamente, o modelo de eficiência variante no tempo não melhorou o ajuste do modelo em nenhum cenário. Por mais que o log-likelihood do modelo com eficiência variante no tempo sempre seja melhor que sua contraparte invariante no tempo, essa diferença nunca se mostrou estatisticamente significativa no likelihood ratio test. Assim, iremos utilizar os modelos invariantes no tempo em nossa análise. No entanto, iremos incluir dummies dos anos na fronteira invariante, como forma de capitar efeitos específicos de cada ano que não foram capitados pelo modelo de evolução linear da eficiência, como choques econômicos ou mudanças na metodologia de registro dos procedimentos. Os modelos "ganhadores" de cada grupo foram:

\begin{tabular}{|c|c|c|c|c|}
\hline \multicolumn{5}{|c|}{ Tabela 3.4 - Performance das funções de custo em saúde } \\
\hline Nome modelo & ll & df & AIC & BIC \\
\hline Translog Concisa & $2.950,30$ & 53 & $-5.794,59$ & $-5.456,16$ \\
\hline Quadrática Média & $2.968,11$ & 33 & $-5.870,23$ & $-5.659,51$ \\
\hline Quadrática Completa & $3.046,50$ & 55 & $-5.983,00$ & $-5.631,80$ \\
\hline
\end{tabular}

\footnotetext{
${ }^{46}$ Lembrando que tanto no caso do AIC, quanto no caso do BIC, quanto mais baixo o número, melhor o ajuste do modelo. No caso do log-likelihood, quanto mais alto o número, melhor o ajuste do modelo.
} 
Tabela 3.5 - Benchmark entre diferentes funções de custo em saúde

\begin{tabular}{|c|c|c|c|c|}
\hline Agregação & Comparação & LR Test & DF & Modelo mais adequado \\
\hline Completa & Quadrática Completa X TV Quadrática Completa & 0,50 & 1 & Quadrática Completa \\
\hline Completa & TV Coob-Douglas Completa X TV Quadrática Completa & 329,83 & 23 & TV Quadrática Completa \\
\hline Completa & TV Coob-Douglas Completa X Quadrática Completa & 329,33 & 22 & Quadrática Completa \\
\hline Completa & Coob-Douglas Completa X TV Quadrática Completa & 329,95 & 24 & TV Quadrática Completa \\
\hline Completa & Coob-Douglas Completa X Quadrática Completa & 329,45 & 23 & Quadrática Completa \\
\hline Completa & Coob-Douglas Completa X TV Coob-Douglas Completa & 0,12 & 1 & Coob-Douglas Completa \\
\hline Concisa & Translog Concisa X TV Translog Concisa & 2,38 & 1 & Translog Concisa \\
\hline Concisa & TV Quadrática Concisa X TV Translog Concisa & 92,87 & 28 & TV Translog Concisa \\
\hline Concisa & TV Quadrática Concisa X Translog Concisa & 90,49 & 27 & Translog Concisa \\
\hline Concisa & Quadrática Concisa X TV Translog Concisa & 95,99 & 29 & TV Translog Concisa \\
\hline Concisa & Quadrática Concisa X Translog Concisa & 93,61 & 28 & Translog Concisa \\
\hline Concisa & Quadrática Concisa X TV Quadrática Concisa & 3,12 & 1 & TV Quadrática Concisa \\
\hline Concisa & TV Coob-Douglas Consisa X TV Quadrática Concisa & 301,49 & 8 & TV Quadrática Concisa \\
\hline Concisa & TV Coob-Douglas Consisa X Quadrática Concisa & 298,38 & 7 & Quadrática Concisa \\
\hline Concisa & Coob-Douglas Consisa X TV Quadrática Concisa & 303,80 & 9 & TV Quadrática Concisa \\
\hline Concisa & Coob-Douglas Consisa X Quadrática Concisa & 300,68 & 8 & Quadrática Concisa \\
\hline Concisa & Coob-Douglas Consisa X TV Coob-Douglas Consisa & 2,31 & 1 & TV Coob-Douglas Consisa \\
\hline Media & Quadrática Media X TV Quadrática Media & 0,63 & 1 & Quadrática Media \\
\hline Media & TV Coob-Douglas Media X TV Quadrática Media & 192,28 & 12 & TV Quadrática Media \\
\hline Media & TV Coob-Douglas Media X Quadrática Media & 191,65 & 11 & Quadrática Media \\
\hline Media & Coob-Douglas Media X TV Quadrática Media & 192,29 & 13 & Quadrática Media \\
\hline Media & Coob-Douglas Media X Quadrática Media & 191,66 & 12 & Quadrática Media \\
\hline Media & Coob-Douglas Media X TV Coob-Douglas Media & 0,01 & 1 & Coob-Douglas Media \\
\hline
\end{tabular}


Podemos verificar que a agregação concisa teve desempenho pior que as demais agregações, seja pelo tanto pelo critério AIC, quanto pelo BIC. Então, iremos descartar essa agregação. Já as duas agregações restantes, a média e a completa, apresentam desempenho diferente a depender do critério utilizado. A agregação completa possui AIC melhor, enquanto a agregação média possui BIC melhor. O Vuong test mostra que o ajuste da agregação completa é levemente superior, então iremos utilizar essa agregação. Assim, este trabalho utilizará a função Quadrática Completa invariante no tempo para estimar a fronteira de produção. 


\section{Capítulo 4 - Escala, desenvolvimento e instituições da eficiência de saúde.}

Neste capítulo iremos utilizar o indicador de eficiência municipal em saúde pública proposto nos capítulos anteriores para testar as hipóteses levantadas no Capítulo 1. Mais especificamente, iremos testar as hipóteses que contrastam diretamente a teoria da modernização e as hipóteses relacionadas à teoria do institucionalismo fiscal.

Os resultados encontrados claramente favorecem a teoria institucionalista, dado que é o padrão de financiamento, e não as condições socioeconômicas, que são as principais determinantes da eficiência local. Verificamos que não podemos afirmar que as cidades pequenas são naturalmente ineficientes, devido a uma suposta escala insuficiente ou a um subdesenvolvimento da sociedade civil. Ao contrário, em muitos casos, as cidades pequenas são mais eficientes que as cidades maiores. Obviamente, existem alguns serviços que não podem ser providos em pequenas cidades, como tratamentos e exames cuja demanda por habitante é muito pequena. Contudo, caso pensarmos na eficiência técnica por real de serviço produzido as cidades pequenas são muito produtivas. Igualmente, não foi encontrada nenhuma evidência de que condições socioeconômicas gerais, como renda, distribuição de renda ou urbanização tenham algum impacto na eficiência. A única característica social das cidades que parece ser sistematicamente benéfica para a eficiência é a densidade populacional. Aparentemente, essa característica reduz os custos de produção em saúde, ao permitir a centralização da provisão de serviços em poucos estabelecimentos. Já as hipóteses que dizem respeito às instituições fiscais, Hipótese 4, Hipótese 5a e Hipótese 5b - foram amplamente confirmadas. Realmente as cidades que possuem recursos abundantes tendem a ser menos eficientes, característica que é acentuada quando esses recursos são providos por contribuintes de fora da jurisdição, através de transferências intergovernamentais. Igualmente, a renda possui um efeito moderador na influência das transferências. Quando as cidades que recebem transferências possuem renda familiar média baixa, a eficiência cai mais do que quando a cidade possui renda familiar alta. 
O presente capítulo se divide em três partes. Abaixo mostraremos a construção da amostra e das variáveis explicativas utilizadas em nosso modelo. Depois haverá uma seção de análise dos resultados. Na parte final, faço uma discussão sobre os resultados encontrados.

\section{1 - Dados e variáveis explicativas}

A amostra do estudo são 630 municípios do Estado de São Paulo de 2009 a 2015. 15 municípios tiveram que ser excluídos da amostra, ou por não apresentarem dados (missing) ou por reportarem uma quantidade anormalmente elevada de procedimentos por real gasto, tal como descrito na seção 2.4. O recorte temporal foi escolhido porque antes de 2008 nem o sistema atual de registro de dados financeiros do TCE-SP nem a classificação atual de procedimentos do SUS haviam sido instituídos. O ano de 2008 não foi escolhido porque esse foi o primeiro ano do sistema de registros financeiros do TCE. Após uma checagem preliminar nos dados, encontramos várias inconsistências nesse ano que provavelmente se devem à falta de experiência dos municípios com o sistema.

Como variável de insumo, usaremos o gasto municipal na função saúde ${ }^{47}$. Como variáveis de produção, usaremos os procedimentos de saúde realizados pelo município, tal como descrito no Sistema de Informações Ambulatoriais (SIA) e no Sistema de Informações Hospitalares (SIH) do DATASUS, separados por tipo de produção (ambulatorial e hospitalar) e por nível de complexidade, conforme disposto na seção 3.3 (função completa quadrática invariante no tempo). As variáveis de insumo e produto estão divididas pela população, como forma de tornar o modelo mais facilmente interpretável e reduzir a reduzir a heterocedasticidade dos erros (FIREBAUGH; GIBBS, 1985, 1986), conforme descrito na seção 2.2.1. A fronteira de custo conta ainda com as seguintes variáveis explicativas: uma dummy para cada ano de análise, com quatro indicadores de preço dos insumos e o inverso da população. As dummies dos anos (modelos de efeitos fixos no tempo) servem para captar o efeito da evolução tecnológica e de situações conjunturais não observadas comuns a todos os municípios. As variáveis de preço dos insumos ajudam a tornar o indicador de eficiência uma medida de qualidade do gestor, e não de características do mercado local de insumos. Por fim, o inverso da população é

\footnotetext{
47 Os valores foram corrigidos pelo IPCA para o ano de 2015.
} 
uma medida para captar a hipótese de que o valor do intercepto do modelo sem as variáveis per capita não é zero. O modelo final pode ser descrito da seguinte forma:

$$
\begin{gathered}
\ln C_{i, t}=\beta_{0}+\beta_{1} \frac{1}{P o p_{i, t}}+\sum_{p=1}^{P} \beta_{p} \ln w_{p, i, t}+\sum_{j=1}^{s} \beta_{j} \ln y_{j, i, t}+\sum_{j=1}^{s} \beta_{j} \ln y_{j, i, t}{ }^{2} \\
+\sum_{t=1}^{T} \beta_{t} \ln d_{t}+v_{i, t}+\mu_{i} \\
\mu_{i}=\delta_{0}+\sum_{k=1}^{K} \delta_{k} z_{k, i} \\
\mu_{i} \sim N^{+}\left(\mu, \sigma_{\mu}^{2}\right) \\
v_{i, t} \sim N\left(0, \mathrm{H}\left(\gamma_{i} z_{i}\right)\right)
\end{gathered}
$$

Onde,

$C_{i}$ é o custo do setor público $i$, no nosso caso, é o gasto na função saúde.

$P o p_{i}$ é a população de $i$, no ano $t$,

$w_{p, i}$ é o indicador de preço dos insumos $p$,

$y_{j, i}$ é o indicador de produção $j$ de $i$,

$d_{t}$ é uma dummie do ano,

$v_{i, t}$ é o erro do modelo e

$\mu_{i}$ é o indicador de ineficiência de $i$.

As variáveis $z$, utilizadas para modelar a estimação de ineficiência, na equação 4.2, são as seguintes. Para averiguar os efeitos de escala das políticas públicas, Hipótese 1, correlacionaremos a eficiência municipal (o termo $\mu_{i}$ ) com a população dos municípios (em log). Contudo, Varela, Martins \& Fávero (2012) ressaltam que não é propriamente o tamanho da população que interfere na eficiência da provisão de serviços, mas sim um fator fortemente correlacionado com a população: a concentração populacional (Hipótese 3). Para avaliar essa hipótese, iremos adicionar a densidade populacional (habitantes por 
quilometro quadrado, em log) e o grau de urbanização em nossa análise. A urbanização, além de avaliar a concentração populacional, também ajuda a testar a hipótese de que os eleitores urbanos tendem a ser mais demandantes que os eleitores rurais, argumento típico da teoria da modernização.

Com relação à Hipótese $\mathbf{2}$ e à Hipótese $\mathbf{2 a}$, sobre as relações entre desenvolvimento e eficiência, utilizaremos duas variáveis explicativas. Em primeiro lugar, testaremos a hipótese de que os municípios mais pobres tendem a ser menos eficientes, para isso, simplesmente usaremos a renda média per capita (em log $)^{48}$. Conforme explicado na seção 1.1.1, poder-se-ia argumentar que o que causa o subdesenvolvimento da sociedade civil não é a renda média, que pode ser muito influenciada pela presença de uma elite rica, mas sim a proporção de eleitores pobres e menos escolarizados. Os cidadãos pobres e pouco escolarizados eram os eleitores típicos do Brasil do século XIX e XX, período onde a política municipal, principalmente nos pequenos municípios, foi identificada com as práticas "coronelistas" (CARVALHO, 2002; LEAL, 1993). Esses eleitores tenderiam e ser menos demandantes do setor público e também seriam menos capazes de cobrar resultados dos governantes. Assim, políticos populistas ou "coronelistas" poderiam manipular esses eleitores para poder se manter no poder, mesmo tendo baixo desempenho administrativo. Para avaliar essa hipótese, iremos analisar a interação da renda média com a desigualdade social. Se a hipótese do "coronelismo" estiver correta, as cidades pobres e desiguais tenderão a ser ineficientes, enquanto as cidades ricas e igualitárias tenderiam a ser eficientes. Essa hipótese não possui uma visão clara sobre como se comportariam as cidades ricas e desiguais (como são quase todas as cidades ricas da amostra) ou as cidades pobres e relativamente igualitárias; mas a presente análise também permite verificar se a eficiência esperada dessas cidades é diferente dos demais grupos.

Já para verificar o efeito das transferências intergovernamentais, Hipótese 4, Hipótese 5a e Hipótese 5b, utilizaremos duas variáveis. Em primeiro lugar, para avaliar a hipótese que os municípios tendem a desperdiçar mais os recursos de transferências que

\footnotetext{
48 Poderíamos também inserir a escolaridade média da cidade, como variável para captar uma sociedade desenvolvida, mas a correlação entre renda e escolaridade na nossa amostra é acima de 0,88, portanto, teríamos problemas de multicolineariedade e aumento de variância no modelo. No entanto, mostramos na seção 2.5, de forma descritiva, a correlação simples entre um indicador simplificado de eficiência e a escolaridade municipal. Como verificamos, os resultados são muito parecidos com a correlação entre a renda e eficiência. Assim, não há motivos para acreditar que as conclusões seriam diferentes se utilizássemos a educação ao invés da renda como proxy do desenvolvimento social do município.
} 
os recursos arrecadados localmente, Hipótese 4, utilizaremos a variável "dependência financeira municipal", que é simplesmente a proporção de transferências correntes sobre o total de receitas. Se a Hipótese 4 estiver certa, os municípios mais dependentes serão menos eficientes. Para avaliarmos a hipótese de que os municípios tendem a usar mal os recursos abundantes Hipótese 5a, utilizaremos a receita total per capita (em log). É importante ressaltar que não é fácil separar o efeito das receitas totais per capita e das receitas de transferências per capita, uma vez que os municípios que normalmente possuem altas receitas também possuem muitas transferências. Para verificar o efeito do aumento das transferências é diferente do aumento de receitas por outros meios, iremos interagir as a receita total com a dependência. Assim, se somente a Hipótese 5a estiver correta, todo aumento de receita será prejudicial, independentemente do nível de dependência financeira. Por outro lado, se a Hipótese 4 estiver correta, a receita per capita somente prejudicará a eficiência quando estiver combinada com uma alta dependência. Em outras palavras, a Hipótese 4 significa que é a combinação de grandes receitas e grande dependência que prejudica a eficiência.

Para verificarmos a Hipótese $\mathbf{5 b}$, de que o efeito das transferências prejudica mais as cidades pobres que as cidades ricas, precisamos de um modelo mais complexo. Iremos interagir a receita pública per capita, dependência financeira e a renda privada, em um modelo de interação tripla. Com isso podemos verificar se a combinação de altas receitas e grande dependência possui um efeito maior sobre a eficiência em cidades pobres do que em cidades ricas.

Por fim, iremos utilizar a proporção de cidadãos com mais de 60 anos como variável de controle. Segundo Varela, Martins, \& Fávero (2012), o número de idosos tende a diminuir a eficiência do sistema, dado os custos e o tempo adicional dos procedimentos envolvendo idosos. Essa variável ajuda a evitar o viés de variável omitida, mas é de importância teórica reduzida nessa análise.

As variáveis sobre renda e população tiveram como fonte o censo demográfico de 2010. Como essas características variam pouco no tempo, o viés causado pela extrapolação intertemporal tende a ser pequeno. As demais variáveis (população, urbanização, número de idosos, etc) foram agregadas na média, pois o modelo utilizado não admite variação no tempo. Mais detalhes sobre esse tópico pode ser obtido em Kumbhakar, Wang, and Horncastle (2014) e Parmeter and Kumbhakar (2014). O resumo das explicativas utilizadas pode ser observado na tabela 4.1. 
Tabela 4.1 -

Dados descritivos das variáveis independentes

\begin{tabular}{|lccccc|}
\multicolumn{1}{|c}{ Variável } & Frequência & Média & $\begin{array}{c}\text { Desvio } \\
\text { Padrão }\end{array}$ & Mínimo & Máximo \\
\hline População (log) & 4383 & 9,688 & 1,411 & 6,694 & 16,247 \\
\hline Urbanização(\%) & 4383 & 0,861 & 0,133 & 0,257 & 1 \\
\hline Densidade Populacional (log) & 4383 & 4,042 & 1,46 & 1,322 & 9,447 \\
\hline Renda privada das família (log) & 4383 & 6,374 & 0,237 & 5,437 & 7,364 \\
\hline Desigualdade de Renda (Gini) & 4383 & 0,475 & 0,038 & 0,356 & 0,613 \\
\hline Dependência Financeira (\%) & 4383 & 0,788 & 0,123 & 0,379 & 0,968 \\
\hline Receita pública per capita (log) & 4383 & 8,098 & 0,352 & 7,061 & 9,551 \\
\hline Proporção de Idosos (\%) & 4383 & 0,147 & 0,032 & 0,078 & 0,263 \\
\hline & & & & & \\
\hline
\end{tabular}

\section{2 - Resultados}

Como mencionado acima, o modelo de fronteiras estocásticas contém duas partes: uma relacionada à fronteira de produção (equação 4.1) e outra relacionada especificamente ao termo de ineficiência (equação 4.2). Os dados da fronteira de produção se encontram no Anexo II. As características da função de custo em saúde são de pouco interesse nesse trabalho, embora possam ser muito úteis para economias da saúde. Assim, iremos tecer apenas alguns breves comentários sobre a fronteira de produção. Em primeiro lugar, o inverso da população se mostrou significativamente correlacionado com o gasto público em saúde. Isso significa que existe um gasto mínimo para a provisão da saúde, mesmo quando, teoricamente, a população é zero (equação 2.5). Apenas três indicadores de preços dos insumos se mostraram significativos na análise: os salários dos médicos, os salários de outros profissionais de nível superior e os salários dos profissionais de saúde de nível médio. O salário dos profissionais administrativos não se mostrou correlacionado com o gasto em saúde. Isso denota que os salários médios locais influem no gasto público municipal de saúde. Os serviços com maior influência no gasto municipal são os gastos médicos com equivalentes no setor privado. Isso é algo esperado, dado que a maior parte dos serviços estão nessa categoria. Alguns procedimentos, como os procedimentos de enfermagem e de odontologia, não se mostraram significativos (rever de acordo com a nova função de custo). Mas esse 
resultado também era esperado, pois os indicadores de produção estão correlacionados entre si, o que diminui a eficiência do modelo em especificar a influência isolada de cada indicador. Porém, isso é um problema menor em nossa análise, pois não é nossa intenção entrar em detalhes sobre a função de custo em saúde. A escolha desse trabalho foi utilizar mais variáveis, para tornar o modelo mais preciso, mesmo que o custo dessa escolha seja maior variância dos parâmetros na fronteira. Por fim, todas as dummies para os anos da amostra se mostraram significativas e altamente influentes. É perceptível que o gasto com saúde aumenta com o passar dos anos, mantido tudo mais constante. Isso demonstra uma tendência de perda de eficiência com o aumento da tecnologia, resultado encontrado em outros estudos (O’DONNELL; NGUYEN, 2013).

A tabela 4.2 (na página 84) contém os resultados da correlação entre a ineficiência $\left(\mu_{i}\right)$ e as variáveis explicativas (equação 4.2). Para evitar confusões, invertemos os sinais do termo de ineficiência (o termo $\mu_{i}$ ), de modo a que quando houver uma um número negativo, isso significa que a variável aumenta eficiência. Igualmente, nos gráficos abaixo, quando o efeito marginal de uma variável está abaixo de zero, significa que quando essa variável aumenta, a eficiência diminui. Utilizamos dois modelos de análise. No primeiro modelo, existe duas interações duplas. A primeira interação é entre as variáveis de renda privada e de desigualdade de renda. A segunda interação é entre receita pública per capita e dependência financeira. No segundo modelo, existe apenas uma interação tripla, entre as variáveis de renda privada, receita pública per capita e dependência financeira. Nesta seção iremos falar sobre as variáveis não interagidas. $\mathrm{O}$ resultado das variáveis interagidas pode ser visto na próxima seção. 
Tabela 4.2

Variável dependente:

Ineficiência do gasto municipal $\left(\mu_{i}\right)$

\section{Variáveis}

Renda familiar per capita (log)

Desigualdade de renda (Gini)

Renda per capita $(\log ) *$ Gini

Receita pública per capita $(\log )$

Dependência Financeira

Receita pública per capita $(\log ) *$

Dependência

População (log)

Densidade Populacional (log)

Urbanização

Proporção de Idosos (\%)

Renda per capita $(\log ) *$ Receita pública per capita $(\log )$

Renda per capita $(\log ) *$ Dependência

Renda per capita $(\log ) *$ Receita pública per capita $(\log ) *$ Dependência

_cons

$N$

AIC

$B I C$

Estatística $t$ entre parênteses

$* p<0.10, * * p<0.05, * * * p<0.01$

Fonte: elaboração própria.

\section{Modelo 1}
0.104
(0.35)
0.382
(0.10)
$-0.0220$
$(-0.04)$

$0.633 * * *$

(5.84)

$-1.333$

$(-1.21)$

$0.224 *$

(1.67)

$0.367 * * *$

(5.17)
$-0.0228 * * *$
$(-2.98)$
$-0.00194$
$(-0.04)$
$-0.0403$
$(-0.17)$

$-2.049 * *$

$(-2.14)$

$-34.06 * * *$

(-3.29)

4.274***

(3.41)

$0.359 * * *$

(4.80)

$-0.0238 * * *$

$-0.00706$

$-0.0640$

$(-0.27)$

$0.417 * * *$

(2.90)

$5.112 * * *$

$-0.632 * * *$

(-3.21)

12.71

$-9.102 * * *$

(1.60)

$(-3.98)$

$-3.276 * * *$

41

4383

4383


Podemos perceber que, ao contrário dos outros trabalhos sobre o tema (GASPARINI; RAMOS, 2004; SAMPAIO DE SOUSA; STOŠIĆ, 2005; VARELA; MARTINS; FÁVERO, 2012), não encontramos ganhos de escala na provisão de serviços públicos. Ao contrário, o modelo demonstrou que, mantido tudo mais constante, quanto menor a população, maior a eficiência dos municípios, demonstrando retorno decrescente de escala dos serviços de saúde. Esse resultado é absolutamente surpreendente, dado que contraria grande parte da literatura. Voltaremos a discutir sobre ele no Capítulo 5. Por outro lado, a densidade populacional está positivamente correlacionada com a ineficiência. Assim, encontramos evidências de que não é propriamente o aumento da população que aumenta a eficiência, mas sim o aumento da densidade populacional. Um município medianamente populoso, mas territorialmente muito grande, como é o caso da cidade de Barretos, por exemplo, tende a ser ineficiente. Uma possível explicação para esse fenômeno é que municípios mais densos tendem a concentrar a provisão de serviços em poucos estabelecimentos, o que tende a gerar ganho de eficiência e melhor controle gerencial. A urbanização, contudo, não se mostrou correlacionada à eficiência. Assim, aparentemente não existe uma diferença marcante entre a provisão de serviços para a população urbana e para a população rural, pelo menos não após os controles utilizados aqui. Por fim, contrastando com o trabalho de Varela et al (2012), a porcentagem de idosos não se mostrou correlacionada com a eficiência.

\subsection{1 - Modelos interativos}

Para avaliar a influência da renda local e da desigualdade e das transferências constituicionais, utilizamos modelos interativos. Esses modelos são mais difíceis de interpretar que os modelos aditivos clássicos. Isso ocorre porque em uma regressão padrão, os parâmetros do modelo (os valores beta) mostram diretamente o efeito marginal das variáveis. Então, se o parâmetro beta for igual a 1, o aumento de uma unidade na variável independente $x$ resulta em um aumento esperado de uma unidade na variável depedendente $y$. Essa simplicidade de interpretação simplesmente não existe nos modelos interativos. Nesses modelos, não podemos saber o efeito marginal das variáveis independentes apenas olhando para um parâmetro isoladamente. Segundo Brambor et al., (2005) e Franzese and Kam (2007), o efeito marginal de uma variável interagida pode ser definido da seguinte forma. 


$$
\begin{gathered}
y=\beta_{0}+\beta_{1} x+\beta_{2} z+\beta_{3} x z \\
\frac{\partial y}{\partial x}=\beta_{1}+\beta_{3} z
\end{gathered}
$$

Assim, para cada valor de $z$, o efeito da variável $x$ sobre y será diferente. Ou seja, o efeito marginal de $x$ depende do valor de $z$. Da mesma forma, a variância do efeito marginal das variáveis depende do valor da variável interagida:

$$
\operatorname{Var}\left(\frac{\partial y}{\partial x}\right)=\operatorname{Var}\left(\beta_{1}+\beta_{3} z\right)=\operatorname{Var}\left(\beta_{1}\right)+z^{2} \operatorname{Var}\left(\beta_{3}\right)+2 z * \operatorname{Cov}\left(\beta_{1}, \beta_{3}\right)
$$

Então, é bem difícil ver o efeito real das variáveis interagidas apenas olhando os resultados da regressão. Assim, iremos seguir a recomendação de Brambor et al., (2005) e Franzese and Kam (2007) de utilizar gráficos para expor os resultados encontrados. Os gráficos seguirão o modelo proposto por Berry, Golder, and Milton (2012), onde o eixo vertical mostrará o efeito marginal de uma variável (equivalente à variável $x$ da equação 4.5) e o eixo horizontal mostrará os diferentes valores da variável interagida (a variável $z$ da equação 4.5) presentes na amostra. O gráfico também mostra o intervalo de confiança de $90 \%$ para o efeito marginal da variável, o que permite ver em qual valor de $z$ a variável é estatísticamente difernte de zero. Ao fundo, há um histograma que permite que o leitor observe a distribuição da variável interagida na amostra.

Começaremos analisando as hipóteses sobre a teoria da modernização, analisadas no modelo 1. No gráfico 4.1, podemos ver o efeito marginal da renda familiar per capita sobre a eficiência, frente a diferentes valores de desigualdade de renda. Podemos perceber que a renda diminui a eficiência em todos os valores de desigualdade econômica. Esse achado é o oposto do esperado pela Hipótese 2, que fala que o desenvolvimento aumenta a eficiência. Quando a desigualdade é mediana, nem muito alta nem muito baixa, o efeito da renda sobre a eficiência é estatísticamente difente de zero, mas isso se deve unicamente ao fato de que temos mais casos nesse intervalo, o que faz com que o intervalo de 
confiança dos parâmetros seja menor. Contudo, devemos considerar que o efeito da renda sobre a eficiência é muito pequeno, mesmo em intervalos onde ele é estatísticamente significativo. Assim, não encontramos evidências nem que o desenvolvimento econômico aumente a eficiência (pelo contrário) nem que essa relação seja afetada pela desigualdade econômica

A irrelevância da renda e da desigualdade para a eficiência pode ser observada analisando o efeito marginal da desigualdade de renda, frente a diferente valores de renda familar. Podemos ver que em nenhum caso o efeito marginal do índice Gini municipal é diferente de zero. Assim, não encontramos evidências que as sociedades mais desenvolvidas ou mais igualitárias sejam mais eficiências, quando são adicionados outros controles. 


\section{Gráfico 4.1 -}

\section{Efeito Efeito Marginal da Renda per Capita}

Variável dependente: Eficiência municipal em saúde

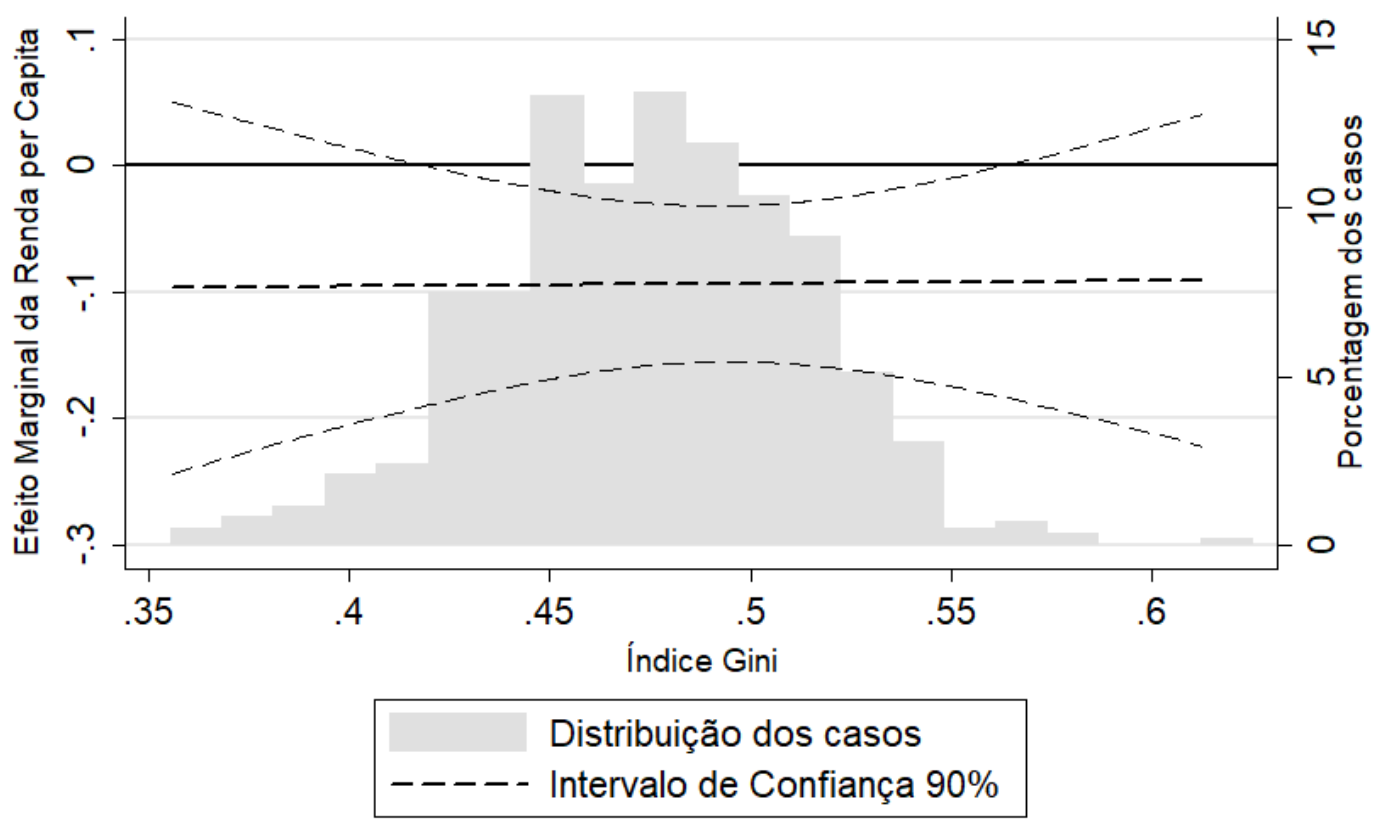

Gráfico 4.2 -

\section{Efeito Marginal da Desigualdade de Renda}

Variável dependente: Eficiência municipal em saúde

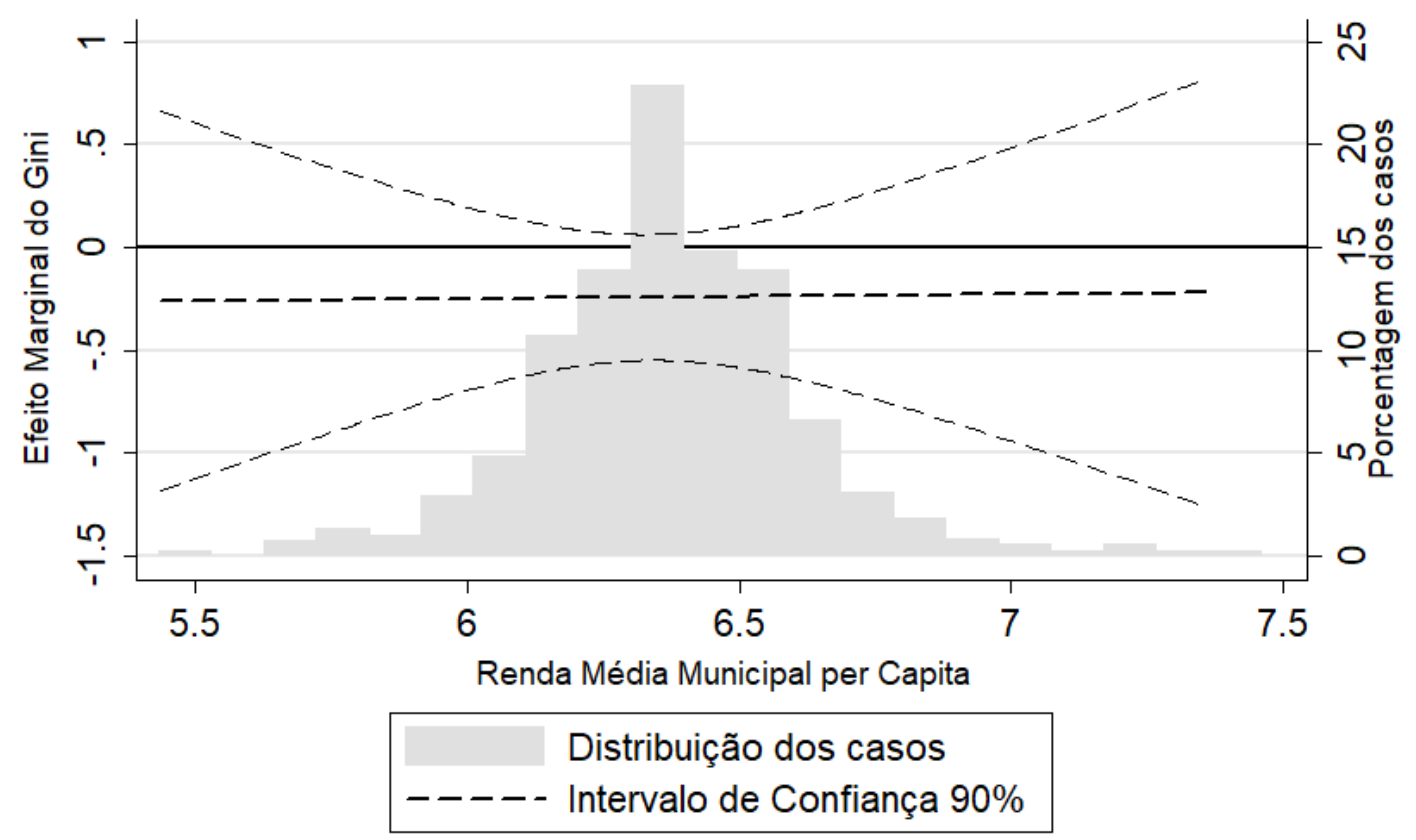


Agora iremos analisar as hipóteses relacionadas ao federalismo fiscal, ainda utilizando o modelo 1. O gráfico 4.3 mostra o efeito da interação entre receita pública per capita e dependência financeira. Podemos perceber que em qualquer nível de dependência, a receita pública diminui a eficiência, corroborando a Hipótese 5a. Assim, podemos dizer que o gasto público possui um retorno marginal decrescente. $O$ interessante do gráfico 4.3 é que esse efeito marginal aumenta conforme aumenta a dependência do municípios, exatamente como o esperado pela Hipótese 4. Assim, temos motivos para acreditar que a receita de transferências possui um efeito mais negativo sobre a eficiência que a receita de recursos próprios (apesar de ambas importarem). No entanto, devemos observar que os intervalos de confiança do efeito marginal da receita total se cruzam em todo os valores observados de dependência financeira. Isso quer dizer que não podemos afirmar que o efeito marginal da receita total é diferente em municípios altamente dependentes e municípios independentes, dentro dos valores observados na amostra. Porém, podemos isso não quer dizer que a dependência não potencialize o efeito das receitas. Podemos perceber que isso ocorre na tabela 4.2, onde vemos que o termo multiplicativo entre receita e dependência é estatísticamente significativo. O que ocorre é que os valores observados de dependência financeira variam apenas entre $40 \%$ e $100 \%$. Caso tivessemos um nível de dependência menor, teriamos valores marginais de receita diferentes uns dos outros.

As hipóteses sobre o efeito negativo das transferências também são reforçadas pelo gráfico 4.4, que mostra os valores marginais da dependência financeira em diferentes valores de receita total. Podemos ver que quando o município é dependente, mas sua receita per capita é muito baixa, a dependência não aumenta a desigualdade. Assim, município que possuem muito poucos recuros, ainda que sejam recursos de transferências, tendem a ser eficientes. Por outro lado, à medida que a receita do município sobe, a dependência (ou seja, a influência das transferências) passa a importar cada vez mais, novamernte, corroborando a hipótese Hipótese 4. Esses achados mostram que a depencia tende a prejudicar a eficiência dos municípios, principalmente se o volume de recursos transferidos são substantivos. 


\section{Gráfico 4.3 -}

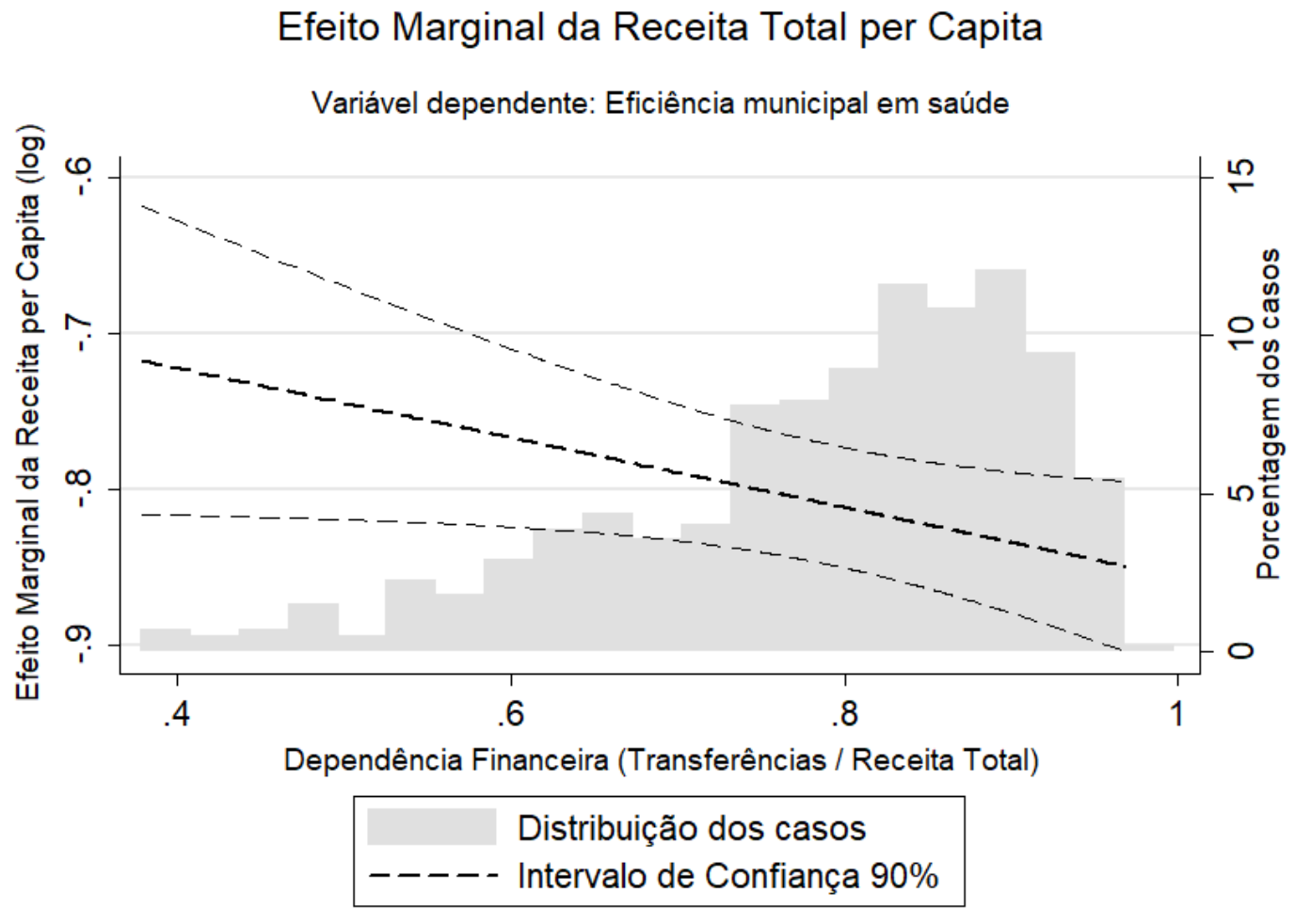

Gráfico 4.4 -

Efeito Marginal da Dependência Financeira

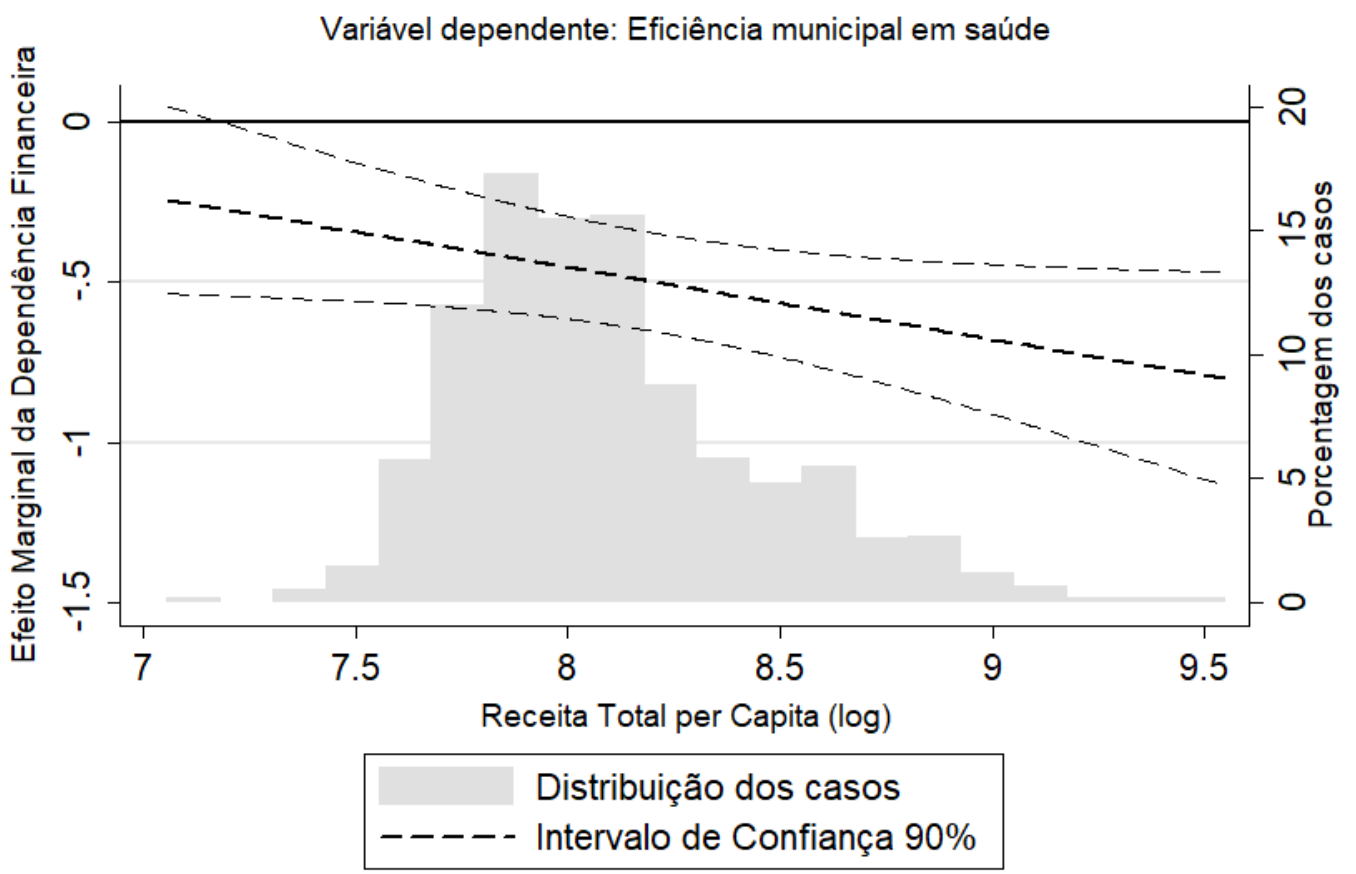


Nos resta então, finalmente, analisar a Hipótese 5b, de que as transferências destinas a municípios pobres prejudicam mais a eficiência que as transferências destinadas a municípios ricos. Analisar esse ponto, utilizamos, no modelo 2, uma interação tripla entre receita pública, renda privada e dependência financeira municipal. Então, replicamos os gráficos gráfico 4.3 e gráfico 4.4, mas mostrando o efeito marginal da receita per capita e da dependência nas cidades ricas e nas cidades pobres. Para deixar bem claro o efeito da renda nas relações estudadas, iremos considerar cidades ricas, ou "com renda per capita alta" a cidade com o $95^{\circ}$ centil de renda e a cidade pobre será a cidade do $5^{\circ}$ centil de renda. O resultado pode ser observado nos gráficos 4.5 e 4.6. O gráfico 4.5 mostra o efeito marginal da renda pública frente a diferentes valores de dependência financeira. Podemos perceber a receita per capita possui valores significativos (negativos) em qualquer valor de dependência, mais uma vez, confirmando a Hipótese 5a. Isso ocorre tanto em cidades ricas quanto em cidades pobres. No entanto, a curva do efeito marginal das cidades pobres é inclinada para baixo, mostrando que quanto mais dependente a cidade, pior o efeito do aumento de receita. Inclusive, ao contrário do gráfico 4.4 os intervalos de confiança não se cruzam nos valores extremos de baixa e alta dependência, que, dentro dos valores observados, o aumento de receita em uma cidade pobre e dependente é diferente do aumento de receita em uma cidade pobre e independente. Já as cidades ricas não parecem confirmar a Hipótese 4. Não há interação entre o efeito marginal da receita pública e a dependência, dado que a linha vermelha do gráfico 4.4 não estão inclinada. Nas cidades ricas, o mero aumento de receita gera perda de eficiência, independente de ser fruto de transferências ou não.

Uma situação parecida ocorre no gráfico 4.5. Nele podemos ver o efeito marginal da dependência em vários valores de receita per capita. No caso dos municípios pobres, quando as receitas são baixas, a dependência não é prejucial à eficiência. Aparentemente, sob uma situação de penúria de recursos, tanto públicos quanto privados, os municípios tendem a utilizar bem os recursos. Porém, à medida que o município pobre ganha recursos, a dependência financeira passa a pesar cada vez mais contra a eficiência. Os municípios ricos, por outro lado, a dependência financeira não interge com o montante de recursos, embora ainda prejudique a eficiência. Assim, temos elementos que corroboram a Hipótese 5b. O impacto das transferências é maior no caso de município pobres que no caso de municípios ricos. 


\section{Gráfico 4.5 -}

\section{Efeito Marginal da Receita Total per Capita}

Variável dependente: Eficiência municipal em saúde

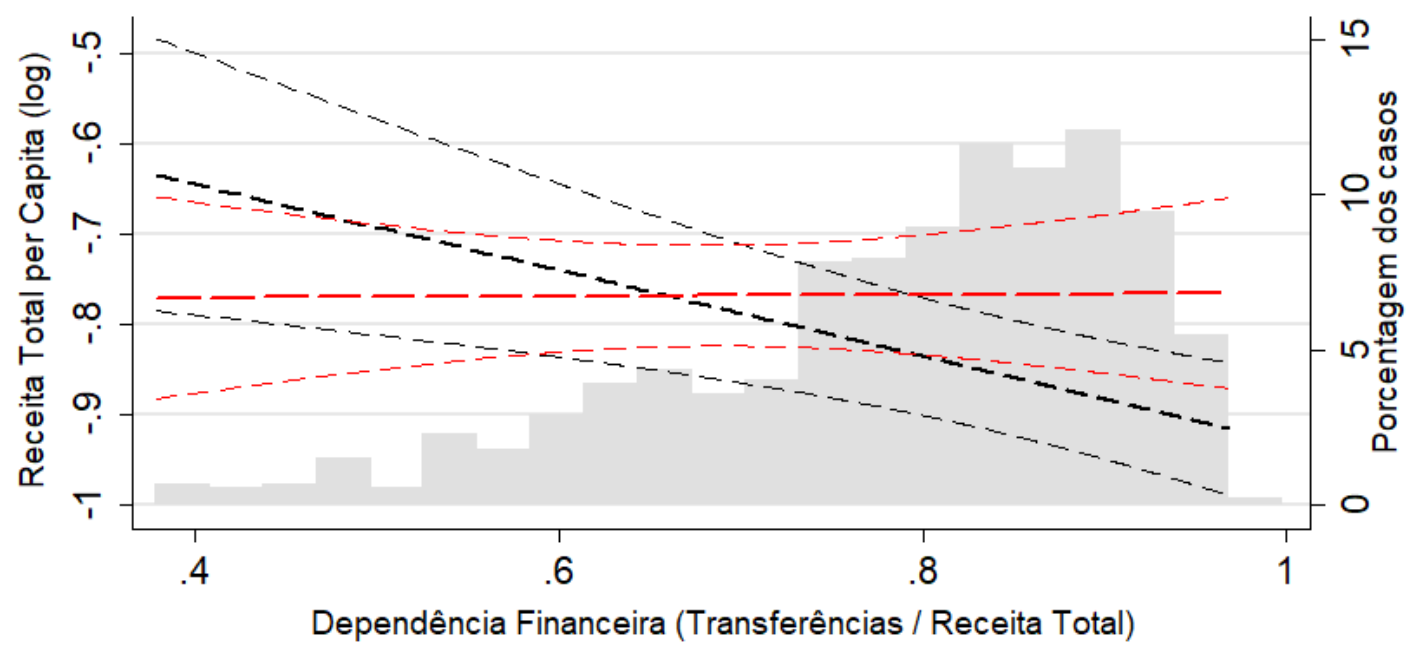

Distribuição dos casos

Intervalo de Confiança $90 \%$

Vermelho: renda alta ; Preto: renda baixa

\section{Gráfico 4.6 -}

\section{Efeito Marginal da Renda per Capita}

Variável dependente: Eficiência municipal em saúde

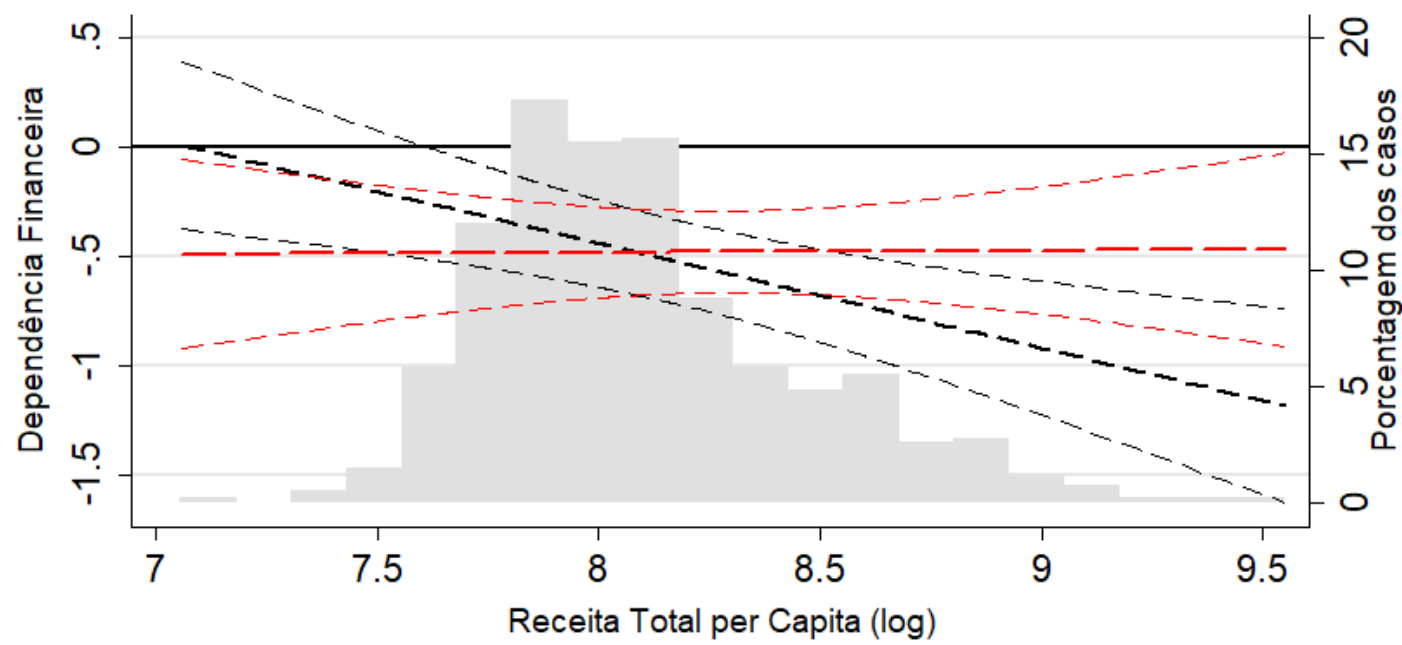

Distribuição dos casos

Intervalo de Confiança $90 \%$

Vermelho: renda alta ; Preto: renda baixa 
Um teste final para a hipótese Hipótese $5 \mathbf{b}$ é ver se a interação entre receita e dependência (que aqui tratamos como a medida de efeito independente das transferências) interage com renda privada. Em outras palavras, verificaremos se o aumento combinado de receita e dependência (ou seja, aumento das transferências) possui um efeito marginal condicionado pela renda do município. Podemos fazer isso calculando uma segunda derivada de um modelo de interação tripla, usando a mesma lógica da equação 4.5, da seguinte forma:

$$
\begin{gathered}
y=\beta_{0}+\beta_{1} x+\beta_{2} z+\beta_{3} w+\beta_{4} x z+\beta_{5} x w++\beta_{6} z w++\beta_{7} x z w \\
\frac{\partial y}{\partial x}=\beta_{1}+\beta_{4} z+\beta_{7} z w \\
\frac{\partial y^{2}}{\partial x \partial z}=\beta_{4}+\beta_{7} w \\
\operatorname{Var}\left(\frac{\partial y^{2}}{\partial x \partial z}\right)=\operatorname{Var}\left(\beta_{4}+\beta_{7} w\right)=\operatorname{Var}\left(\beta_{4}\right)+w^{2} \operatorname{Var}\left(\beta_{7}\right)+2 w \operatorname{Cov}\left(\beta_{4}, \beta_{7}\right)
\end{gathered}
$$

O resultado se encontra no gráfico 4.7. Podemos ver que a receita pública per capita somente interage com a dependência em cidades com renda per capita menor que $\log$ de 6,3 (cerca de $\mathrm{R} \$ 545$ ), mais ou menos a mediana da amostra. Para cidades mais ricas que esse valor, a dependência não potencializa o efeito da renda. Assim, podemos afirmar que as transferências possuem um efeito mais forte para a eficiência em cidades pobres que em cidades ricas, corroborando a Hipótese $\mathbf{5 b}$. 


\section{Gráfico 4.7 -}

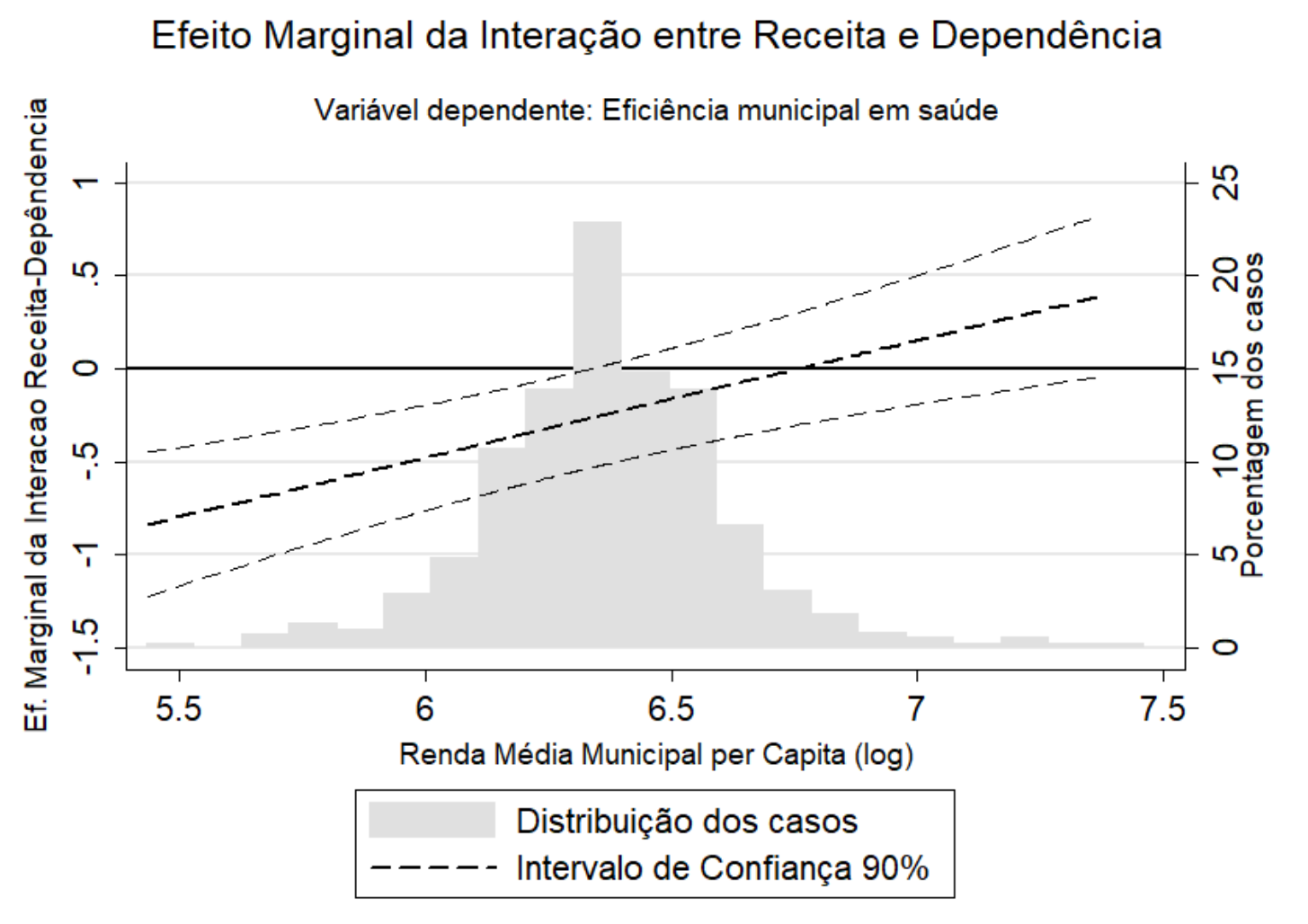

\section{3- Discussão}

Na seção anterior verificamos que, ao contrário do que afirma a maior parte da literatura, os municípios menos populosos são mais eficientes que os grandes municípios. Não está claro os motivos desse retorno decrescente de a perda de escala. Uma possibilidade é que os custos de produção sejam mais baratos nos municípios menores. Por mais que tenhamos colocado controles de preços dos salários em nossa análise, existem outros preços de insumos que não estão em nosso modelo, como o preço dos imóveis, dos materiais de consumo e dos serviços privados contratados pelo setor público. Outra possibilidade é que o fato de os municípios menores concentrarem sua produção em serviços de baixa complexidade aumentando a eficiência de seus sistemas de saúde. Existe ainda a possibilidade dos serviços de saúde providos pelos pequenos municípios serem de pior qualidade e, portanto, mais baratos, do que os serviços dos grandes municípios. Apesar dessa última possibilidade não ser totalmente excluída do presente 
estudo, a metodologia adotada enfraquece fortemente essa possibilidade. Os procedimentos analisados estão ponderados pelo seu custo. Em outros estudos, onde não existe essa ponderação, poder-se-ia argumentar que em grandes municípios, as ações realizadas são de procedimentos complexos, enquanto em pequenos municípios, as ações realizadas são de procedimentos simples. Por exemplo, enquanto nos pequenos municípios os diagnósticos por imagem se restringem ao raio- $\mathrm{X}$, os grandes municípios se utilizam de procedimentos mais complexos, como ultrassonografias. Mas esse argumento não pode ser utilizado no presente estudo, pois existe ponderação de custo de cada procedimento. Se um município provê exames de ultrasonografia, tudo mais constante, o seu indicador de produção tende a ser maior que um município que fornece apenas exames de raio-X. O argumento da qualidade teria que afirmar que o procedimento $k$ realizado por um pequeno município possui qualidade inferior (e é ao mesmo tempo mais barato) que o procedimento $k$ realizado por um grande município. Por exemplo, o raio-X realizado pelo município pequeno teria que ser de qualidade inferior (e mais barato) que o raio-X realizado por um grande município. Isso é possível, mas tende a ser pouco provável, dada a padronização existente na área da saúde.

Esse achado levanta a questão: por que os estudos anteriores encontraram um resultado diferente, mostrando que os municípios maiores tendem a serem mais eficientes? Provavelmente, existem duas explicações para isso. Em primeiro lugar, alguns estudos analisam apenas um nível de atenção à saúde, como a atenção básica, por exemplo. Esses estudos possuem um viés para cima na eficiência dos grandes municípios, devido à sub-reportagem dos gastos em saúde, conforme mostrado no Capítulo 2. Em segundo lugar, outros estudos utilizam indicadores sociais como indicadores de output do sistema de saúde, o que pode gerar viés de variável omitida. Esse viés surgiria porque existem outros fatores que influem no sistema de saúde das grandes cidades, além do setor público municipal. Os candidatos mais óbvios seriam a provisão de serviços privados e de serviços públicos estaduais, mais abundantes em grandes cidades. Poderíamos pensar também que a maior renda e escolaridade dos moradores dos centros urbanos tenham um impacto positivo em sua saúde, independentemente da qualidade do serviço público de saúde. Contudo, os resultados desse trabalho não permitem afirmar que o que diferencia as grandes e pequenas cidades seja a diferença na provisão de serviços públicos municipais. Portanto, a visão comum, que até o momento era corroborada pela literatura econômica, de que as cidades pequenas eram ineficientes, não se confirma. 
Das hipóteses levantadas pela teoria da modernização, apenas uma encontrou ancoragem nos dados: a Hipótese 3, que fala que quanto mais concentrada a população, maior a eficiência pública. Contudo, a explicação para esse fato provavelmente se deve mais a facilidades administrativas e logísticas que a efeitos sociológicos sobre o setor público. De certa forma, esse é um fator que está além do controle do gestor público, sendo mais uma característica do território. Tanto é assim que o outro indicador de concentração populacional, o índice de urbanização, muito mais citados pelos autores que estudam a teoria da modernização, não se mostrou relevante para análise.

As variáveis sociais, por outro lado, como renda e desigualdade não se comportaram como o esperado pela teoria da modernização, não corroborando as Hipótese 2 e Hipótese 2a. A renda das famílias mostrou uma (pequena) correlação negativa com a eficiência. Não está claro o motivo desse fenômeno, mas é bem possível que em cidades de renda mais alta, mais pessoas possuam planos de saúde privado, diminuindo o número de usuários do serviço público. Como, por determinação constitucional, no mínimo $15 \%$ do orçamento municipal precisa ser gasto em saúde pública, é possível que exista um gasto público maior por usuários efetivos do SUS em comunidades ricas. Outra possível explicação é que cidades de renda mais alta tenham tendência a gastos não observados nos nossos indicadores de produção, como investimentos em prédios mais luxuosos, por exemplo. Com relação à distribuição de renda, seu efeito marginal sobre a eficiência não é distinguível de zero em qualquer nível de renda. Assim, a eficiência de sociedades locais relativamente igualitárias ou de sociedades enormemente desiguais é a mesma, na média. Assim, as evidências mostram que o funcionamento interno do setor público segue uma dinâmica própria, relativamente independente da sociedade local, ou, pelo menos, relativamente independente das variáveis sociais utilizadas nesse trabalho.

Quanto às transferências, ao contrário do tópico anterior, o presente estudo confirmou a visão dominante da literatura institucionalista sobre a influência das instituições fiscais sobre o comportamento dos governos locais. Igualmente, poucos estudos anteriores que abordagem a influência das transferências (FURTADO, 2012; SAMPAIO DE SOUSA; CRIBARI-NETO; STOSIC, 2005) foram corroborados. Nossa análise indica que as transferências per capita, principalmente quando elas são abundantes, diminuem a eficiência técnica dos grandes municípios. Um ponto que escapou aos estudos anteriores, mas foi demonstrado aqui, é que o aumento de receitas 
tributárias também gera perda de eficiência. Ao que tudo indica, cada unidade a mais de recursos para o setor público diminui a eficiência, pois o gasto público em saúde possui retorno marginal decrescente. No entanto, se esse aumento receitas for fruto de transferências constitucionais, o rendimento marginal do real gasto é ainda menor que o aumento de receitas pela via tributária. Verificamos também que a mera dependência de recursos externos não necessariamente leva a uma perda de eficiência, desde que o montante de recursos do setor público seja baixo. É possível que isso ocorra porque existem regras, determinadas pelo governo federal, que determinam um nível mínimo de serviços por habitante. A saúde é a área de políticas públicas onde o governo central possui maior capacidade de induzir o comportamento dos governos subnacioanais (ARRETCHE, 2002). Assim, quando o montante de recursos do setor público é moderado, ainda que seja fruto de transferências, não há muito espaço para desperdício. O problema ocorre quando o montante de receitas chega a um nível onde é possível cumprir as exigências mínimas impostas pelo SUS e ainda desperdiçar recursos.

Por fim, a análise mostrou que a influência do desenvolvimento social na eficiência dos municípios é altamente condicionada pelo padrão de financiamento. Conforme levantado na Hipótese 5b, a abundância de recursos no setor público tende a favorecer mais o desperdício quando o setor público local é muito mais rico que a sociedade civil local. Isso significa que uma parcela maior dos recursos é desperdiçada em cidades pobres com receita elevada do setor público do que em cidades ricas com uma receita igualmente elevada. A combinação de alta receita per capita do setor público e baixa renda privada não é incomum em nossa amostra. Isso tende a ocorrer em três possibilidades. O primeiro caso ocorre quando a cidade apresenta uma população muito pequena. Isso faz com que a receita per capita do FPM seja alta. Podemos citar o município de Aspásia ${ }^{49}$, que em 2011 contava com uma população de 1804 habitantes e uma renda per capita de $\mathrm{R} \$ 422,34$ (a média do Estado era de $\mathrm{R} \$ 852,84$ ). No mesmo ano, sua renda de FPM foi de R\$3.306,51. Diga-se de passagem, o conjunto total de transferências para Aspásia foi de $\mathrm{R} \$ 4805,81$, o equivalente a 95\% da renda privada anual média, de $\mathrm{R} \$ 5068,08$. Em segundo lugar, a cidade pode ter algumas empresas (em alguns casos, apenas uma empresa) que geram um grande valor adicionado fiscal. Isso faz com que as transferências da cota-parte do ICMS seja alta. Porém, nem sempre o valor

\footnotetext{
49 Neste caso, não convém citar novamente o icônico município de Borá, pois ele não é um caso de município de renda alta, devido à presença de um usina de cana-de-açúcar em seu território.
} 
adicionado local se transforma em renda para os moradores locais. Em alguns casos, a empresa consegue gerar muito valor com uma quantidade relativamente modesta de empregados, muitos deles que nem sequer são moradores da cidade onde a empresa se localiza. Podemos citar os casos de Sandovalina, Narandiba e Iporanga. Por fim, existem cidades que possuem uma grande fonte de receita em royalties decorrentes da exploração de recursos hídricos ou minerais. Podemos citar os casos de Nantes e Suzanápolis, dois municípios muito pobres que receberam consideráveis quantias de royalties no período. Nossa análise mostrou que a combinação de transferências per capita alta e renda local baixa tende a reduzir a eficiência do setor público. 


\section{Capítulo 5 - Conclusão}

Nesse trabalho usamos o indicador inédito de eficiência do setor público para testar algumas proposições levantadas no Capítulo 1. As conclusões contrariam algumas visões comuns da literatura. Pudemos verificar que não existe ganho de escala na provisão de serviços de saúde. Ao contrário, as pequenas prefeituras conseguem produzir mais serviços por real gasto do que as prefeituras maiores. Se existe alguma debilidade estrutural na provisão de serviços de saúde das pequenas cidades, o arranjo organizacional do SUS consegue mais do que compensa-las. A renda privada local e a desigualdade de renda, isoladamente não são capazes, sozinhas de elevar o desempenho do setor público. Encontramos, em verdade, evidências de que a produção por real gasto diminui levemente em cidades de alta renda. O padrão de financiamento, por outro lado, se mostrou altamente correlacionado com o desempenho do setor público. As cidades que possuem alta receita per capita tendem a gastar pior os recursos que dispõe. Essa tendência se torna mais forte conforme aumenta a parcela da receita que é fruto de transferências intergovernamentais. Em particular, a combinação de um governo rico por causa das transferências em meio a uma comunidade pobre, tende a ser danoso para a eficiência.

Esse trabalho, de certa forma, vai ao encontro do pensamento de Oliver Wendell Holmes, jurista da Suprema Corte dos Estados Unidos, que no início do século XX afirmava que "Os impostos são o preço que pagamos por uma sociedade civilizada". Essa frase é mais profunda do que parece. Evidentemente que ninguém gosta de pagar impostos, mas esse ato cívico, quando feito de forma clara e consciente, tende a fortalecer os laços mútuos de lealdade entre o governo e a comunidade local. Evidentemente que quase todos os recursos públicos foram, em algum momento, fruto do pagamento de impostos. Mas parece existir uma diferença muito grande entre um imposto direto, onde o cidadão sabe exatamente o quanto que está pagando e para quem está pagando, de um imposto que, ou é quase invisível, como é o caso dos impostos indiretos (sobre produtos) no Brasil ou então passa por uma complexa rende de intermediários, onde sua origem se perde, como é o caso das transferências. Quando o governo é "desobrigado" de cobrar impostos de seus eleitores e pode se sustentar por transferências (ou seja, por 
contribuintes anônimos de outras regiões), ele também acaba se sentindo desobrigado de utilizar bem os recursos públicos. Não podemos deixar de pensar que a relação estabelecida aqui, restrita ao caso da provisão dos serviços de saúde, também não esteja se repetindo em outras políticas públicas. Contudo, esse é um assunto para futuros trabalhos. 


\section{Bibliografia:}

AFONSO, J. R.; GOBETTI, S. Rendas do petróleo no Brasil: alguns aspectos fiscais e federativos. Revista do BNDES, v. 15, n. 30, p. 231-269, 2008.

AIGNER, D.; LOVELL, C. A. K.; SCHMIDT, P. Formulation And estimation Of Stochastic Frontier Production Function Models. Journal of Econometrics, v. 6, n. 1, p. 21-37, 1977.

ARRETCHE, M. Federalismo e relações intergovernamentais no Brasil: a reforma de programas sociais. Dados, v. 45, n. 3, p. 431-458, 2002.

ATKInSON, A. B.; STIGLITZ, J. E. Lectures on Public Economics. [s.1.] Princeton University Press, 2015.

ATKINSON, G.; HAMILTON, K. Savings, Growth and the Resource Curse Hypothesis. World Development, v. 31, n. 11, p. 1793-1807, 2003.

AUTY, R. M. Natural resources, capital accumulation and the resource curse. Ecological Economics, v. 61, n. 4, p. 627-634, 2007.

AVELAR, L.; LIMA, F. D. DE. Lentas mudanças: o voto e a política tradicional. Lua Nova: Revista de Cultura e Política, n. 49, p. 195-223, 2000.

AVELAR, L.; WALTER, M. I. M. T. Lentas mudanças: o voto e a política tradicional. Opinião Pública, v. 14, n. 1, p. 96-122, 2008.

BADUNENKO, O.; KUMBHAKAR, S. C. When, where and how to estimate persistent and transient efficiency in stochastic frontier panel data models. European Journal of Operational Research, v. 255, n. 1, p. 272-287, 2016.

BATTESE, G. E.; COELLI, T. J. Frontier production functions, technical efficiency and panel data: With application to paddy farmers in India. Journal of Productivity Analysis, v. 3, n. 1-2, p. 153-169, 1992.

BATTESE, G. E.; COELLI, T. J. A model for technical inefficiency effects in a stochastic frontier production function for panel data. Empirical Economics, v. 20, n. 2, p. 325-332, jun. 1995.

BAUER, P. A technique for estimating a cost system that allows for inefficiency.

Federal Reserve Bank of Cleaveland Working Paper, v. 20, 1987. 
BERRY, W. D.; GOLDER, M.; MILTON, D. Improving Tests of Theories Positing Interaction. The Journal of Politics, v. 74, n. 3, p. 653-671, 2012.

BOSCH, N.; ESPASA, M.; MORA, T. Citizen control and the efficiency of local public services. ENVIRONMENT AND PLANNING C-GOVERNMENT AND POLICY, v. 30, n. 2, p. 248-266, 2012.

BOUERI, R.; ROCHA, F.; RODOPOULOS, F. Avaliação da Qualidade do Gasto Público e Mensuração da Eficiência. p. 463, 2015.

BRAMBOR, T. et al. Understanding Interaction Models: Improving Empirical Analyses. Political Analysis, v. 13, p. 1-20, 2005.

BROLLO, F. et al. The Political Resource Curse. American Economic Review, v. 103, n. 5, p. 1759-1796, ago. 2013.

BUARQUE DE HOLANDA, S. Raizes do Brasil. [s.l: s.n.].

CALIARI, T. et al. LONGE DOS PARTIDOS E PERTO DA FEDERAÇÃO: UMA AVALIAÇÃO DOS GASTOS MUNICIPAIS NA SAÚDE PÚBLICA. Pesquisa e Planejamento Econômico, v. 39, n. 3, 2009.

CARVALHO, J. M. DE. Cidadania no Brasil: o longo caminho. Rio de Janeiro: Civilização Brasileira, 2002.

CAVALCANTE, P. A competição eleitoral gera governos mais eficientes? Um estudo comparado das prefeituras no Brasil. Rev. Adm. Pública - Rio de Janeiro, v. 47, n. 6, p. 1569-591, 2013.

COELLI, T. J. et al. An Introduction to Efficiency and Productivity Analysis. 2nd editio ed. [s.1.] Springer, 2005.

COSSÍO, F. A. B. Disparidades econômicas inter-regionais, capacidade de obtençao de recursos tributários, esforço fiscal e gasto publico no federalismo brasileiro. p. 134, 1998.

COURANT, P.; GRAMLICH, E.; RUBINFELD, D. The stimulative effects of intergovernmental grants: Or why money sticks where it hitsFiscal federalism and grants-in-aid, 1978.

DAHL, R. A. Who governs? : democracy and power in an American city. [s.1.] Yale University Press, 2005. 
DIAZ-CAYEROS, A.; MAGALONI, B.; WEINGAST, B. R. Tragic Brilliance: Equilibrium Party Hegemony in Mexico. SSRN Electronic Journal, 2003.

DUNLEAVY, P.; CARRERA, L. N. Growing the productivity of government services. 2013.

EASTON, D. A framework for political analysis. [s.1.] Prentice-Hall, 1965.

FARIA, F. P.; JANNUZZI, P. DE M.; SILVA, S. J. DA. Eficiência dos gastos municipais em saúde e educação: uma investigação através da análise envoltória no estado do Rio de Janeiro. Revista de Administração Pública, v. 42, n. 1, p. 155-177, fev. 2008.

FARRELL, M. J. The Measurement of Productive Efficiency. Journal of the Royal Statistical Society. Series A (General), v. 120, n. 3, p. 253-290, 1957.

FIREBAUGH, G.; GIBBS, J. P. User's Guide to Ratio Variables. American Sociological Review, v. 50, n. 5, p. 713, out. 1985.

FIREBAUGH, G.; GIBBS, J. P. Using Ratio Variables to Control for Population Size. Sociological Methods \& Research, v. 15, n. 1-2, p. 101-117, nov. 1986.

FRANZESE, R.; KAM, C. Modeling and Interpreting Interactive Hypotheses in Regression Analysis. Ann Arbor, MI: University of Michigan Press, 2007.

FURTADO, B. A. Heterogeneidades em Receitas Orçamentárias, Eficiência e seus Determinantes: evidências para municípios brasileiros em 2010. Textos para discussão, v. 1796, p. 58, 2012.

FURTADO, C. Subdesenvolvimento e estagnação na América Latina. Rio de Janeiro: Civilização Brasileira, 1966.

FURTADO, C. Formação econômica do Brasil. [s.1.] Companhia das Letras, 2006.

GASPARINI, C. E.; RAMOS, F. S. Incentivos à eficiência na descentralização fiscal brasileira: o caso do FPM no estado de São Paulo. Pesquisa e Planejamento Econômico, v. 34, n. 1, p. 123-199, 2004.

GERVASONI, C. A Rentier Theory of Subnational Regimes: Fiscal Federalism, Democracy, and Authoritarianism in the Argentine Provinces. World Politics, v. 62 , n. 2, p. 302-340, 2010.

GEYS, B.; HEINEMANN, F.; KALB, A. Voter involvement, fiscal autonomy and 
public sector efficiency: Evidence from German municipalities. European Journal of Political Economy, v. 26, n. 2, p. 265-278, 2010.

GODOY, D. V. Eficiência na gestão pública municipal em educação e saúde. Brasília: Monografia premiana no XIX Prêmio Tesouro Nacional, categoria Qualidade do Gasto Público, 2014.

GREENE, W. H. Maximum likelihood estimation of econometric frontier functions. Journal of Econometrics, v. 13, n. 1, p. 27-56, 1980.

GREENE, W. H. The Econometric Approach to Efficiency Analysis. In: FRIED, H. O.; LOVELL, C. A. K.; SCHMIDT, S. S. (Eds.). . The Measurement of Productive Efficiency and Productivity Growth. [s.l: s.n.]. p. 68-119.

HALL, P. A.; TAYLOR, R. C. R. As três versões do neo-institucionalismo. Lua Nova: Revista de Cultura e Política, n. 58, p. 193-223, 2003.

HUANG, C. J.; LIU, J. T. Estimation of a non-neutral stochastic frontier production function. Journal of Productivity Analysis, v. 5, n. 2, p. 171-180, 1994.

JONDROW, J. et al. On the estimation of technical inefficiency in the stochastic frontier production function model. Journal of Econometrics, v. 19, n. 2-3, p. 233-238, ago. 1982.

KALB, A. Public Sector Efficiency: Applications to Local Governments in Germany. [s.1.] Springer Science \& Business Media, 2010.

KUMBHAKAR, S. C.; WANG, H. Estimation of growth convergence using a stochastic production frontier approach. Production, v. 88, p. 300-305, 2005.

KUMBHAKAR, S.; LOVELL, C. A. K. Stochastic frontier analysis. [s.1.] Cambridge University Press, 2003.

KUMBHAKAR, S.; WANG, H.-J.; HORNCASTLE, A. A practitioner's guide to stochastic frontier analysis using Stata. [s.l: s.n.].

LAI, H.; HUANG, C. J. Likelihood ratio tests for model selection of stochastic frontier models. Journal of Productivity Analysis, v. 34, n. 1, p. 3-13, 19 ago. 2010.

LAMBERT, J. Os dois Brasís. Rio de Janeiro: INEP, Ministério da Educação e Cultura, 1959.

LEAL, V. N. Coronelismo, enxada e voto : o municipio e o regime representativo 
no brasil. 2. ed. São Paulo: Alfa-Omega, 1993.

LIPSET, S. M. O homem político. [s.l: s.n.].

MAINWARING, S. Sistemas partidários em novas democracias: o caso do Brasil. Porto Alegre: Mercado Aberto, 2001.

MATTOS, E. et al. Economias de escala na oferta de serviços públicos de saúde: um estudo para os municípios paulistas. Textos para discussão, 2010.

MATTOS, E.; ROCHA, F.; ARVATE, P. Flypaper Effect Revisited: Evidence for Tax Collection Efficiency in Brazilian Municipalities. Estudos Econômicos, v. 41, n. 2, p. 239-267, 2011.

MEEUSEN, W.; BROECK, J. VAN DEN. Efficiency Estimation from Cobb-Douglas Production Function with Composed Error. international economic review, v. 18, n. 2, p. 435-444, 1977.

MEHLUM, H.; MOENE, K.; TORVIK, R. Institutions and the resource curse. Economic Journal, v. 116, n. 508, p. 1-20, jan. 2006.

MENDES, C. C.; SOUSA, M. DA C. S. DE. Estimando a demanda por serviços públicos nos municípios brasileiros. Revista Brasileira de Economia, v. 60, n. 3, p. 281-296, set. 2006.

MENDES, M.; MIRANDA, R. B.; COSIO, F. B. Transferências intergovernamentais no Brasil: Diagnóstico e proposta de reforma. Textos para Discussao Senado Federal, p. 1-111, 2008.

MENDES, M.; MIRANDA, R. B.; COSSÍO, F. A. B. O fundo de participação dos municípios precisa mudar. In: Constituição de 1988: o Brasil 20 anos depois. Brasília - DF: Instituto Legislativo Brasileiro - Senado Federal, 2008. p. 245267.

MOTTA, R. S. DA; MOREIRA, A. Political factors and the efficiency of municipal expenditure in Brazil. Eclética Química, v. 13, n. 4, p. 353-370, dez. 2009.

NISKANEN, W. A. Bureaucracy and Representative Government. Chicago: [s.n.].

NORTH, D. C. Institutions, institutional change, and economic performance. [s.l: s.n.].

O’DONNELL, C. J.; NGUYEN, K. An econometric approach to estimating support 
prices and measures of productivity change in public hospitals. Journal of Productivity Analysis, v. 40, n. 3, p. 323-335, 19 dez. 2013.

OATES, W. E. An Essay on Fiscal Federalism. Journal of Economic Literature, v. 37, n. 3, p. 1120-1149, 1999.

OTTMANN, G. Cidadania mediada: processos de democratização da política municipal no Brasil. Novos Estudos, v. 74, n. 1, p. 155-175, 2006.

PARMETER, C. F.; KUMBHAKAR, S. C. Efficiency Analysis: A Primer on Recent Advances. Foundations and Trends® in Econometrics, v. 7, n. 3-4, p. 191$385,2014$.

PETERSON, P. E. The price of federalism. [s.1.] Brookings Institution, 1995.

PETERSON, P. E.; ROM, M. C. Welfare magnets : a new case for a national standard. [s.1.] Brookings Institution, 1990.

PRADO, S. A questão fiscal na federaçao brasileira: Diagnóstico e alternativas. CEPAL, Oficina de Brasília, p. 145, 2007.

PRUD'HOMME, R. The dangers of decentralization. World Bank Research Observer, v. 10, n. 2, p. 201-220, 1995.

ROCHA, F. et al. Health spending autonomy and infant mortality rates: A matter of local administrative capacity? The Journal of Developing Areas, v. 50, n. 2, p. 293-309, 2016.

ROUSSEAU, J.-J. O Contrato Social. [s.l: s.n.].

SACHS, J. D.; WARNER, A. M. The curse of natural resources. European Economic Review, v. 45, p. 827-838, 2001.

SAMPAIO DE SOUSA, M. D. C.; CRIBARI-NETO, F.; STOSIC, B. D. Explaining DEA Technical Efficiency Scores in an Outlier Corrected Environment : The Case of Public Services in Brazilian Municipalities. Brazilian Review of Econometrics, v. 25, n. 2, p. 287-313, 2005.

SAMPAIO DE SOUSA, M. D. C.; STOŠIĆ, B. Technical efficiency of the Brazilian municipalities: Correcting nonparametric frontier measurements for outliers. Journal of Productivity Analysis, v. 24, n. 2, p. 157-181, 2005.

SCHLEGEL, R. RAÍZES DO BRASIL, 1936: O ESTATISMO ORGÂNICO COMO 
CONTRIBUIÇÃO ORIGINAL. Revista Brasileira de Ciências Sociais, v. 32, n. 93, p. 1, 2017.

SIMAR, L.; WILSON, P. W. Estimation and inference in two-stage, semi-parametric models of production processes. Journal of Econometrics, v. 136, n. 1, p. 3164, 2007.

SOUSA, M. D. C. S. DE; CRIBARI-NETO, F.; STOSIC, B. D. Explaining DEA Technical Efficiency Scores in an Outlier Corrected Environment : The Case of Public Services in Brazilian Municipalities. Brazilian Review of Econometrics, v. 25, n. 2, p. 287-313, 2005.

TIBEOUT, C. M. A Pure Theory of Local Expenditures. Journal of Political Economy, v. 64, n. 5, p. 416-424, 1956.

TREVISAN, A. P.; VAN BELLEN, H. M. Avaliação de políticas públicas: uma revisão teórica de um campo em construção. Revista de Administração Pública, v. 42, n. 3, p. 529-550, jun. 2008.

TSEBELIS, G. Jogos Ocultos: Escolha Racional no Campo da Política Comparada. [s.l.] EdUSP, 1998.

VARELA, P. S.; MARTINS, G. DE A.; FÁVERO, L. P. L. Desempenho dos municípios paulistas: uma avaliação de eficiência da atenção básica à saúde. Revista de Administração (São Paulo), p. 624-637, 2012.

VARSANO, R. A Evolução do Sistema Tributário Brasileiro ao Longo do Século: anotações e reflexões para futuras reformas. Pesquisa e Planejamento Econômico, v. 27, n. 1, p. 1-40, 1997.

VIANA, O. Instituições políticas brasileiras. Belo Horizonte: Itatiaia/ EDUSP, 1987.

WANG, H.; SCHMIDT, P. One-Step and Two-Step Estimation of the Effects of Exogenous Variables on Technical Efficiency Levels. Journal of Productivity Analysis, v. 18, n. 2, p. 129-144, 2002.

WEINGAST, B. The economic role of political institutions: market preserving federalism and economic development. Journal of Law, Economics, and Organization, v. 11, n. 1, p. 1, 1995.

WEINGAST, B. R. Second Generation Fiscal Federalism: Political Aspects of 
Decentralization and Economic Development. World Development, v. 53, p. 14-25, 2014. 


\begin{tabular}{|c|c|c|}
\hline Sigla & Descrição & $\begin{array}{l}\text { Presente na } \\
\text { agregação: }\end{array}$ \\
\hline Domic_A & Procedimentos domiciliares e de saúde da família. & Todas \\
\hline VigSan_A & Vigilância Sanitária & Todas \\
\hline Prev_A & Prevenção em saúde & Todas \\
\hline Psi & Atendimentos Psicosociais. & Todas \\
\hline Enfer & Procedimentos de enfermagem & Concisa \\
\hline Med & $\begin{array}{l}\text { Procedimentos médicos com equivalência no setor } \\
\text { privado }\end{array}$ & Concisa \\
\hline Odon & Procedimentos odontológicos & Concisa \\
\hline SUS & $\begin{array}{l}\text { Procedimentos médicos com ponderação pelos } \\
\text { valores do SUS }\end{array}$ & Concisa \\
\hline Enfer_A & Procedimentos de enfermagem ambulatoriais & Média \\
\hline Med_A & $\begin{array}{l}\text { Procedimentos médicos com equivalência no setor } \\
\text { privado, ambulatoriais. }\end{array}$ & Média \\
\hline Odon_A & Procedimentos odontológicos, ambulatoriais. & Média \\
\hline SUS_A & $\begin{array}{l}\text { Procedimentos médicos com ponderação pelos } \\
\text { valores do SUS, ambulatoriais }\end{array}$ & Média \\
\hline Enfer_H & Procedimentos de enfermagem hospitalares & Média \\
\hline Med_H & $\begin{array}{l}\text { Procedimentos médicos com equivalência no setor } \\
\text { privado, hospitalares. }\end{array}$ & Média \\
\hline Odon_H & Procedimentos odontológicos, hospitalares. & Média \\
\hline SUS_H & $\begin{array}{l}\text { Procedimentos médicos com ponderação pelos } \\
\text { valores do SUS, hospitalares }\end{array}$ & Completa \\
\hline EnferAB_A & $\begin{array}{l}\text { Procedimentos de enfermagem de atenção básica, } \\
\text { ambulatoriais }\end{array}$ & Completa \\
\hline EnferAB_H & $\begin{array}{l}\text { Procedimentos de enfermagem de atenção básica, } \\
\text { hospitalares }\end{array}$ & Completa \\
\hline EnferMC_A & $\begin{array}{l}\text { Procedimentos de enfermagem de média } \\
\text { complexidade, hospitalares }\end{array}$ & Completa \\
\hline EnferMC_H & $\begin{array}{l}\text { Procedimentos de enfermagem de média } \\
\text { complexidade, ambulatoriais }\end{array}$ & Completa \\
\hline MedAB_A & $\begin{array}{l}\text { Procedimentos médicos com ponderação pelos } \\
\text { valores do SUS, atenção básica, ambulatoriais }\end{array}$ & Completa \\
\hline MedAB_H & $\begin{array}{l}\text { Procedimentos médicos com ponderação pelos } \\
\text { valores do SUS, atenção básica, hospitalares }\end{array}$ & Completa \\
\hline MedAC_A & $\begin{array}{l}\text { Procedimentos médicos com ponderação pelos } \\
\text { valores do SUS, alta complexidade, ambulatoriais }\end{array}$ & Completa \\
\hline MedAC_H & $\begin{array}{l}\text { Procedimentos médicos com ponderação pelos } \\
\text { valores do SUS, alta complexidade, hospitalares }\end{array}$ & Completa \\
\hline MedMCNA_A & $\begin{array}{l}\text { Procedimentos médicos com ponderação pelos } \\
\text { valores do SUS, média complexidade e "não se } \\
\text { aplica", ambulatoriais }\end{array}$ & Completa \\
\hline MedMCNA_H & $\begin{array}{l}\text { Procedimentos médicos com ponderação pelos } \\
\text { valores do SUS, média complexidade e "não se } \\
\text { aplica", hospitalares }\end{array}$ & Completa \\
\hline
\end{tabular}




\begin{tabular}{|c|c|c|}
\hline OdonAB_A & $\begin{array}{l}\text { Procedimentos odontológicos, atenção básica, } \\
\text { ambulatoriais. }\end{array}$ & Completa \\
\hline OdonAB_H & $\begin{array}{l}\text { Procedimentos odontológicos, atenção básica, } \\
\text { hospitalares. }\end{array}$ & Completa \\
\hline OdonMAC_A & $\begin{array}{l}\text { Procedimentos odontológicos, média e alta } \\
\text { complexidade e "não se aplica", ambulatoriais. }\end{array}$ & Completa \\
\hline OdonMC_H & $\begin{array}{l}\text { Procedimentos odontológicos, média complexidade, } \\
\text { hospitalares. }\end{array}$ & Completa \\
\hline SUSAC_A & $\begin{array}{l}\text { Procedimentos médicos com ponderação pelos } \\
\text { valores do SUS, alta complexidade, ambulatoriais }\end{array}$ & Completa \\
\hline SUSAC_H & $\begin{array}{l}\text { Procedimentos médicos com ponderação pelos } \\
\text { valores do SUS, alta complexidade, hospitalares }\end{array}$ & Completa \\
\hline SUSMC_A & $\begin{array}{l}\text { Procedimentos médicos com ponderação pelos } \\
\text { valores do SUS, alta complexidade, ambulatoriais }\end{array}$ & Completa \\
\hline SUSMCNA_H & $\begin{array}{l}\text { Procedimentos médicos com ponderação pelos } \\
\text { valores do SUS, média complexidade e "não se } \\
\text { aplica", hospitalares }\end{array}$ & Completa \\
\hline SUSNA_A & $\begin{array}{l}\text { Procedimentos médicos com ponderação pelos } \\
\text { valores do SUS, complexidade "não se aplica", } \\
\text { ambulatoriais }\end{array}$ & Completa \\
\hline
\end{tabular}


Anexo II - Resultado completo dos modelos 1 e 2.

Variável dependente: Gasto municipal em saúde (log)

\begin{tabular}{|c|c|c|}
\hline & Modelo 1 & Modelo 2 \\
\hline $\begin{array}{l}\text { frontier } \\
\text { lninvpopulacaoT }\end{array}$ & $\begin{array}{c}0.211 * * \\
(2.45)\end{array}$ & $\begin{array}{c}0.203 * * \\
(2.27)\end{array}$ \\
\hline lnSaudeMedicoPP & $\begin{array}{c}0.0324 * \\
(1.67)\end{array}$ & $\begin{array}{c}0.0323 * \\
(1.67)\end{array}$ \\
\hline lnSaudeOutrosSupPP & $\begin{array}{c}0.0639 * * \\
(2.13)\end{array}$ & $\begin{array}{c}0.0640 * * \\
(2.14)\end{array}$ \\
\hline lnSaudeMedioPP & $\begin{array}{c}0.0804^{*} \\
(1.80)\end{array}$ & $\begin{array}{c}0.0794^{*} \\
(1.78)\end{array}$ \\
\hline lnSaudeAdmMedPP & $\begin{array}{c}-0.000256 \\
(-0.01)\end{array}$ & $\begin{array}{c}-0.000489 \\
(-0.01)\end{array}$ \\
\hline lnDomic_APP & $\begin{array}{c}0.00276 \\
(1.57)\end{array}$ & $\begin{array}{c}0.00269 \\
(1.53)\end{array}$ \\
\hline lnEnferAB_APP & $\begin{array}{c}-0.00656 \\
(-1.42)\end{array}$ & $\begin{array}{c}-0.00659 \\
(-1.43)\end{array}$ \\
\hline lnEnferAB_HPP & $\begin{array}{c}-0.0192 \\
(-1.56)\end{array}$ & $\begin{array}{c}-0.0196 \\
(-1.59)\end{array}$ \\
\hline lnEnferMC_APP & $\begin{array}{c}0.00552 \\
(0.39)\end{array}$ & $\begin{array}{c}0.00496 \\
(0.35)\end{array}$ \\
\hline lnEnferMC_HPP & $\begin{array}{c}0.00171 \\
(0.16)\end{array}$ & $\begin{array}{c}0.000897 \\
(0.08)\end{array}$ \\
\hline lnMedAB_APP & $\begin{array}{c}-0.0473 \\
(-1.12)\end{array}$ & $\begin{array}{c}-0.0464 \\
(-1.10)\end{array}$ \\
\hline lnMedAB_HPP & $\begin{array}{c}-0.00110 \\
(-0.58)\end{array}$ & $\begin{array}{c}-0.00118 \\
(-0.62)\end{array}$ \\
\hline lnMedAC_APP & $\begin{array}{c}0.0116^{* * * *} \\
\quad(4.15)\end{array}$ & $\begin{array}{c}0.0114 * * * \\
\quad(4.10)\end{array}$ \\
\hline lnMedAC_HPP & $\begin{array}{c}-0.00239 \\
(-0.61)\end{array}$ & $\begin{array}{c}-0.00262 \\
(-0.66)\end{array}$ \\
\hline
\end{tabular}


lnMedMCNA_APP

$\begin{array}{cc}\begin{array}{c}0.00669 * * * \\ (4.96)\end{array} & \begin{array}{c}0.00673 * * * \\ (4.98)\end{array} \\ 0.0136 * * * & 0.0136 * * * \\ (6.06) & (6.09) \\ & \\ -0.00116 & -0.00114 \\ (-0.19) & (-0.19) \\ -0.0162 & -0.0154 \\ (-0.99) & (-0.94) \\ & \\ -0.000791 & -0.000817 \\ (-0.56) & (-0.57) \\ & \\ -0.00503 & -0.00564 \\ (-0.40) & (-0.45) \\ & \\ 0.000949 & 0.000880 \\ (0.56) & (0.52) \\ 0.00369 & 0.00382 \\ (0.96) & (0.99)\end{array}$

lnMedMCNA_HPP

lnOdonAB_APP

lnOdonAB_HPP

lnOdonMAC_APP

lnOdonMC_HPP

lnPrev_APP

$0.0148 * * *$

$0.0147 * * *$

InSUSAC_APP

$-0.00799$

lnSUSAC_HPP

$(-1.23)$

$-0.00807$

$(-1.25)$

lnSUSMC_APP

$-0.000257$

$(-0.04)$

0.0000810

(0.01)

lnSUSMCNA_HPP

0.00805

0.00775

(1.14)

(1.10)

lnSUSNA_APP

$0.00402 * *$

(2.16)

$0.00406 * *$

lnVigSan_APP

0.00263

0.00267

(0.98)

(0.99)

lnDomic_A2PP

-0.0000300
$(-0.17)$

$-0.0000340$

0.000340

$(-0.20)$

lnEnferAB_A2PP

$(-0.82)$

$-0.000340$

(-0.82)

lnEnferAB_H2PP

$-0.00108 *$

$-0.00110^{*}$

$(-1.72)$

(-1.75) 


\begin{tabular}{|c|c|c|}
\hline lnEnferMC_A2PP & $\begin{array}{c}0.000116 \\
(0.18)\end{array}$ & $\begin{array}{c}0.0000920 \\
(0.15)\end{array}$ \\
\hline lnEnferMC_H2PP & $\begin{array}{c}0.000166 \\
(0.31)\end{array}$ & $\begin{array}{c}0.000129 \\
(0.24)\end{array}$ \\
\hline lnMedAB_A2PP & $\begin{array}{c}0.00807 * * \\
\quad(2.08)\end{array}$ & $\begin{array}{c}0.00802 * * \\
(2.07)\end{array}$ \\
\hline lnMedAB_H2PP & $\begin{array}{c}-0.0000633 \\
(-0.39)\end{array}$ & $\begin{array}{c}-0.0000692 \\
(-0.43)\end{array}$ \\
\hline lnMedAC_A2PP & $\begin{array}{c}0.00133^{* * * *} \\
(2.99)\end{array}$ & $\begin{array}{c}0.00132 * * * \\
(2.96)\end{array}$ \\
\hline lnMedAC_H2PP & $\begin{array}{c}-0.000373 \\
(-1.03)\end{array}$ & $\begin{array}{c}-0.000393 \\
(-1.09)\end{array}$ \\
\hline lnMedMCNA_A2PP & $\begin{array}{c}0.00219^{* * * *} \\
\quad(7.09)\end{array}$ & $\begin{array}{c}0.00220 * * * \\
\quad(7.12)\end{array}$ \\
\hline lnMedMCNA_H2PP & $\begin{array}{c}0.00114^{*} \\
\quad(1.73)\end{array}$ & $\begin{array}{c}0.00115^{*} \\
\quad(1.74)\end{array}$ \\
\hline lnOdonAB_A2PP & $\begin{array}{c}0.000805 \\
(0.88)\end{array}$ & $\begin{array}{c}0.000794 \\
(0.87)\end{array}$ \\
\hline lnOdonAB_H2PP & $\begin{array}{c}-0.00110 \\
(-0.90)\end{array}$ & $\begin{array}{c}-0.00103 \\
(-0.85)\end{array}$ \\
\hline lnOdonMAC_A2PP & $\begin{array}{c}-0.0000262 \\
(-0.12)\end{array}$ & $\begin{array}{c}-0.0000348 \\
(-0.16)\end{array}$ \\
\hline lnOdonMC_H2PP & $\begin{array}{c}-0.000211 \\
(-0.29)\end{array}$ & $\begin{array}{c}-0.000247 \\
(-0.34)\end{array}$ \\
\hline lnPrev_A2PP & $\begin{array}{c}0.000544^{* *} \\
\quad(2.33)\end{array}$ & $\begin{array}{c}0.000539 * * \\
\quad(2.31)\end{array}$ \\
\hline $\operatorname{lnPsi} 2 \mathrm{PP}$ & $\begin{array}{c}0.000127 \\
(0.48)\end{array}$ & $\begin{array}{c}0.000135 \\
(0.51)\end{array}$ \\
\hline lnSUSAC_A2PP & $\begin{array}{c}0.00130^{* * *} \\
\quad(2.85)\end{array}$ & $\begin{array}{c}0.00128 * * * \\
\quad(2.79)\end{array}$ \\
\hline lnSUSAC_H2PP & $\begin{array}{c}-0.00108^{*} \\
(-1.78)\end{array}$ & $\begin{array}{c}-0.00109^{*} \\
(-1.79)\end{array}$ \\
\hline lnSUSMC_A2PP & -0.000415 & -0.000364 \\
\hline
\end{tabular}




\begin{tabular}{|c|c|c|}
\hline & $(-0.45)$ & $(-0.40)$ \\
\hline lnSUSMCNA_H2PP & $\begin{array}{c}0.00119 \\
(1.27)\end{array}$ & $\begin{array}{c}0.00114 \\
(1.22)\end{array}$ \\
\hline lnSUSNA_A2PP & $\begin{array}{c}0.000331 \\
(1.46)\end{array}$ & $\begin{array}{c}0.000338 \\
(1.49)\end{array}$ \\
\hline lnVigSan_A2PP & $\begin{array}{l}0.000293 \\
(1.42)\end{array}$ & $\begin{array}{c}0.000297 \\
(1.44)\end{array}$ \\
\hline dumyear2010 & $\begin{array}{l}0.0497 * * * \\
\quad(7.75)\end{array}$ & $\begin{array}{l}0.0497 * * * \\
\quad(7.76)\end{array}$ \\
\hline dumyear2011 & $\begin{array}{c}0.0989 * * * \\
(11.35)\end{array}$ & $\begin{array}{c}0.0990 * * * \\
(11.34)\end{array}$ \\
\hline dumyear2012 & $\begin{array}{c}0.165^{* * * *} \\
(13.20)\end{array}$ & $\begin{array}{c}0.165^{* * *} \\
(13.19)\end{array}$ \\
\hline dumyear2013 & $\begin{array}{c}0.183 * * * \\
(10.03)\end{array}$ & $\begin{array}{c}0.183 * * * \\
(10.02)\end{array}$ \\
\hline dumyear2014 & $\begin{array}{c}0.203 * * * \\
\quad(9.25)\end{array}$ & $\begin{array}{c}0.203 * * * \\
\quad(9.25)\end{array}$ \\
\hline dumyear2015 & $\begin{array}{c}0.126^{* * * *} \\
(4.84)\end{array}$ & $\begin{array}{c}0.126^{* * * *} \\
(4.84)\end{array}$ \\
\hline _cons & $\begin{array}{c}8.899 * * * \\
(13.66)\end{array}$ & $\begin{array}{c}8.804 * * * \\
(12.86)\end{array}$ \\
\hline $\begin{array}{l}\text { mu } \\
\text { meanlnRendaPP }\end{array}$ & $\begin{array}{l}0.104 \\
(0.35)\end{array}$ & $\begin{array}{c}-3.276 * * * \\
(-2.73)\end{array}$ \\
\hline Gini & $\begin{array}{l}0.382 \\
(0.10)\end{array}$ & $\begin{array}{l}0.241 \\
(1.29)\end{array}$ \\
\hline Int_Renda_Gini & $\begin{array}{c}-0.0220 \\
(-0.04)\end{array}$ & \\
\hline lnmeanRecTotPP & $\begin{array}{c}0.633 * * * \\
(5.84)\end{array}$ & $\begin{array}{c}-2.049 * * \\
(-2.14)\end{array}$ \\
\hline meandependencia & $\begin{array}{l}-1.333 \\
(-1.21)\end{array}$ & $\begin{array}{c}-34.06 * * * \\
(-3.29)\end{array}$ \\
\hline Int_Dep_lnRecTotPP & $\begin{array}{l}0.224 * \\
(1.67)\end{array}$ & $\begin{array}{l}4.274 * * * \\
(3.41)\end{array}$ \\
\hline
\end{tabular}




\begin{tabular}{|c|c|c|}
\hline lnmeanpopulacaoT & $\begin{array}{c}0.367 * * * \\
(5.17)\end{array}$ & $\begin{array}{c}0.359 * * * \\
(4.80)\end{array}$ \\
\hline lnmeanDensidade & $\begin{array}{c}-0.0228 * * * \\
(-2.98)\end{array}$ & $\begin{array}{c}-0.0238^{* * *} * \\
(-2.99)\end{array}$ \\
\hline meanUrb & $\begin{array}{c}-0.00194 \\
(-0.04)\end{array}$ & $\begin{array}{c}-0.00706 \\
(-0.13)\end{array}$ \\
\hline meanElder & $\begin{array}{c}-0.0403 \\
(-0.17)\end{array}$ & $\begin{array}{c}-0.0640 \\
(-0.27)\end{array}$ \\
\hline Int_Renda_lnRecTotPP & & $\begin{array}{c}0.417 * * * \\
(2.90)\end{array}$ \\
\hline Int_Rend_Dep & & $\begin{array}{l}5.112 * * * \\
(3.14)\end{array}$ \\
\hline Int_Rend_Dep_lnRecTotPP & & $\begin{array}{c}-0.632 * * * \\
(-3.21)\end{array}$ \\
\hline _cons & $\begin{array}{c}-9.102 * * * \\
(-3.98)\end{array}$ & $\begin{array}{l}12.71 \\
(1.60)\end{array}$ \\
\hline $\begin{array}{l}\text { usigmas } \\
\text { _cons }\end{array}$ & $\begin{array}{c}-4.099 * * * \\
(-64.18)\end{array}$ & $\begin{array}{c}-4.104 * * * \\
(-64.27)\end{array}$ \\
\hline $\begin{array}{l}\text { vsigmas } \\
\text { meanlnRendaPP }\end{array}$ & $\begin{array}{c}-0.603 * * * \\
(-3.96)\end{array}$ & $\begin{array}{c}-0.603 * * * \\
(-3.97)\end{array}$ \\
\hline Gini & $\begin{array}{c}2.928 * * * \\
(3.40)\end{array}$ & $\begin{array}{c}2.926 * * * \\
(3.40)\end{array}$ \\
\hline lnmeanRecTotPP & $\begin{array}{c}0.196^{* *} \\
(2.21)\end{array}$ & $\begin{array}{c}0.195^{* *} \\
(2.20)\end{array}$ \\
\hline meandependencia & $\begin{array}{l}-0.518 \\
(-1.26)\end{array}$ & $\begin{array}{l}-0.516 \\
(-1.25)\end{array}$ \\
\hline lnmeanpopulacaoT & $\begin{array}{c}-0.193 * * * \\
(-3.74)\end{array}$ & $\begin{array}{c}-0.193 * * * \\
(-3.74)\end{array}$ \\
\hline lnmeanDensidade & $\begin{array}{c}0.216 * * * \\
(6.57)\end{array}$ & $\begin{array}{c}0.215 * * * \\
\quad(6.56)\end{array}$ \\
\hline meanUrb & $\begin{array}{c}-0.346^{*} \\
(-1.70)\end{array}$ & $\begin{array}{c}-0.346^{*} \\
(-1.70)\end{array}$ \\
\hline meanElder & $\begin{array}{c}-3.981 * * * \\
(-3.76)\end{array}$ & $\begin{array}{c}-3.975 * * * \\
(-3.75)\end{array}$ \\
\hline
\end{tabular}




\begin{tabular}{lcc} 
_cons & -1.960 & -1.948 \\
& $(-1.34)$ & $(-1.34)$ \\
\hline$N$ & 4383 & 4383 \\
$A I C$ & -7785.7 & -7784.5 \\
$B I C$ & -7281.3 & -7267.3 \\
\hline
\end{tabular}

$t$ statistics in parentheses

$* p<0.10, * * p<0.05, * * * p<0.01$

Fonte: elaboração própria. 